\title{
TRANSFERENCIA DE UN GEN NEURO- PROTECTOR EN ANIMALES DURANTE EL ENVEJECIMIENTO REPRODUCTIVO
}

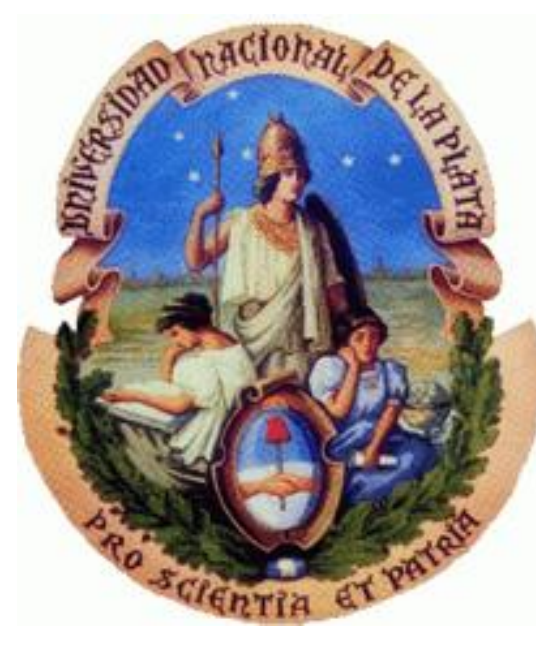

Tesis Doctoral

Universidad Nacional de La Plata

Facultad de Ciencias Exactas

Departamento de Ciencias Biológicas

- 2015 -

Tesista: Bioq. Silvia Susana Rodríguez

Director: Dr. Rodolfo Gustavo Goya

Co-Director: Dr. Omar Jorge Rimoldi

Asesor Académico: Dra. Susana Beatriz Etcheverry 
In memoriam

Dedicamos este trabajo a la memoria del Dr. Omar Rimoldi, fallecido en julio de 2015, quien fue un estrecho colaborador de nuestro grupo. Su amistad e inestimable ayuda a lo largo de los años nos deja el más cálido de los recuerdos. 


\section{Agradecimientos}

Al llegar a la recta final del camino que he recorrido para desarrollar mi trabajo de tesis doctoral, me detengo, miro hacia atrás y me resulta evidente que hubiese sido imposible llegar hasta acá sin el apoyo de muchas personas y algunas instituciones. Es por eso que deseo dejar aquí plasmado mi agradecimiento:

En lo Institucional al FONCYT y CONICET que financiaron mis horas de trabajo. También al INIBIOLP que abrió sus puertas para ofrecerme el lugar donde realizar mi tesis.

A Rodolfo, por la confianza que deposito en mí y la oportunidad de ingresar en el mundo de la investigación.

A Omar por aceptar ser mi codirector, por todo lo que me permitió aprender.

A mis compañeros del laboratorio:

Ignacio, por tu apoyo incondicional, confianza y paciencia. Jole, por el tiempo que dedicaste desinteresadamente a enseñarme, escucharme y aconsejarme siempre que lo necesite. Gus, por tu ayuda con la microscopia, también por los buenos momentos y amigos compartidos. Paula, por las horas que invertiste interpretándome y ayudando a que exprese mis ideas. Yoly, por compartir tu conocimiento. Rubén, por cuidar los animales que utilice. Bren y Yani, por el aire fresco y juvenil que trajeron.

A los chicos del primero:

Sole, Gaby y Nahuel por permitirme invadirlos cada tanto, por los mates y las charlas. A Wendy por tu buena predisposición para auxiliarme siempre que lo necesité.

A Claudio y Alicia, por su colaboración en el procesamiento de los ovarios y por ayudarme a valorar el trabajo realizado.

A Gloria y todas las chicas de Histología, por ser buenas vecinas. 
A mis nuevos compañeros por soportarme este último trecho, en los buenos y, sobre todo, en los malos días, alentándome a llegar a la meta.

A mis amigas del resto de la vida:

Naty y Carola, por acobijarme en sus familias y no permitir que me desconecte de ese mundo. Al Boyo, por tenerme en cuenta siempre y facilitarme muchas veces las cuestiones cotidianas que me superan.

Al Pela, por presentarte justo en los momentos de crisis y quedarte un rato hasta que pasen.

A Flor, por muchísimos motivos, si la vida no hubiese cruzado nuestros caminos, jamás hubiera llegado hasta acá. Gracias por las horas de estudio compartidas, por tu hospitalidad, las charlas infinitas, los mates lavados, por ver mis cualidades y disculpar mis defectos.

A mis padres, por inculcarme la perseverancia y la responsabilidad que me permitieron recorrer este camino.

A mis hermanos, por acompañarme.

A mis sobrinos, por la luz que arriman a mi vida. 


\section{INDICE}

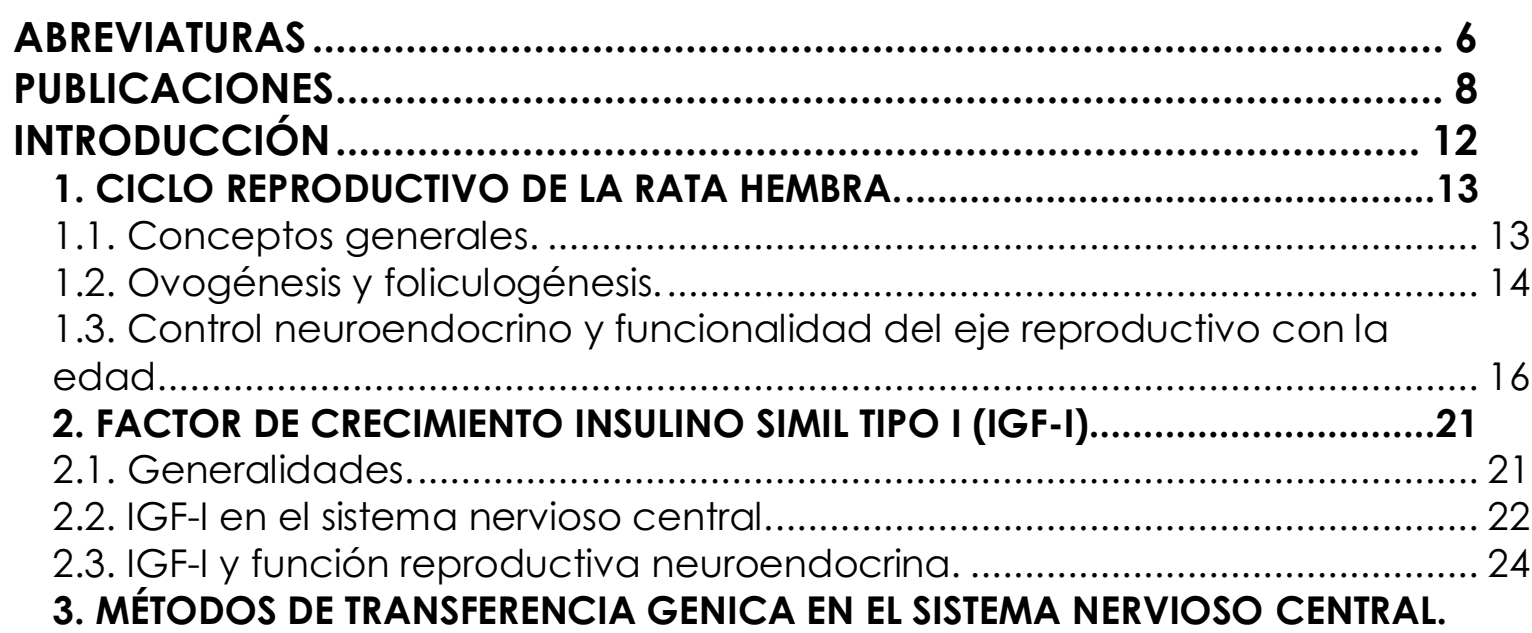

. .26

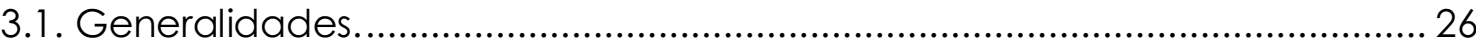

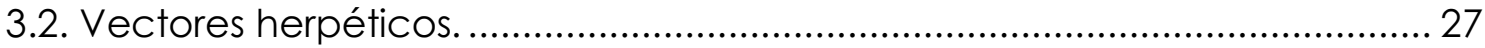

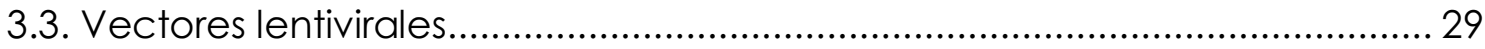

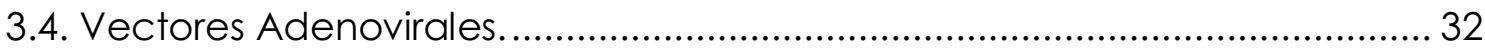

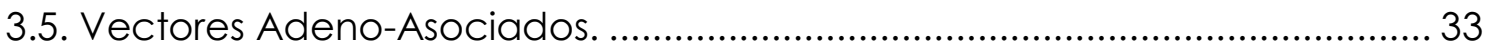

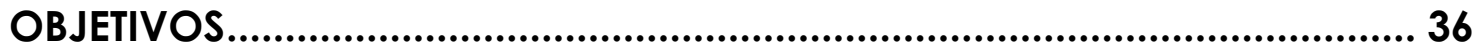

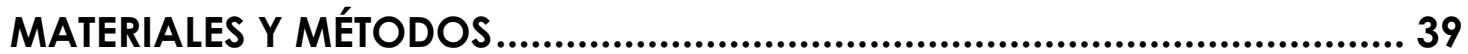

1. DISEÑO EXPERIMENTALL........................................................................

1.1. Caracterización de la ciclicidad estral de ratas de tres grupos etarios. ..... 40

1.2. Caracterización de los vectores adenoasociados........................................ 41

1.3. Evaluar los efectos del IGF-I sobre el eje hipotálamo-hipofiso-ovárico en ratas de mediana edad.

2. MODELOS EXPERIMENTALES.

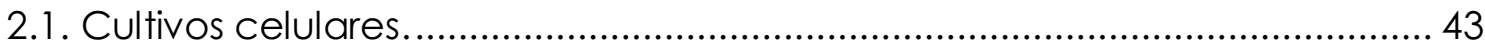

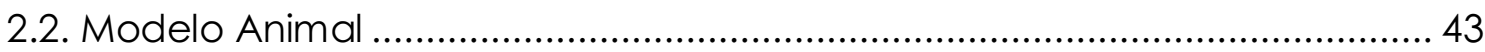

3. VECTORES VIRALES..................................................................................44

4. PROTOCOLOS GENERALES DE TRABAJO PARA EL CULTIVO DE CÉLULAS. ......45

5. PROTOCOLOS GENERALES DE TRABAJO PARA EL MANEJO DE ANIMALES Y

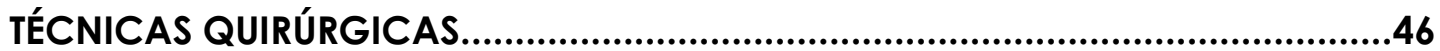

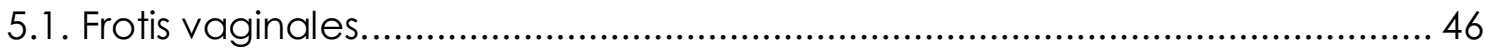

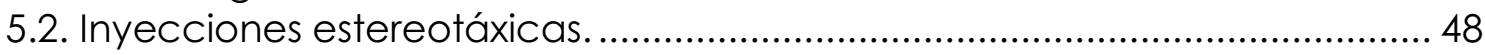

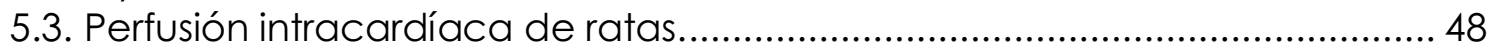

5.4. Obtención de órganos para procedimientos histológicos. ............................ 48

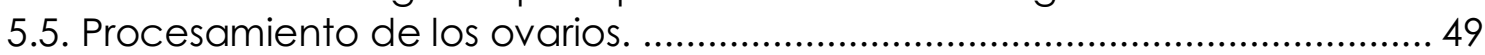

5.6. Obtención del encéfalo para la medida de IGF-I........................................... 49

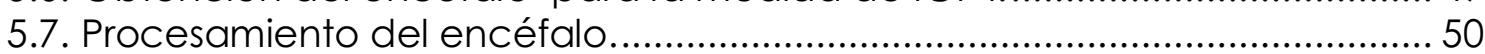

6. PROTOCOLOS GENERALES DE TRABAJO PARA EL DOSAJE HORMONAL..........50

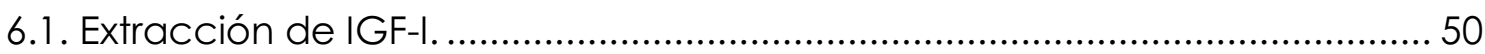

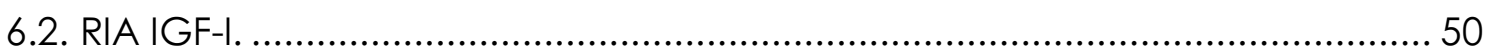

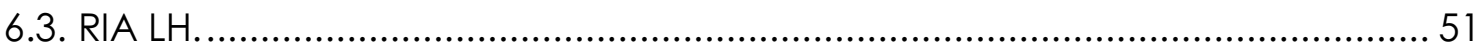

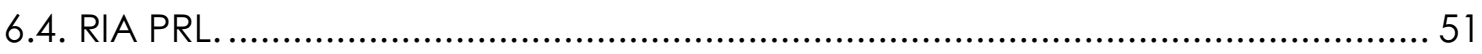

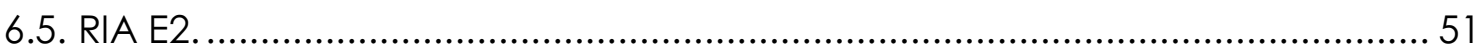

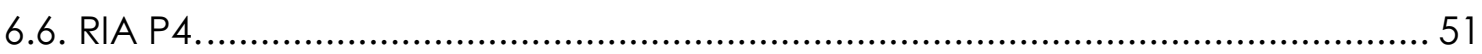

7. ANALISIS ESTADÍSTICO. ......................................................................................51

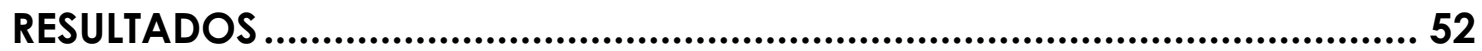


1. RESULTADOS LA DETERMINACIÓN DE LOS PARAMETROS REPRODUCTIVOS Y MORFOMÉTRICOS OBTENIDOS EN LAS RATAS HEMBRAS DE NUESTRA COLONIA.

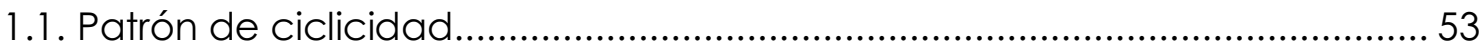

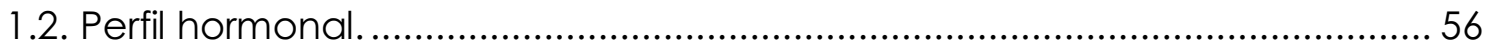

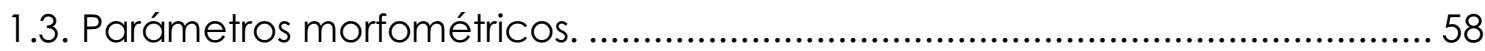

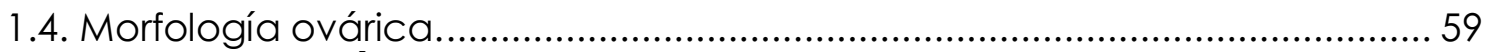

2. CARACTERIZACIÓN DE LOS VECTORES ADENOASOCIADOS. ........................61

2.1. Expresión de IGF-I y DsRed2 en células en cultivo..........................................61 61

2.2. Expresión de DsRed2 en cerebro de rata. .......................................................63 63

3. EFECTO DEL IGF-I SOBRE LOS PARAMETROS REPRODUCTIVOS DE RATAS

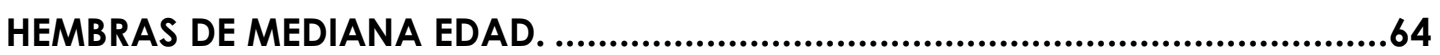

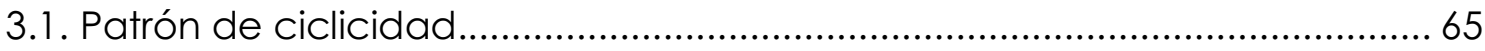

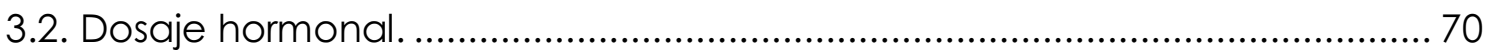

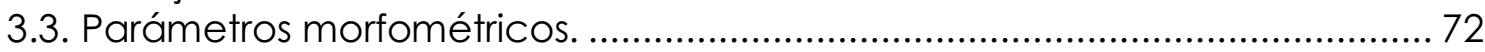

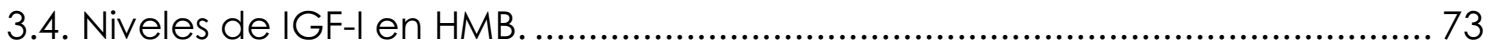

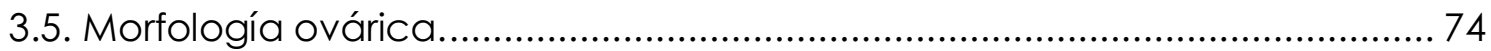

DISCUSIÓN ...................................................................................... 78

1. PARAMETROS REPRODUCTIVOS EN LAS RATAS HEMBRAS DE NUESTRA

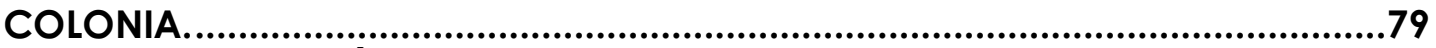

2. CARACTERIZACIÓN DE LOS VECTORES ADENOASOCIADOS. ........................83

3. EFECTO DEL IGF-I SOBRE LOS PARAMETROS REPRODUCTIVOS DE RATAS

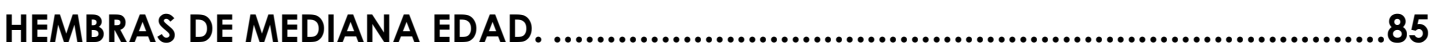

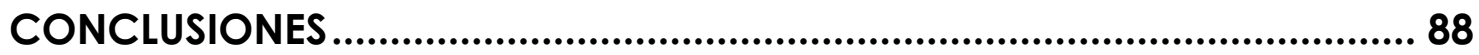

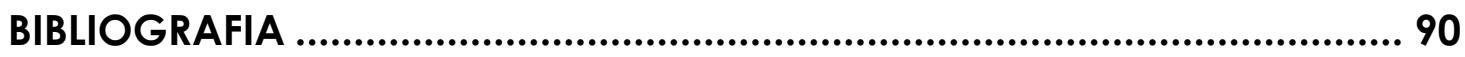




\section{ABREVIATURAS}

3V

AAV

Ad

ARC

AVPV

CC

D

Dp

DsRed2

E

E2

EM

ER

FSH

GABA

$\mathrm{GnRH}$

$\mathrm{HHO}$

$\mathrm{HMB}$

HSV-1

IGFBP

|GF-I

IGF-IR

IN

IRES

IRS

ITR

Kiss

$\mathrm{LH}$

LTR

LV

$M$

ORFs tercer ventrículo

virus adenoasociados

adenovirus

núcleo arcuato

núcleo anteroventral periventricular

corteza cerebral

Diestro

Diestro-proestro

proteína fluorescente roja de Discosoma sp

Estro

estradiol

eminencia media

receptor de estrógenos

hormona folículo estimulante ácido $\mathrm{Y}$-aminobutirico hormona liberadora de gonadotropina eje hipotálamo- hipofiso- ovárico hipotálamo medio basal Virus Herpes Simplex tipo I proteínas de unión a los factores de crecimiento insulino similes factor de crecimiento insulino simil tipo I receptor de factores de crecimiento insulino similes tipo 1 integrasa sitio de entrada al ribosoma sustrato para el receptor de insulina repeticiones terminales invertidas kisspeptina hormona luteinizante repeticiones terminales largas vectores lentivirales Metestro marcos de lectura abiertos Proestro 
PBS

pCMV

PD

$\mathrm{Pe}$

PR

PRL

rAAV

RIA

RRE

RT

SD

SNC

TIDA

$\mathrm{VIH}-1$

$\mathrm{VL}$

$\Psi$ \\ buffer fosfato salino \\ promotor del citomegalovirus \\ enfermedad de Parkinson \\ Proestro-estro \\ proteasa \\ prolactina \\ vectores virales derivados de los AAV \\ radioinmunoensayos \\ elemento de respuesta a Rev \\ transcriptasa inversa \\ Sprague Dawley \\ sistema nervioso central \\ virus de la Inmunodeficiencia Humana tipo I \\ ventrículo lateral \\ señal de empaquetamiento
} neuronas centrales dopaminérgicas tuberoinfundibulares 


\section{PUBLICACIONES}

Parte de este trabajo de tesis recibió la mención especial por el trabajo titulado: EXPRESIÓN DE VECTORES BICISTRÓNICOS DERIVADOS DE UN VIRUS ADENOASOCIADO: ENSAYOS IN VITRO E IN VIVO, autores: Rodríguez SS, Schwerdt JI, Goya RG., otorgado en el marco de las XVIII Jornadas de jóvenes investigadores de la Asociación de Universidades del Grupo Montevideo. Santa Fe, 19- 21 de Octubre de 2010.

Los resultados de la presente tesis fueron publicados en el trabajo que se cita a continuación:

Rodríguez SS, Schwerdt JI, Barbeito CG, Flamini MA, Han Y, Bohn MC, Goya RG. HYPOTHALAMIC INSULIN-LIKE GROWTH FACTOR-I GENE THERAPY PROLONGS ESTRAL CYCLICITY AND PROTECTS OVARIAN STRUCTURE IN MIDDLE-AGED FEMALE RATS. Endocrinology, 2013 Jun;154(6):216673

Trabajos publicados relacionados a esta tesis:

Pardo J, Morel GR, Astiz M, Schwerdt J, León ML, Rodríguez SS, Hereñú CB, Goya RG. GENE THERAPY AND CELL REPROGRAMMING FOR THE AGING BRAIN: ACHIEVEMENTS AND PROMISE. Current Gene Therapy, 2014 Feb;14(1):24-34.

Flamini M.A., Rodríguez SS., Bohn M.C., Goya R.G., Barbeito C.G.. RECUPERACIÓN DE LA CICLICIDAD SEXUAL Y DE LA MORFOLOGÍA OVÁRICA EN RATAS MEDIANTE EL USO DE TERAPIA GÉNICA PARA IGF-I. Terceras Jornadas Internacionales del Instituto de Investigación y Tecnología 
en Reproducción Animal - INITRA. Facultad de Ciencias Veterinarias. U.B.A. Buenos Aires, 15 - 16 de Noviembre 2012.

Rodríguez SS, Schwerdt JI, Barbeito CG, Flamini AM, Han Y, Bohn MC, Goya RG. HYPOTHALAMIC INSULIN-LIKE GROWTH FACTOR-I GENE THERAPY PROLONGS REGULAR ESTRAL CYCLICITY IN MIDDLE-AGED FEMALE RATS. XXVII Congreso Anual de la Sociedad Argentina de Investigación en Neurociencia. Huerta Grande, Córdoba, 1-5 de Octubre de 2012. Abstract publicado en el libro de resúmenes de la SAN; Pág. 231.

Rodríguez SS, Schwerdt JI, Reggiani PC, Barbeito CG, Zucolilli GO, Bohn MC, Goya RG. LA SOBREEXPRESION DE IGF-I EN EL HIPOTÁLAMO MEDIO BASAL-EMINENCIA MEDIA (HMB-EM) PREVIENE LA DISMINUCIÓN DE LA CICLICIDAD NORMAL EN LA RATA HEMBRA DE MEDIANA EDAD. (Poster) LVI Reunión Anual de la SAIC. Mar del Plata, 16-19 Noviembre de 2011 . Abstract publicado en Medicina; Vol. 71 (Supl. III); Pág. 231.

Rodríguez SS, Schwerdt JI, Goya RG. EXPRESION DE VECTORES BICISTRONICOS DERIVADOS DE UN VIRUS ADENOASOCIADO: ENSAYOS IN VITRO E IN VIVO (comunicación oral y póster). XVIII Jornadas de jóvenes investigadores de la Asociación de Universidades del Grupo Montevideo. Santa Fe, 19- 21 de Octubre de 2010. Abstract publicado en Libro de resúmenes XVIII Jornadas de jóvenes investigadores de AUGM; Pág. 143.

Colaboraciones y trabajos realizados durante el desarrollo de a esta tesis:

Camihort GA, Hereñú CB, Luna GC, Rodríguez SS, Bracamonte MI, Goya RG, Cónsole GM. MORPHOLOGICAL CHANGES INDUCED BY INSULIN-LIKE GROWTH FACTOR-I GENE THERAPY IN PITUITARY CELL POPULATIONS IN EXPERIMENTAL PROLACTINOMAS. Cells Tissues Organs. $2010 ; 191(4): 316-25$. 
Morel GR, Sosa YE, Bellini MJ, Carri NG, Rodríguez SS, Bohn MC, Goya RG. GLIAL CELL LINE-DERIVED NEUROTROPHIC FACTOR GENE THERAPY AMELIORATES CHRONIC HYPERPROLACTINEMIA IN SENILE RATS. NeUroscience, 2010 May 19;167(3):946-53.

Morel RG, Carón RW, Cónsole GM, Soaje M, Sosa YE, Rodríguez SS, Jahn GA, Goya RG. ESTROGEN INHIBITS TUBEROINFUNDIBULAR DOPAMINERGIC NEURONS BUT DOES NOT CAUSE IRREVERSIBLE DAMAGE. Brain Research Bulletin, 2009 Dic; 80(6): 347-352

Rodríguez SS, Castro MG, Brown OA, Goya RG, Cónsole GM . GENE THERAPY FOR THE TREATMENT OF PITUITARY TUMORS. Expert Review of Endocrinology \& Metabolism, 2009 Jul, 4(4): 359-370.

Reggiani PC, Morel GR, Cónsole GM, Barbeito CG, Rodríguez SS, Brown OA, Bellini MJ, Pléau JM, Dardenne M, Goya RG. THE THYMUSNEUROENDOCRINE AXIS: PHYSIOLOGY, MOLECULAR BIOLOGY AND THERAPEUTIC POTENTIAL OF THE THYMIC PEPTIDE THYMULIN Annals Of The New York Academy Of Sciences 2009 Feb;1 153:98-106.

Morel GR, Reggiani PC, Cónsole GM, Rimoldi OJ, .Vesenbeckh SM, García-Bravo MM, Rodríguez SS, Brown OA, Goya R G... POTENTIAL OF GENE THERAPY FOR RESTORATION OF ENDOCRINE THYMIC FUNCTION IN THYMUS-DEFICIENT ANIMAL MODELS. Current Gene Therapy 2008 Feb;8(1):49-53.

Reggiani PC, Flamini MA, Rodríguez SS, Goya RG, Barbeito CG PREVENTIVE ACTION OF NEONATAL GENE THERAPY WITH THE THYMIC HORMONE THYMULIN ON THE OVARIAN ATROPHY OF ADULT NUDE MICE. Biocell $2008 ; 32(1): 137$.

Rodríguez SS, Reggiani PC, Schwerdt JI, Bohn MC, Rimoldi OJ, Goya RG. CONTROL OF RED FLUORESCENT PROTEIN EXPRESSION BY TETRACYCLINE IN AN ADENOVIRAL BIVECTORIAL SYSTEM (Póster). XLVI Reunión Anual SAIB. Puerto Madryn, Chubut, 30 de Noviembre-3 de Di- 
ciembre de 2010. Abstract publicado en BIOCELL 2010, Vol. 34 (Supl.); Pág. 60.

Morel GR, Bellini MJ, Rodríguez SS, Goya RG. TERAPIA GÉNICA CON GDNF MEDIANTE VECTORES ADENOVIRALES RECOMBINANTES EN UN MODELO MURINO DE NEURODEGENERACIÓN DOPAMINÉRGICA SENIL (comunicación oral y póster). XVI Jornadas de jóvenes investigadores de la Asociación de Universidades del Grupo Montevideo. Montevideo, Uruguay,27- 29 de Octubre de 2008.

Reggiani PC, Barbeito CG, Flamini MA, Rodríguez SS, Cónsole GM, Dardenne M, Goya RG NEONATAL THYMULIN GENE THERAPY PREVENTS THE CHARACTERISTIC OVARIAN ATROPHY OF ADULT NUDE MICE (Póster) 7th International Congress of International Society for NeurolmmunoModulation, Río de Janeiro, Brasil, 24-27 Abril 2008. Abstract publicado en VII ISNIM Congress; Pág. 37. 
INTRODUCCIÓN 


\section{CICLO REPRODUCTIVO DE LA RATA HEMBRA.}

\subsection{Conceptos generales.}

La función reproductiva en los mamíferos es regulada mediante una compleja red neurohormonal que se encarga de trasmitir las señales que se originan e impactan en los tres niveles del eje hipotálamo- hipofiso- ovárico (HHO).

Desde el punto de vista neuroendocrino el eje $\mathrm{HHO}$ es gobernado por la hormona liberadora de gonadotropina $(\mathrm{G} n \mathrm{RH}$, por sus siglas en ingles de Gonadotropin-releasing hormone) (Monahan et al., 1971; Schally et al., 1971a), la que es sintetizada en el hipotálamo por neuronas especializadas. Estas neuronas envían sus proyecciones hacia la eminencia media (EM) donde la GnRH es secretada de manera pulsátil al sistema porta hipofisario y transportado hacia la hipófisis anterior. La GnRH actúa aquí sobre sus células diana, los gonadotropos, estimulando la síntesis y secreción a circulación, de las dos gonadotropinas: la hormona luteinizante (LH, por sus siglas en ingles de Luteinizing hormone) y la folículo estimulante (FSH, sus siglas en ingles de Follicle-stimulating hormone) (Levine and Ramirez, 1982; Schally et al., 1971b). En las hembras los órganos diana de la FSH y LH son los ovarios, donde dirigen la foliculogenesis, inducen la ovulación y estimulan la secreción de esteroides sexuales. Los esteroides sexuales transportados vía sanguínea actúan sobre sus receptores en el hipotálamo y la hipófisis para regular la secreción de GnRH y LH mediante circuitos de retroalimentación negativa y positiva (Sisk and Foster, 2004).

Estos cambios hormonales que conducen a la ovulación ocurren a intervalos regulares de tiempo, dando lugar a lo que se denomina ciclo reproductivo. En particular, en la rata hembra, el ciclo reproductivo se conoce como ciclo estral y puede dividirse en cuatro etapas o estadios. La primera etapa del ciclo se denomina proestro y se corresponde con el momento en que un animal "entra en celo". El próximo estadio 
llamado estro (celo) es el momento en que la hembra está dispuesta para recibir el coito masculino y ser fecundada. Si la concepción no se produce durante el celo, la actividad de los órganos genitales disminuye gradualmente, este estadio es llamado metestro. La última etapa del ciclo, el diestro, es un breve período de inactividad. Luego el animal comienza un nuevo ciclo desde la etapa de proestro (Heape, 1900). Estos estadios del ciclo estral están asociados a modificaciones en los ovario en respuesta a los cambios neuroendocrinos que se producen en el eje HHO. De esta forma, un método relativamente no invasivo que proporciona un índice del estado funcional del eje HHO es la evaluación de los cambios de la citología vaginal (Goldman et al., 2007).

\subsection{Ovogénesis y foliculogénesis.}

Durante la vida prenatal, en el ovario del embrión se produce la primera división meiótica del ovocito que progresa solo hasta el estadio diploteno de la profase donde se mantiene hasta que es seleccionado para la maduración durante el proestro en la rata adulta. Una vez seleccionado, el ovocito comienza el paso final madurativo dentro del folículo, el número de cromosomas se reduce a partir del contenido diploide de 42 al número haploide de 21, generándose un cuerpo polar (Ayalon et al., 1972; Tsafriri and Kraicer, 1972). Una vez que el primer cuerpo polar es expulsado, se produce la ovulación. El óvulo recién ovulado es haploide y tiene los cromosomas metafásicos alineados a lo largo del huso mitótico. Al pasar a las trompas, ya se encuentra en la metafase II y está disponible durante el estro para ser fecundado por el espermatozoide haploide (Mandl, 1963). La segunda división meiótica procede si el óvulo es fecundado. En ausencia de la fecundación, el óvulo se involuciona y un nuevo grupo de ovocitos intrafoliculares inician la maduración en el próximo proestro.

Cuando un ovocito, en el periodo fetal de la rata, se rodea de una capa definida de células escamosas que forman una capsula alrededor de él, es considerado un folículo primordial (Fig. 1). Luego del na- 
cimiento aparecen los folículos primarios, en ellos el epitelio escamoso se transforma en cuboide y a esta capa epitelial se la conoce como células de la granulosa. Posteriormente las células de la granulosa se multiplican, formando primero una capa doble y finalmente una capa múltiple, a estas estructuras se las identifica como folículos secundarios. Alrededor de la capa de células granulosas que se amplifico se desarrolla una vaina exterior derivada del estroma ovárico, la teca que se puede dividir en una teca interna y teca externa. A continuación en la multicapa de la granulosa se forman espacios llenos de líquido que se agrandan y finalmente se funden en una sola cavidad más grande, el antro. A esta estructura se la denomina folículo terciario o folículo antral. El contenido líquido del antro aumenta en volumen cuando se aproxima la ovulación y estos folículos son llamados folículos preovulatorios (Cappellen, 1998). Luego de cada ovulación se forman espontáneamente a partir de las células de la teca y de la granulosa los cuerpos lúteos. Estos adquieren su máximo tamaño en el diestro de un ciclo y lo mantienen hasta el metestro del próximo ciclo, momento en el cual sufre una regresión(Hilliard, 1973). Cada cuerpo lúteo puede persistir por 12 o 14 días, de forma que en el ovario de una rata que cicla pueden coexistir tres o más generaciones de cuerpos lúteos, provenientes de las sucesivas ovulaciones (Greenwald and Rothchild, 1968).

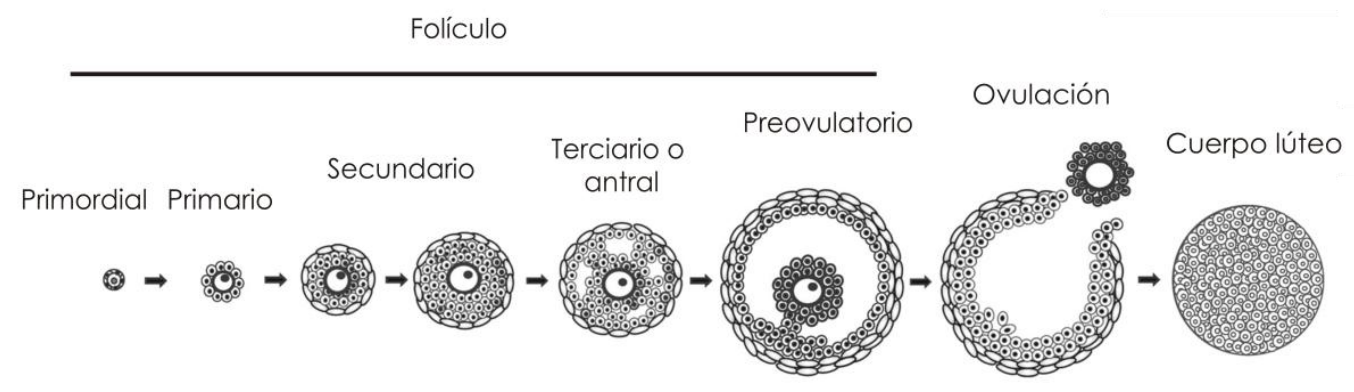

Figura 1: Etapas de la foliculogénesis. (Modificado de Edson et al., 2009)

No todos los folículos presentes en el ovario en el momento del nacimiento están destinados a ovular. En la rata hay una disminución en el número total de ovocitos de aproximadamente 35.000 en el momen- 
to del nacimiento hasta cerca de 2.000 a los 947 días de vida (Arai, 1920). Está descripto que en ratas, entre los días 1 y 3 postnatales, hay entre un $50-70 \%$ de los ovocitos que permanecen desnudos, generalmente degenerados. Por lo tanto, antes de la formación de los folículos, se produce la pérdida masiva de células germinales. Los folículos también se pierden por un proceso degenerativo llamado atresia, que se caracteriza histológicamente por el desprendimiento de la membrana basal de las células de la granulosa, la presencia de núcleos picnóticos y una reducción masiva en el número de células de la granulosa. Siendo atresicos aproximadamente el 70\% de los folículos antrales (Hsueh et al., 1994).

\subsection{Control neuroendocrino y funcionalidad del eje reproductivo con la edad.}

El principal mecanismo por el cual el organismo altera su estado reproductivo durante el desarrollo es la modulación de la frecuencia de los pulsos de GnRH (Sisk and Foster, 2004). Tempranamente en la vida prenatal de las ratas comienza la secreción de GnRH, la que se incrementa hacia el final del periodo gestacional (Aubert et al., 1985) posteriormente disminuye durante todo el período prepuberal y se incrementa gradualmente al comienzo de la pubertad (Sisk et al., 2001). Entre los días 35 y 45 luego del nacimiento se produce la apertura vaginal y las ratas comienzan a ciclar de forma regular (Ojeda and Skinner, 2006). Entonces la secreción de GnRH se mantiene alta para estimular la secreción de gonadotropinas y hormonas esteroides, dando como resultado la maduración gonadal completa y la capacidad de expresar el comportamiento reproductivo (Sisk and Foster, 2004).

En ratas adultas que ciclan regularmente el patrón de secreción de GnRH presenta dos modos: uno pulsátil y el otro en forma de una clara elevación o pico en la tarde del proestro (Levine and Ramirez, 1982; Sarkar and Fink, 1980). El modo pulsátil de secreción es el que se presenta en la mayoría de los estadios del ciclo estral y es el responsable de la 
estimulación de la liberación pulsátil de LH desde la hipófisis anterior para modular el desarrollo folicular y la esteroidogénesis en el ovario. El otro modo, el pico de GnRH en la tarde del proestro, induce el aumento de LH que conduce a la ovulación. Ambos modos de secreción están regulados por la acción de los esteroides ováricos mediante mecanismos de retroalimentación. El estrógeno regula negativamente la secreción pulsátil de GnRH para evitar un exceso de liberación de gonadotropinas hasta que se produce la maduración completa de los folículos. Cuando esto sucede, se produce un aumento de estrógeno en circulación que induce el pico de GnRH por un mecanismo de retroalimentación positiva (Uenoyama et al., 2009). Los dos mecanismos de retroalimentación que ejercen los estrógenos sobre las neuronas productoras de GnRH no están completamente dilucidados, si bien se cree que se produce en forma indirecta a través de vías estimulatorias e inhibitorias aferentes (Radovick et al., 2012).

Entre los principales neurotransmisores y neuropéptidos involucrados en la transmisión de la retroalimentación de los esteroides ováricos y de esta forma moduladores de los modos de la liberación de GnRH durante el ciclo estral, se encuentran la kisspeptina (Kiss), el ácido Yaminobutirico (GABA) y el glutamato. La Kiss es producida por neuronas que en su mayoría (90\%) expresan el receptor de estrógenos alfa $(E R \alpha)(L e h m a n$ et al., 2010). Estas neuronas están concentradas en dos áreas del cerebro, el núcleo arcuato (ARC) y en el núcleo anteroventral periventricular (AVPV). Las neuronas productoras de Kiss localizadas en el ARC son las que intervienen en la regulación del modo pulsátil de secreción de GnRH (Li et al., 2009), mientras que la población del AVPV controla el pico preovulatorio, mediando así la retroalimentación positiva de los estrógenos (Adachi et al., 2007).

Las neuronas que producen GABA también expresan ER (Flügge et al., 1986). La liberación de GABA se reduce durante el pico de LH y se incrementan durante la supresión de LH inducidos por estradiol (E2) 
(Herbison et al., 1991; Jarry et al., 1995). Está descripto que el tratamiento con E2 que evoca el pico de LH produce alteraciones en la frecuencia de transmisión de GABA a las neuronas de GnRH. En la mañana cuando hay una supresión de la secreción de LH causada por la retroalimentación negativa la frecuencia de transmisión de GABA esta reducida, mientras que en la tarde cuando se produce el pico de secreción de $\mathrm{GnRH/LH}$ hay un aumento de esta frecuencia. Estos hallazgos involucran a las neuronas GABAérgicas en la transmisión de la retroalimentación positiva y negativa sobre la liberación de GnRH (Christian and Moenter, 2007).

Las neuronas productoras de GnRH expresan receptores para glutamato (Eyigor and Jennes, 1996). Este neurotransmisor facilita la pulsátilidad e incrementa la secreción de GnRH (Maffucci and Gore, 2009). La liberación de glutamato se incrementa durante la liberación de LH inducida por E2 y el uso de antagonistas de receptores para glutamato bloquean el pico preovulatorio de LH, evidenciando que las acciones de retroalimentación positiva de esteroides incluyen la estimulación de la liberación de glutamato (Jarry et al., 1995).

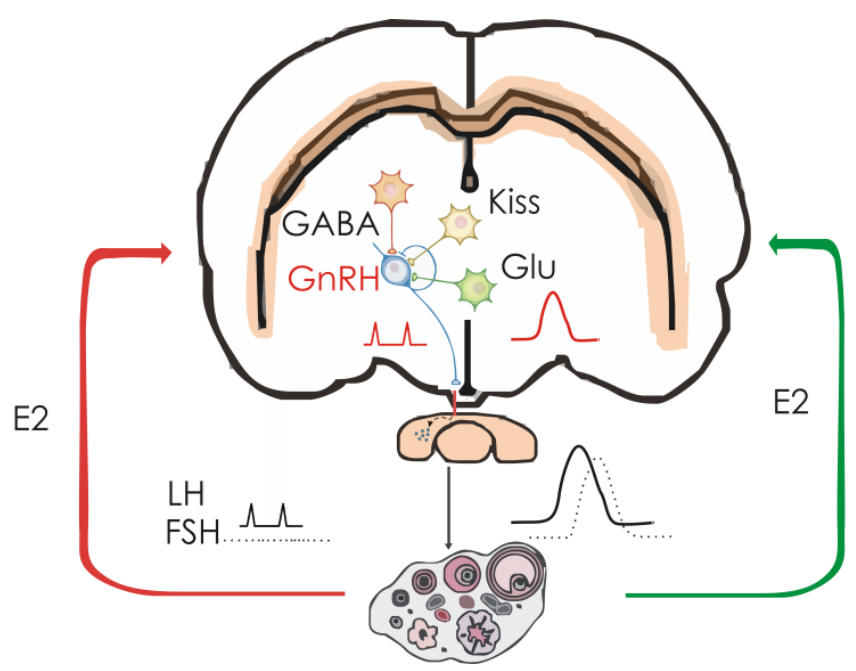

Figura 2: Diagrama esquemático de los principales moduladores del eje hipotálamo- hipofiso- ovárico de una rata hembra adulta jóven. 
En ratas hembra de mediana edad (8-12 meses) tanto la capacidad reproductiva como la incidencia de ciclos estrales regulares se encuentran disminuidas respecto de las ratas adultas jóvenes (Acuña et al., 2009; Ingram et al., 1958; Matt et al., 1986). Los cambios en la ciclicidad estral asociados a la edad que se observan en ratas de mediana edad son acompañados por un retraso y atenuación del pico preovulatorio de LH (Wise, 1984), niveles séricos de FSH aumentados y un perfil de E2 sérico alterado con ausencia del pico en el mediodía del proestro respecto de las ratas jóvenes, (Wise, 1982).

Aschheim y col. demostraron que si a ratas seniles que ciclaban en forma irregular o estaban en un estado de estro constante se las trasplantaba con ovarios provenientes de ratas jóvenes, éstas no logran recuperar la regularidad en los ciclos estrales (Aschheim, 1964), demostrando claramente que el ovario no es la causa determinante de la senescencia reproductiva. La alteración en la secreción de LH no se debe a una capacidad de respuesta hipofisaria reducida a la GnRH (Wise and Ratner, 1980a). A nivel hipotalámico, mediciones de perfusión pushpull de GnRH desde el hipotálamo mediobasal de ratas de mediana edad sugieren que la liberación de GnRH es atenuada en condiciones de retroalimentación positiva de E2 (Rubin and Bridges, 1989) y esta observación no es atribuible al número reducido, o a la morfología anormal de las neuronas productoras de GnRH (Krajnak et al., 2001; Rubin et al., 1994), ni a un contenido reducido de péptido de GnRH, que se mantiene sin cambios o incluso aumenta con la edad (Rubin et al., 1984). Tomados en conjunto, los datos disponibles sugieren que los cambios que se presentan en la transición hacia la senescencia reproductiva reflejan la alteración en la activación que sufren las neuronas productoras de GnRH bajo condiciones de retroalimentación positiva de estrógenos.

En ratas de mediana edad se ha observado que el E2 induce la expresión del RNAm de Kiss en menor grado que en ratas jóvenes (NealPerry et al., 2009), también se halló que el número de neuronas inmu- 
noreactivas para Kissl esta reducido en el AVPV el día del pico de LH (Lederman et al., 2010). En cuanto a los niveles de glutamato se ha documentado que se encuentran reducidos en el área preóptica de ratas de mediana edad ovariectomizadas y tratadas con E2 (Neal-Perry et al., 2005). En el área preóptica de ratas hembras de mediana edad se observa un aumento de la liberación de GABA. La relación total glutamato:GABA se reduce significativamente en ratas de mediana edad respecto de las ratas jóvenes, lo que sugiere un aumento en la neurotransmisión inhibitoria y una disminución en la neurotransmisión excitatoria (Neal-Perry et al., 2008). En conjunto esta información demuestra que las ratas de mediana edad no responden a la retroalimentación positiva del E2 con una apropiada modulación de los neurotransmisores excitatorias e inhibitorias en el hipotálamo, que a su vez causan la reducción de la liberación de GnRH. Si bien estas alteraciones son las que conducen finalmente a la senescencia reproductiva existen otras moléculas involucradas en este proceso.

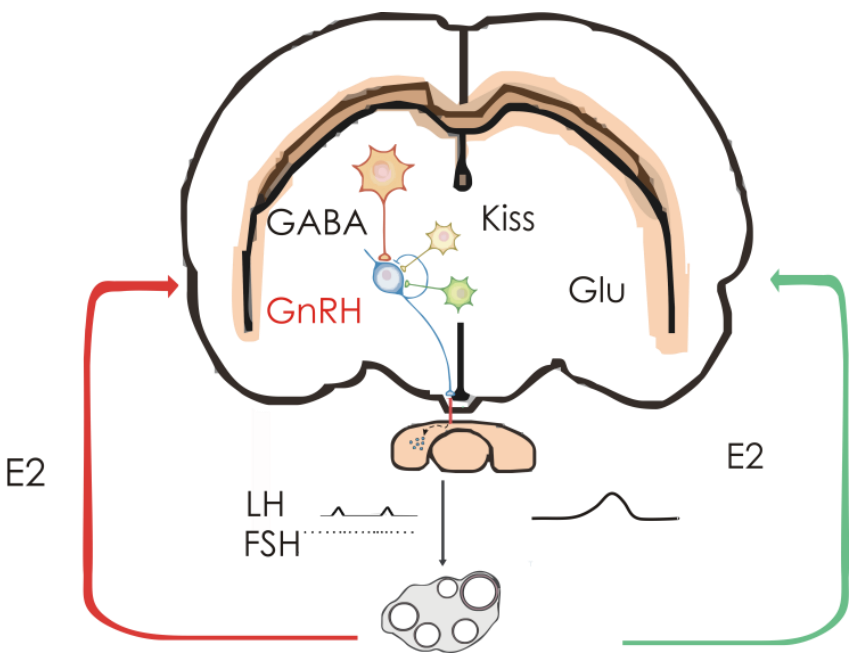

Figura 3: Diagrama esquemático de los principales moduladores del eje hipotálamo- hipofiso- ovárico de una rata hembra de mediana edad. 


\section{FACTOR DE CRECIMIENTO INSULINO SIMIL TIPO I (IGF-I)}

\subsection{Generalidades.}

El factor de crecimiento insulino simil tipo I (IGF-I, por sus siglas en ingles de Insulin-like growth factor type I) es un polipéptido que pertenece a la familia de la insulina (Blundell and Humbel, 1980) sintetizado en múltiples órganos incluyendo hígado, pulmones, riñones, timo, corazón, músculo, gónadas y cerebro (D’Ercole et al., 1984). En el medio extraceIular el IGFI-I se une a moléculas con las que tienen alta afinidad, Ilamadas proteínas de unión a los factores de crecimiento insulino similes (IGFBP, por sus siglas en ingles de Insulin-like growth factor-binding protein), las IGFBPs son capaces de regular la cantidad de IGF-I en circulación, su transporte hacia células y tejidos determinados, su disponibilidad para interaccionar con sus receptores específicos, y la acción de los IGF-I en sus células diana, potenciándola o inhibiéndola (Clemmons, 1990; Firth and Baxter, 2002). La mayoría de las funciones biológicas del IGF-I se producen a través de su unión al receptor de factores de crecimiento insulino similes tipo 1 (IGF-IR, por sus siglas en ingles de insulin-like growth factor 1 receptor), el cual se encuentra en músculo, ovario, hipófisis y cerebro (Cardona-Gómez et al., 2000; Vendola et al., 1999; Werther et al., 1989). El IGF-IR es un receptor heterotetrámerico con actividad tirosín quinasa compuesto por dos subunidades a y dos $\beta$ unidas por puentes disulfuro. La subunidad a posee el sitio de unión a ligando, en tanto que la subunidad $\beta$ posee la actividad tirosín quinasa (LeRoith et al., 1995). El IGF-IR se autofosforila al ser activado por IGF-I y también es capaz de fosforilar otros sustratos que contienen tirosinas, tales como el sustrato para el receptor de insulina (IRS, por sus siglas en ingles de Insulin receptor substrate) y la proteína SHC. La fosforilación de IRS activa la vía de la enzima fosfatidil-inositol-3 quinasa, la cual está implicada en procesos celulares de crecimiento y antiapoptóticos (Yuan and Yankner, 2000). La fosforilación de la SHC lleva a la activación de la vía de las MAP quinasas, que ha sido relacionada con diferenciación celu- 
lar (Kim et al., 1998; Kurihaar et al., 2000), y con la regulación de la maquinaria de apoptosis (Hwang et al., 2007; Valentinis et al., 1999).

\subsection{IGF-I en el sistema nervioso central.}

Los tres componentes del sistema de IGF-I, es decir IGF-I, IGF-IR y las IGFBPs están localizados y son sintetizados en el sistema nervioso central (SNC) (Goodyer et al., 1984; Marks et al., 1991; Ocrant et al., 1990; Rotwein et al., 1988; Werther et al., 1989), pudiendo actuar de manera paracrina en algunas áreas del cerebro. El IGF-I posee acciones neurotróficas observadas en cultivos de líneas celulares neuronales o en cultivos primarios neuronales, tales como la proliferación celular (Påhlman et al., 1991; Werther et al., 1993), la supervivencia (Torres-Aleman et al., 1990; Torres-Aleman et al., 1992), el crecimiento de las neuritas (TorresAleman et al., 1990) y la diferenciación (Brooker et al., 2000). También se ha demostrado que el IGF-I es un modulador específico de la eficacia sináptica mediante la regulación de la formación de sinapsis, la liberación neurotransmisores y la exicitabilidad neuronal (O'Kusky et al., 2000; Torres-Aleman, 1999).

Durante la embriogénesis el IGF-1 se expresa en múltiples regiones del cerebro, tales como bulbo olfatorio, corteza cerebral, hipocampo, cuerpo estriado, tálamo e hipotálamo (Bondy, 1991; García-Segura et al., 1991). Después del nacimiento la expresión de IGF-1 desciende hasta alcanzar niveles muy bajos en el cerebro adulto (Miller and Gore, 2001; Park and Buetow, 1991; Rotwein et al., 1988). Sin embargo, en respuesta a diferentes tipos de injuria el cerebro produce factores de crecimiento, incluyendo el IGF-I (Gluckman et al., 1992; Kazanis et al., 2004; Yamaguchi et al., 1991), este hallazgo impulso el estudio de los efectos del IGF-I frente a diversos tipos de injuria. Cuando se evaluó el efecto de la inyeción de IGF-I frente a un insulto neurotóxico, la desaferenciación de la corteza cerebelosa con 3-acetilpiridina, se produjo una reducción en el número de astrocitos reactivos, mientras que el bloqueo de la actividad endógena de IGF-I ocasionó el efecto opuesto (Fernandez et al., 
1997). En injurias traumáticas, la sobreexpresión condicional de IGF-1 en ratones genera un aumento progresivo de los niveles de IGF-1 acompañados de una mejora de la astrocitosis reactiva y la reducción aguda de la neurodegeneración hipocampal, culminando en una mayor supervivencia de las neuronas después de una lesión producida por una contusión cerebral. Además, la sobreexpresión de IGF-I resulta en la mejora de la función motora y cognitiva de los ratones con lesión cerebral (Madathil et al., 2013). En el mismo sentido, la inyección intracerebroventricular de IGF-I en ratas con una injuria cerebral hipoxica-isquemica reduce la perdida neuronal (Gluckman et al., 1992). Toda esta evidencia conduce a proponer al IGF-I como posible agente neuroprotector.

Sumada a la evidencia anterior, el descenso en los niveles cerebrales de IGF-1 se relaciona con el deterioro de las funciones cognitivas asociadas al envejecimiento, como la enfermedad de Alzheimer (Rivera et al., 2005; Steen et al., 2005). Cuando se evaluó el efecto del IGF-I sobre cultivos neuronales de hipocampo de rata tratados con péptidos derivados del péptido $\beta$ amiloide, fue posible prevenir y rescatar los cultivos del daño neurotóxico (Doré et al., 1997). En ratones APP/PS2, modelos de la enfermedad de Alzheimer, el tratamiento con IGF-I revierte el deterioro del aprendizaje espacial y la memoria. Además, reduce la cantidad total de $\beta$ amiloide y gliosis asociada a las placa amiloides (Carro et al., 2006). También se encontraron niveles de IGF-I disminuidos en la esclerosis-lateral-amiotrófica, una enfermedad neurodegenerativas que afecta las neuronas motoras espinales y del tronco cerebral, lo que lleva a la atrofia de las extremidades y los músculos respiratorios (Wilczak et al., 2003). En modelos animales de la enfermedad, aprovechando la capacidad de los vectores virales adenoasociados de ser transportados de manera eficiente desde el músculo a las neuronas motoras de la médula espinal, se ha transferido el gen del IGF-1, logrando el retraso de la aparición de los síntomas y prolongando la vida de los animales tratados(Kaspar et al., 2003). Más aún el IGF-I se ha evaluado como agente terapéutico para la esclerosis-lateral-amiotrófica en varios 
ensayos clínicos, revelando leves pero significativos efectos beneficiosos del tratamiento con IGF-I (Beauverd et al., 2012). En otra enfermedad neurodegenerativa, la enfermedad de Parkinson (PD, por sus siglas en ingles de Parkinson's disease), hay una degeneración de las neuronas dopaminérgicas nigroestriatales. Los pacientes con PD presentan, además de las deficiencias motoras, alteraciones funcionales en el eje hipotálamo-hipofisisario (Bellomo et al., 1991; Stypuła et al., 1996). En nuestro laboratorio hemos utilizado ratas seniles en las que el envejecimiento provoca una disfunción progresiva y pérdida de neuronas centrales dopaminérgicas tuberoinfundibulares (TIDA), las cuales están involucradas en el control inhibitorio tónico de prolactina (PRL), para evaluar la eficacia del IGF-I en la protección de estas neuronas. Con este estudio demostramos que la terapia con IGF-I es capaz de revertir la disfunción TIDA en ratas seniles (Hereñú et al., 2007). En conjunto toda la evidencia existente demuestra que es plausible la utilización del IGF-I como agente terapéutico en procesos que llevan al deterioro o disfunción neuronal.

\subsection{IGF-I y función reproductiva neuroendocrina.}

El IGF-I además de actuar en el eje somatotrófico, puede intervenir en la regulación de otros ejes neuroendocrinos. Existe evidencia que apoyan el rol del IGF-I sobre el establecimiento y mantenimiento de la función reproductiva, con acciones en los tres niveles del eje HHO. En particular, a nivel central, el IGF-I ha sido postulado como un regulador de las neuronas productoras de GnRH. En estudios in vitro realizados en líneas celulares hipotálamicas que expresan, sintetizan y liberan GnRH se ha observado que el tratamiento con IGF-I incrementa los niveles de ARNm, la biosíntesis y secreción de GnRH (Anderson et al., 1999; Longo et al., 1998; Zhen et al., 1997). Además, en EM provenientes de ratas hembras prepuberes se comprobó que el IGF-I era capaz de provocar la liberación de GnRH (Hiney et al., 1991), aportando evidencia que el IGF-I es una de las múltiples señales que participan en la iniciación de la pubertad. También, la inyección de IGF-I en el tercer ventrículo (3V) de 
ratas peripuberes incrementó la liberación de LH y adelantó la edad de la apertura vaginal (Hiney et al., 1996). Por otro lado la inyección en $3 \mathrm{~V}$ de un antagonista específico del IGF-IR, el JB-1, inhibe la capacidad reproductiva, evidenciada por el cese prolongado de los ciclos estrales (Todd et al., 2007), asimismo atenúa y retarda la liberación de LH (Todd et al., 2010). En conjunto esta evidencia indica que el IGF-I a nivel central está involucrado tanto en el inicio de la pubertad, como en el mantenimiento de la capacidad reproductiva y que la inhibición de su acción conduce a la perdida de la misma.

Las neuronas productoras de GnRH son reguladas directa e indirectamente por E2 (Kelly and Qiu, 2010; Petersen et al., 2003; Rønnekleiv et al., 2010) y se ha demostrado que el IGF-IR interactúa con los ERs para regular diferentes procesos neuronales, tales como la supervivencia neuronal y la diferenciación en cultivos primarios hipotalámicos de rata, y en la inducción de la plasticidad sináptica en el hipotálamo de ratas hembra adultas (Dueñas et al., 1996; Fernandez-Galaz et al., 1997; Fernandez-Galaz et al., 1999). En base a esta evidencia se cree que el IGF-I podría estar interactuando con el E2 en la regulación de las neuronas productoras de GnRH. En apoyo a esta hipotesis se ha encontrado que el IGF-IR colocaliza con el ER en varias regiones del cerebro, incluídas el área preóptica y el hipotálamo, regiones en donde se encuentran las neuronas productoras de GnRH (Cardona-Gómez et al., 2000; Miller and Gore, 2001). Asimismo se ha encontrado que los niveles de ARNm de IGF-I tanto en AVPv como en hipotálamo medio basal (HMB) eminencia media son significativamente menores en ratas de mediana edad respecto de ratas jóvenes (Miller and Gore, 2001). Teniendo en cuenta esta evidencia podemos sugerir que la disminución en los niveles de IGF-I es una de las señales involucradas en el inicio de la pérdida de función reproductiva asociada al envejecimiento. Consecuentemente, el aumento de los niveles de IGF-I hipotalámico podría preservar la función reproductiva. 


\section{MÉTODOS DE TRANSFERENCIA GENICA EN EL SISTEMA NERVIOSO}

\section{CENTRAL.}

\subsection{Generalidades.}

La transferencia génica se ha convertido en una de las herramientas más utilizadas para la investigación básica y clínica actual. Típicamente, el término transferencia génica hace referencia al uso de ácidos nucleicos para incrementar, disminuir o suprimir la expresión de una proteína de interés (De Laporte et al., 2006). La transferencia de ácidos nucléicos desnudos resulta dificultosa debido a su rápida eliminación, la presencia de nucleasas que limitan su vida media y la baja eficiencia de captación celular (Takakura et al., 2001). Para sortear estas limitaciones se han diseñado vehículos de transferencia especializados que mejoran la eficiencia y especificidad de la transferencia génica. Algunas de la propiedades que debería poseer un vector de transferencia génica ideal son: una elevada eficiencia de transferencia, un alto grado de especificidad, baja toxicidad e inmunogenicidad, una expresión duradera y una aceptable bioseguridad (Patil et al., 2005). Además, el sistema nervioso central por sus características estructurales y funcionales, presenta dificultades particulares al momento de diseñar estrategias viables para la transferencia génica, entre las que se encuentran la difícil accesibilidad, la heterogeneidad celular y la naturaleza postmitótica de las neuronas (Hsich et al., 2002; P. de Lima et al., 2005; Sapolsky, 2003). Los vehículos de transferencia génica más utilizados en el SNC son los vectores virales (Gene therapy Clinical Trials Worldwide., 2014). Los virus representan sistemas naturales donde los genes se introducen y son expresados en las células diana, por lo cual representan un método lógico para lograr la transferencia génica con construcciones artificiales (Shen and Post, 2007). Para asegurar la transferencia eficiente del material génico a la célula diana, el genoma viral está protegido por una cobertura proteica codificada por el mismo. En forma adicional, algunos virus tienen una bicapa lipídica, que deriva de la célula diana y po- 
see proteínas virales que le garantizan la unión a receptores celulares que le otorgan espicificidad de infección y le facilitan el ingreso a otras células. Una vez dentro de la misma pueden controlar la maquinaria génica permitiendo la expresión de los componentes virales. Aunque estas propiedades innatas de los virus resultan ventajosas en el desarrollo de vectores para la transferencia génica, debido a que muchos de los virus pueden causar enfermedades, los vectores derivados de ellos tienen el riesgo potencial de ser patógenos. Otras desventajas de estos vectores residen en la complejidad de la producción y purificación de los mismos. Se han desarrollado numerosos vectores virales y cada uno ofrece características particulares para la transferencia génica. Así, la elección del vector viral se realiza teniendo en cuenta la especificidad de transducción, duración e intensidad de la expresión del transgén, la capacidad de empaquetamiento y la complejidad en su proceso de producción y purificación(Lentz et al., 2012). Los vectores virales más utilizados en el SNC son los que derivan del Virus Herpes Simplex tipo I (HSV1), del virus de la Inmunodeficiencia Humana tipo I(VIH-1), de adenovirus (Ad) y de virus adenoasociados (AAV) (Gray et al., 2010), los que describiremos brevemente a continuación.

\subsection{Vectores herpéticos.}

Los vectores herpéticos derivan del Virus Herpes Simplex tipo I. El HSV-1 es un virus envuelto que posee tropismo por el sistema nervioso. El virión consiste en un núcleo de ADN bicatenario, de 152 kbp aproximadamente, el cual codifica más de 85 genes, rodeado por una cápside icosadeltahedral. La envoltura lipídica externa contiene glicoproteínas virales que sirven para mediar la entrada del virus a la célula. Entre la cápside y la envoltura se halla una capa amorfa conocida como el tegumento que contiene proteínas responsables de la inducción de la expresión génica viral y de la inhibición de la síntesis de proteínas del huésped. 
Los vectores herpéticos tienen como características destacables la capacidad de transferir genes de hasta $150 \mathrm{Kbp}$ de ADN ya que contiene aproximadamente 40 genes que no son esenciales para la replicación del virus y por lo tanto se pueden eliminar sin la perturbar la producción del vector. Son capaces de transferir genes a la mayoría de las células en división y quiescentes de mamíferos. Como el ADN del virus no se integra en los cromosomas del huésped, tiene bajo riesgo de mutagénesis insercional. Existen tres tipos diferentes de vectores derivados de HSV-1 (Epstein, 2009).

Los virus atenuados recombinantes que tienen capacidad de replicarse pero contienen mutaciones que restringen la propagación y la replicación viral lítica a las células cancerosas sin causar gran toxicidad para los tejidos sanos. Se utilizan principalmente como virus oncolíticos (Epstein, 2009).

Los vectores con replicación deficiente son aquellos en que se han mutado o suprimido los genes esenciales para la replicación viral. Por lo tanto, estos mutantes no pueden replicarse en cualquier célula, solo lo hacen en las líneas celulares transformadas con los genes que fueron mutados o suprimidos. Hasta la fecha, se han construido varios vectores con replicación deficiente en el que algunos de los genes que se trascriben tempranamente luego de la infección viral se han eliminado en varias combinaciones (Berto et al., 2005).

Los amplicones son vectores en los que el genoma viral es reemplazado por un concatámero de ADN plasmídico, llamado plásmido de amplificación, cuya secuencia tienen un origen de replicación y la señal de empaquetamiento del HSV-1, además de las secuencias del gen que se quiere transferir. La ventaja de los amplicones como herramientas de transferencia génica es el hecho de que por no llevar los genes del virus y por lo tanto no inducir la síntesis de proteínas del virus son completamente no tóxicos para las células infectadas y no patógenos para los organismos transducidos. Además, la ausencia de genes del 
virus en el plásmido de amplificación reduce el riesgo de reactivación, la complementación o la recombinación con genomas latentes presentes en el hospedador. Durante su producción, el plásmido de amplificación se replicará generando largos concatámeros de repeticiones en tándem. Como las partículas virales siempre empaquetan aproximadamente $150 \mathrm{Kbp}$ ADN, el número de repeticiones que un amplicón particular transporta y entrega depende del tamaño del plásmido de amplificación original. Esto también permite utilizarlos para transferir transgenes de gran tamaño(Epstein, 2009).

\subsection{Vectores lentivirales.}

La mayoría de los vectores lentivirales (LV) derivan del virus de la inmunodeficiencia humana tipo 1 ( $\mathrm{VIH}-1)$, un lentivirus miembro de la familia viral Retroviridae, caracterizada por poseer una transcriptasa inversa viral (RT) y una integrasa (IN) que son utilizadas por el virus para lograr la inserción estable de la información genómica viral en el genoma del huésped (Sakuma et al., 2012). A diferencia de otros retrovirus, los lentivirus pueden replicarse en células que no se dividen. El genoma del $\mathrm{VIH}-1$ es una hebra monocatenaria positiva de ARN, con componentes que actúan en trans y otros que lo hacen en cis. Los componentes trans consisten en 9 marcos de lectura abiertos (ORFs). Los tres ORFs más grandes codifican para tres proteínas estructurales: Gag, Pol y Env. El gen gag codifica las proteínas del núcleo viral, que alberga el genoma del virus. El gen pol codifica para una poliproteína que se escinde en tres enzimas esenciales una proteasa (PR), la RT y la IN, que son responsables de la escisión proteolítica de los precursores de poliproteína viral, la transcripción inversa del genoma de ARN viral en ADN, y la integración de ADN viral en el genoma de la célula huésped, respectivamente. El gen env codifica para dos proteínas estructurales, una de superficie y otra transmembrana, que se hallan en la membrana externa de la envoltura viral. Además de estas proteínas, el genoma viral también codifica las proteínas reguladoras Tat y Rev. Tat actúa como un transactiva- 
dor de la elongación transcripcional, que favorece la transcripción del genoma viral, incrementándola de entre 100 y 500 veces. Rev, es la proteína responsable de permitir que el ARNm procesado o sin procesar salga del núcleo al multimerizar a lo largo de la un elemento de respuesta a Rev (RRE) y unir factores celulares a una señal de exportación nuclear dentro de Rev. Los complejos así formados (que contienen el ARNm sin procesar) son exportados hacia el citoplasma. Otros cuatro genes codifican proteínas accesorias Vif, Vpr, Vpu y Nef, que desempeñan una o varias funciones en la progresión de la enfermedad o patogénesis en el hombre. Los componentes que llevan a cabo las funciones cis son las repeticiones terminales largas (LTR, por sus siglas en inglés de long terminal repeat), la secuencia RRE y la señal de empaquetamiento $(\Psi)$. Los LTRs cuyas secuencias flanquean el genoma viral, se requieren para la transcripción viral, la transcripción reversa y la integración. La secuencia RRE es un elemento estructurado de ARN en el gen env que, cuando se une a la proteína Rev, impide que el ARNm sea procesado. $\psi$ consta de dos secuencias cortas que se encuentran entre el 5-LTR y el gen gag formando un elemento estructurado de ARN el cual permite el reconocimiento y empaquetamiento selectivo de ARN genómico viral en la cápside viral antes del ensamblaje y brotación del virus.

Los vectores LV se consideran atractivas herramientas de transferencia de genes del SNC debido a su capacidad para transducir establemente células que se dividen lentamente o no se dividen, la posibilidad de transferir genes de hasta 8 kpb y la falta de expresión de genes virales (Blömer et al., 1997; Naldini et al., 1996a; Naldini et al., 1996b). Se ha demostrado que los LV pueden transducir la mayoría de los tipos de células en el SNC in vivo, incluyendo neuronas, astrocitos, células madre neuronales adultos, los oligodendrocitos y células de glioma (Consiglio et al., 2004). Entre las desventajas que tienen estos vectores podemos citar los bajos rendimientos de producción, la inestabilidad de las proteínas de la cubierta, los aspectos relacionados con la bioseguridad, tales como el riesgo de la generación de partículas virales replicativas y 
los patrones de integración semialeatorias que representan un riesgo de mutagénesis por inserción (Burns et al., 1993; Pauwels et al., 2009).

Actualmente existen vectores LV de tercera generación que constan de cuatro plásmidos (dos de empaquetamiento, uno de envoltura y uno de transferencia) que aportan los elementos necesarios para generar el vector deficiente para la replicación. Estos sistemas incrementan la bioseguridad de los vectores debido a que los plásmidos tendrían que someterse a eventos de recombinación múltiple para regenerar una entidad competente para la replicación. Asimismo, en la construcción de empaquetamiento se han eliminado los genes que codifican para proteínas accesorias asociados a la patogénesis. Para reducir la dependencia de los genes reguladores (tat y rev) todas las construcciones dentro del sistema de vector dependen de promotores diferentes de los LTRs, en las construcciones de empaquetamiento y envoltura se utilizan promotores heterólogos, generalmente el promotor del citomegalovirus (pCMV). En el caso del plásmido de transferencia y dado que algunas partes de los LTR del lentivirus se necesitan para la transcripción inversa y la integración del vector, no puede ser sustituido por un promotor heterólogo. En su lugar, una parte de éste se sustituye por una parte del LTR de un retrovirus aviar, lo que resulta en un promotor quimérico que permite la transcripción independiente de Tat en las líneas celulares productoras de vectores. Rev es necesaria para la exportación nuclear de ARNm sin procesar y además, en ausencia de Rev el ARNm se vuelve inestable y es degradado. Por estas dos razones, el gen rev en vectores de tercera generación no es eliminado sino que es aportado en un plásmido separado. También se sustituyó la proteína de la envoltura por la proteína de otro virus para que pudiera infectar células diferentes a las CD4+. Muy a menudo, para lograr este objetivo se utiliza la glicoproteína del virus de la estomatitis vesicular cuyo receptor fosfolípidico se expresa de forma ubicua en células de mamífero y que también le aporta estabilidad, lo que permite la concentración del vector por ultracentrifugación. Para evitar la posible movilización del genoma viral 
luego de su integración se diseñaron los vectores auto inactivantes, que se generan mediante la supresión de la región U3 del 3'LTR viral (excepto para una pequeña región denominada ATT necesaria para la integración), entonces durante el proceso normal de la transcripción inversa, esta eliminación se duplica y se transfiere al 5'LTR de manera que tras la integración del ADNc viral, ambos LTRs se inactivan. Estos vectores, además de proporcionar mayor seguridad biotecnológica, tienen el beneficio adicional de reducir la interferencia del promotor mediante la inactivación de la LTR. Es decir que la expresión transgénica es impulsada por el promotor heterólogo que contiene el vector de transferencia por impedimento de la activación de la función promotora del LTR en algunos tipos celulares.

\subsection{Vectores Adenovirales.}

Los vectores adenovirales derivan de los adenovirus (Ad), que pertenecen a la familia Adenoviridae. Entre los más de cincuenta serotipos descritos y clasificados (Davison et al., 2003), el más comúnmente utilizado como vector para la transferencia de genes es el Ad-5 (Lentz et al., 2012). Los Ad pueden infectar células de diversos tejidos, tales como las vías respiratorias, urinarias, los ojos y el hígado. En humanos, los Ad causan infecciones oculares, respiratorias e intestinales y no son oncogénicos (Chen and Lee, 2014). La partícula adenoviral posee un tamaño de 70 a $100 \mathrm{~nm}$ y se compone de una cápside proteica iscosaedrica formada por tres subunidades, el hexón, el pentón y la fibra. El hexón es la subunidad dominante que constituye las caras de la cápside, mientras que el pentón y fibra forman las espinas que se extienden en los ángulos de la cápside. El genoma adenoviral es un ADN lineal de doble cadena de $36 \mathrm{~kb}$ flanqueadas por repeticiones terminales invertidas (ITR, por sus siglas en inglés Inverted Terminal Repeat)) (Davison et al., 2003).

Inicialmente, para la generación de los primeros vectores adenovirales se suprimieron los genes que se transcriben tempranamente del genoma viral, lo que los volvía incapaces de replicarse evitando así la 
infección viral generalizada y permitiendo transferir genes de aproximadamente $8 \mathrm{~kb}$. Sin embargo estos vectores retenían una proporción significativa del genoma viral que permite la expresión residual de genes virales y conduce a la eliminación por el sistema inmune de las células transducidas en tan sólo unas semanas (Bett et al., 1994). Los vectores adenovirales de última generación están completamente desprovistos de secuencias de codificación virales, tiene un mejor perfil inmunogénico permitiendo la expresión más sostenida del transgén en las células transducidas y además tienen una capacidad de clonación de 36 kb, pero requieren de sofisticados sistemas de producción que implican un virus auxiliar capaz de proporcionar en trans todos los elementos necesarios para la encapsidación, lo que genera a menudo su contaminación con el virus auxiliar (Alba et al., 2005; Parks and Graham, 1997; Zou et al., 2000). Además, todavía causan una respuesta inflamatoria del huésped a las proteínas de la cápside en el momento de la administración. Por todo esto, los vectores adenovirales son adecuados para la expresión transitoria de un transgén.

\subsection{Vectores Adeno-Asociados.}

Los virus adeno-asociado (AAV) son miembros de la familia de los parvovirus, del género Dependovirus ya que requieren de la coinfección con virus auxiliares tales como adenovirus o virus herpes simplex para generar una infección productiva (Atchison et al., 1965; Georg-Fries et al., 1984). Los AAV son virus desnudos cuyas partículas presentan simetría icosaédrica de entre 18 a $25 \mathrm{~nm}$ de diámetro y ya se han aislado de tejido humano y no humano más de 100 serotipos de AAV (Wu et al., 2006). El genoma del AAV serotipo 2, uno de los más estudiados, es una molécula de ADN lineal, de cadena sencilla de $4.7 \mathrm{Kbp}$ (Srivastava et al., 1983), compuesto de dos genes que codifican cuatro proteínas de replicación (Rep), tres proteínas de la cápside (VP) y una proteína de activación del ensamblaje, flanqueado a ambos lados por ITR (Lusby et al., 1980; Sonntag et al., 2010; Srivastava et al., 1983). El AAV2 se une a la 
superficie de la célula blanco mediante la interacción de las proteínas de la cápside con proteoglucano heparán sulfato (Summerford and Samulski, 1998) además, interacciona con uno o más coreceptores, entre los que se incluyen el receptor del factor de crecimiento fibroblásti$c o$, las integrinas av $\beta 5$ y el receptor del factor de crecimiento de hepatocitos (Kashiwakura et al., 2005; Qing et al., 1999; Summerford et al., 1999). La unión con estos receptores inicia la internalización a través de depresiones revestidas de clatrina, seguido por la liberación de la partícula viral en el citosol y translocación al núcleo, donde la expresión génica tiene lugar (Bartlett et al., 2000). En humanos, cuando el virus auxiliar está ausente, el ADN de AAV puede permanecer como un episoma circular o puede ser integrado en el cromosoma en el sitio de integración AAVS1 (Samulski et al., 1991). En presencia de un virus auxiliar o estrés celular, tanto la transcripción como la replicación del ADN se reactivan y AAV completa su ciclo de replicación.

Los vectores virales derivados de los AAV ( $\mathrm{rAAV}$ )se han convertido en uno de los más importantes por la simplicidad de su genoma, no inducer reacción inflamatoria ni respuesta inmune deletérea, presentar una elevada eficiencia de transducción y mantener la expresión de genes por periodos largos, en un amplio rango de células post-mitóticas in vivo. Como las ITRs que flanquean ambos lados del genoma son los únicos elementos necesarias que actúan en cis para la replicación del genoma, la integración, y la encapsidación, los rAAV, se pueden generar mediante la sustitución de los genes de replicación y de la cápside por un promotor y el gen de interés. Para la producción de los vectores, los genes rep y cap se expresan en trans codificados en un plásmido diferente que carece de los ITR. Los Ad y HSV también son necesarias para la replicación y la producción de vectores AAV, pudiendo permanecer como contaminantes. Para evitar la contaminación con Ad, se diseñó un método de producción que incorpora un tercer plásmido el cual suministra los genes esenciales del Ad para la generación del rAAV. Se han realizado otras modificaciones para mejorar la producción de rA- 
AV. Una de ellas redujo los niveles de expresión de la proteína Rep incrementando los de proteínas Cap. Esto, a su vez, conduce a una mayor producción de rAAV por célula (Li et al., 1997). La segunda mejora se logró cruzando el serotipo del genoma con diferentes serotipos de capside (Rabinowitz et al., 2002). La ventaja de utilizar este sistema es que genoma se empaqueta dentro de diferentes cápsides lo que permite la comparación directa de tropismo in vivo en modelos animales (Rabinowitz et al., 2002; Zincarelli et al., 2008).

Las principales desventajas de los rAAV son su difícil producción, el poco espacio que poseen para alojar genes terapéuticos (por el tamaño de su genoma) y la inmunidad preexistente (Scaffer y col., 2009). A pesar de las desventajas que presentan estos vectores son los que utilizaremos para la realización de esta tesis ya que el gen del IGF-I se encuentra dentro de los límites que el vector puede empaquetar. Por otro lado existen estudios que demuestran que la respuesta inmune humoral producida por la inyección de AAV en el sistema nervioso central no es significativa y permite la expresión a largo plazo del transgen (Mastakov et al., 2002). Asimismo, contamos con un grupo colaborador que posee la tecnología necesaria para la producción de los mismos. 
OBJETIVOS 
Está postulado que el IGF-I es una de las señales que participan en la iniciación de la pubertad, particularmente a nivel central y se propone que actúa como regulador de las neuronas productoras de GnRH. Durante la senescencia reproductiva se producen alteraciones en la activación que sufren las neuronas productoras de GnRH bajo condiciones de retroalimentación positiva de estrógenos. Los niveles cerebrales de IGF-I disminuyen con la edad, por lo que esta disminución estaria implicada o podría ser una de las señales que contribuyen a la desregulación de las neuronas productoras de GnRH asociada a la edad. El objetivo general de este estudio es aportar nueva evidencia respecto del rol de un factor neurotrófico, el IGF-I, sobre la función reproductiva. Más específicamente este ensayo aspira a contribuir a la elucidación del papel del IGF-I en la senescencia reproductiva.

Para llevar adelante el objetivo general de esta tesis se plantearon los siguientes objetivos específicos.

\section{1- Determinar los parámetros reproductivos y morfométricos de ratas} hembras de nuestra colonia de animales.

La primera ovulación en ratas hembras de la mayoría de las cepas se produce entre los 35 y 45 días de edad, la cual se evidencia por la apertura del canal vaginal (Ojeda and Skinner, 2006). A partir de este momento los animales muestran una competencia reproductiva completa (Evans, 1986). Tanto la ciclicidad estral regular como la fertilidad decrece con la edad hasta que se alcanza un estado de infertilidad cuando los ciclos estrales regulares cesan (Matt et al., 1986). El momento en que esto ocurre puede diferir entre las diferentes cepas y entornos de laboratorio. Es por ello que consideramos necesario determinar los cambios reproductivos que presentaban las ratas hembras de la colonia criadas en el bioterio de nuestro Instituto. 


\section{2- Caracterizar la funcionalidad de los vectores virales adenoaso- ciados.}

En nuestro laboratorio tenemos experiencia en la generación, producción y utilización de vectores derivados de adenovirus, los cuales han sido utilizados para la transferencia de genes en el sistema nervioso central con el objetivo de estudiar la capacidad terapéutica de los mismos para revertir la neurodegeneración en neuronas dopaminérgicas (Hereñú et al., 2007; Morel et al., 2010). Una características de los vectores adenovirales es que la expresión del transgén se mantiene por tiempos cortos, aproximadamente 45 días en cerebro (Akli et al., 1993; Parr et al., 1998). Sin embargo, para el siguiente objetivo, necesitábamos contar con una expresión del IGF-I que fuera más prolongada en el tiempo. Los vectores virales adenoasociados son capaces de transducir células que no se están dividiendo y generan una expresión del transgen por períodos de hasta 25 meses (Klein et al., 2002), razón por la cual mediante una colaboración con la Dra. Martha Bohn, North Western University, Chicago, cuyo laboratorio dispone de la tecnología de construcción de rAAV, obtuvimos los vectores para la realización de esta tesis. En este marco, decidimos evaluar la eficiencia de expresión de rAAV bicistrónicos construidos en el laboratorio de la Dra. Bohn, tanto in vitro como a largo plazo in vivo.

\section{3- Evaluar los efectos del IGF-I sobre el eje hipotálamo-hipofiso- ovárico en ratas de mediana edad.}

Ya que los niveles de IGF-I en áreas del cerebro relevantes para la función reproductiva disminuyen con la edad nosotros estamos particularmente interesados en determinar si la expresión prolongada de IGF-I transgénico en ratas de mediana edad tiene la capacidad de prevenir la disminución asociados a la edad de la capacidad reproductiva que experimentan los animales. 


\section{MATERIALES Y MÉTODOS}




\section{DISEÑO EXPERIMENTAL.}

\subsection{Caracterización de la ciclicidad estral de ratas de tres grupos etarios.}

Para evaluar la funcionalidad del eje reproductivo se tomó como parámetro el patrón de ciclicidad estral. Para ello se utilizaron ratas hembras criadas en nuestro bioterio de tres edades diferentes, jóvenes de 13 semanas (3 meses), mediana edad de 43 semanas (10 meses) y seniles de 113 semanas (26 meses) al inicio del estudio. Diariamente durante 32 días se realizaron frotis vaginales para evaluar el estadio estral de los animales y establecer un perfil de cicliciad para cada grupo.

Además, para analizar las diferencias que pudieran presentar, a nivel sérico, las hormonas involucradas en la función reproductiva se extrajo semanalmente sangre de la cola y se almacenó el suero a $-70^{\circ} \mathrm{C}$. Sobre ellos se determinaron los niveles de cuatro hormonas relevantes a nivel reproductivo, LH, E2, P4 y PRL, mediante radioinmunoensayos (RIA) específicos.

Luego de los 32 días de observación los animales se pesaron y se sacrificaron. Los ovarios se disecaron, se pesaron y se fijaron para su posterior análisis histológico (Fig.1).

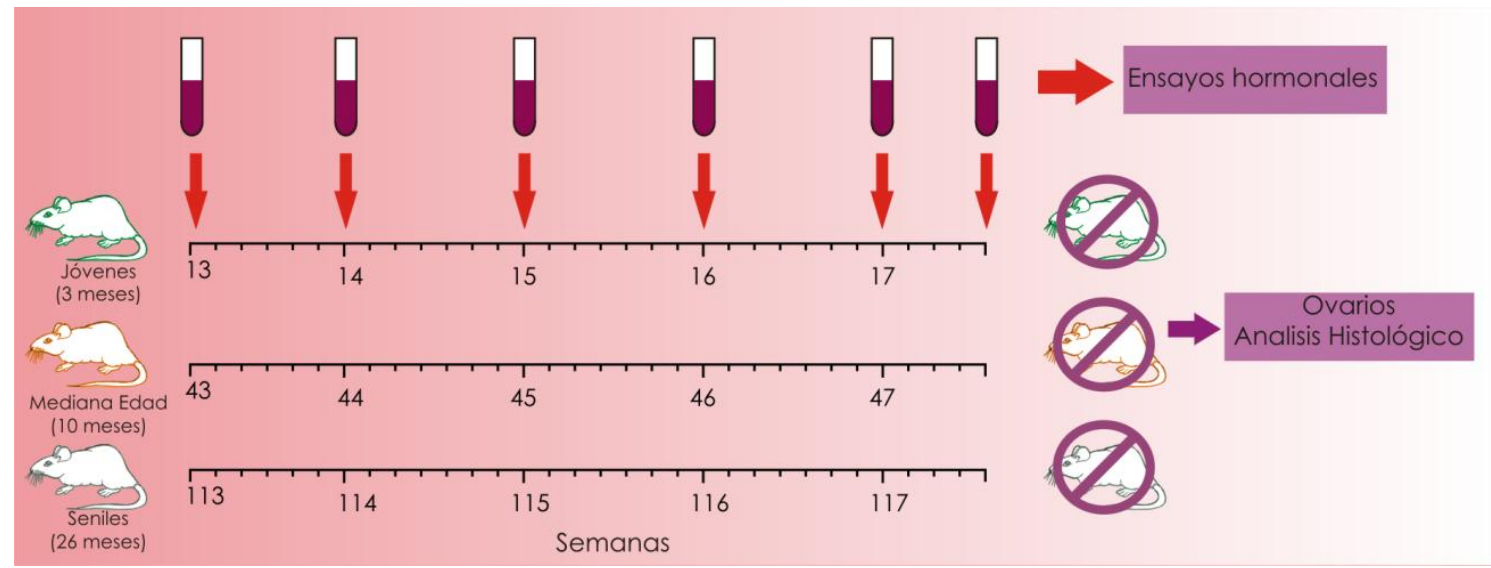

Figura 1: Diseño experimental para caracterizar la ciclicidad estral de las ratas crecidas en el bioterio del INIBIOLP. A ratas de 3, 10 y 26 meses de edad se les 
realizaron diariamente por 32 días extendidos vaginales para establecer el perfil de ciclicidad estral. Semanalemente se extrajo sangre de la vena caudal para realizar ensayos hormonales. Los animales se sacrificaron al final del periodo de estudio y se extrajeron los ovarios para realizar el estudio histológico de los mismos.

\subsection{Caracterización de los vectores adenoasociados.}

\subsubsection{Experimentos in vitro.}

Con el propósito de estudiar la expresión in vitro de los transgenes que contienen los rAAVs que serán utilizados en el desarrollo de este trabajo se realizaron transducciones de células HEK 293 con 4,8 X $10^{9} \mathrm{vg}$ de rAAV-IGF-IIRES-DsRed2 o 2,5 X 109 vg de rAAV-IRES-DsRed2, como control se utilizaron células sin transducir. Las células se observaron diariamente en un microscopio invertido de fluorescencia y el medio de cultivo se recolectó diariamente y se reemplazó por medio fresco. El medio recolectado se almacenó a $-70^{\circ} \mathrm{C}$ hasta para la posterior medida del contenido de IGF-I con un RIA específico. A las 96 hs las células se lisaron con tritón $0,1 \%$ en PBS. Para eliminar los restos de membranas el lisado se centrifugó a 3000 rpm por 5 min, el sobrenadante se recogió y sobre el mismo se midió la emisión a 586 nm en un fluorómetro para cuantificar la expresión de la DsRed2.

\subsubsection{Experimentos in vivo.}

Para estudiar la duración de la expresión de estos rAAVs en diferentes regiones del cerebro de la rata, se inyectaron bilateralmente $2 \mu \mathrm{l}$ de rAAV -IRES-DsRed2 o rAAV-IGF-IIRES-DsRed2 en el HMB o en el ventrículo lateral (VL). A las 4, 8, 11 y 14 semanas post inyección los animales se sacrificaron y los cerebros se procesaron para ser observados en un microscopio de fluorescencia y así confirmar la expresión de la DsRed2 (Fig.2). 


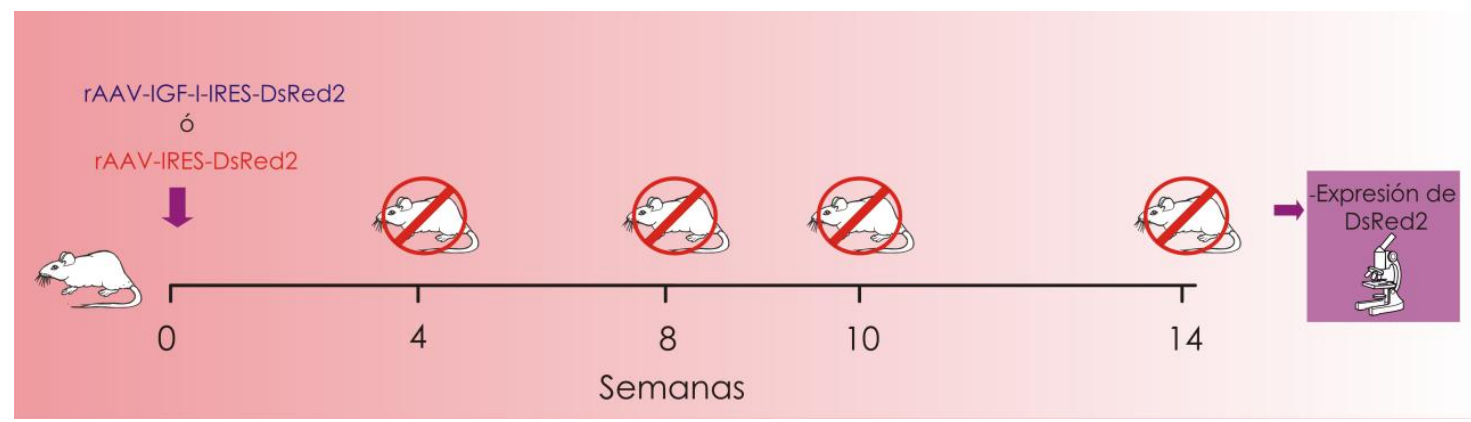

Figura 2: Diseño experimental para caracterizar la duración de la expresión de los rAAVs. Se inyectaron animales intrahipotalámicamente y en ventriculo lateral con rAAV-IRES-DsRed2 o rAAV-IGF-I-IRES-DsRed2. A las 4, 8, 11 y 14 semanas post inyección los cerebros se procesados se observaron en un microscopio de fluorescencia para confirmar la expresión de la DsRed2.

\subsection{Evaluar los efectos del IGF-I sobre el eje hipotálamo-hipofiso- ovárico en ratas de mediana edad.}

Para estudiar el efecto del IGF-I en el HMB sobre la función reproductiva en ratas hembras de mediana edad se utilizaron animales de 34,5 semanas de edad. Comenzando el día experimental -13, se estudió la ciclicidad estral de los animales mediante frotis vaginales que se realizaron diariamente. También se tomaron semanalmente muestras seriadas de sangre (0,3-0,4 ml) para ensayos hormonales. En el día experimental 0 , los animales se dividieron en tres grupos al azar:

Un grupo de ratas intactas a las que en adelante llamadas Control.

Un grupo de ratas inyectadas intrahipotalámicamente con rAAVIRES-DsRed2, en adelante DsRed.

Un grupo de ratas que inyectadas intrahipotalámicamente con un rAAV-IGF-I-IRES-DsRed2, en adelante IGF-I.

Diariamente hasta el final del experimento, cuando los animales tenían 49,5 semanas de edad, se realizaron frotis vaginales para estudiar la ciclicidad estral y semanalmente se tomaron muestras de sangre, el suero se almacenó a $-70^{\circ} \mathrm{C}$ hasta el momento de medir los niveles hormonales por RIA. 
Al momento del sacrificio se disecaron los cerebros y ovarios de las ratas. El hemiencéfalo izquierdo de cada rata se procesó para determinar los niveles de IGF-I en HMB y corteza cerebral (CC). Los ovarios se pesaron, se fijaron y posteriormente se realizó el análisis histológico de los mismos (Fig.3).

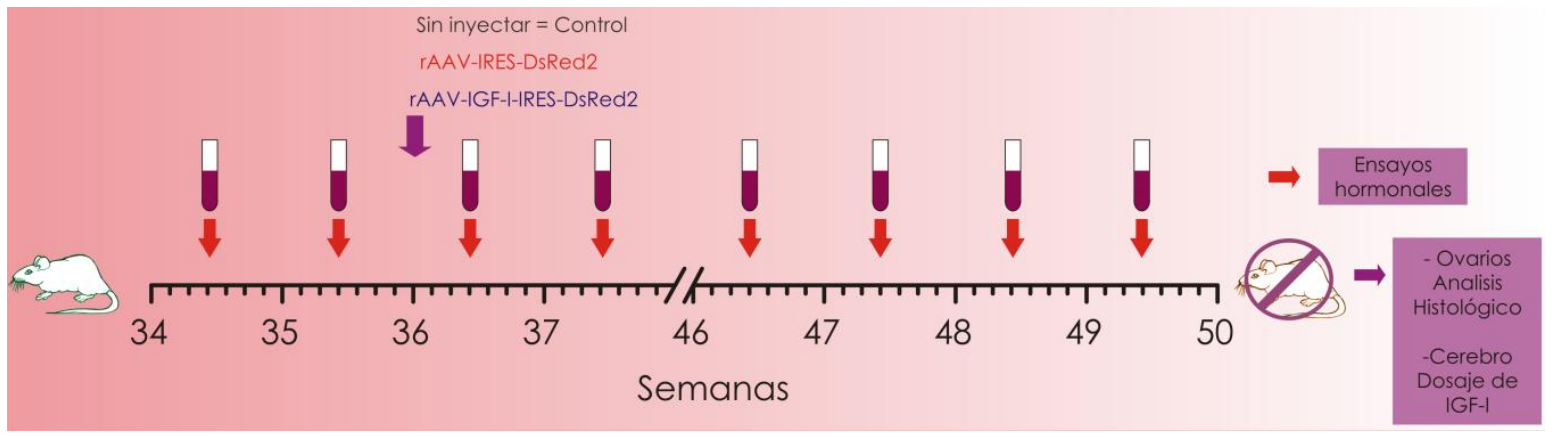

Figura 3: Diseño experimental para estudiar el efecto de la sobreexpresión del IGF-I en el HMB sobre la ciclicidad estral de ratas de mediana edad. Se utilizaron tres grupos de ratas hembras de 34,5 semanas de edad: Grupo Control, ratas intactas, Grupo DsRed, inyectadas intrahipotalámicamente con rAAV- IRES-DsRed2 y Grupo IGFI, inyectadas intrahipotalámicamente con rAAV-IGF-I-IRES-DsRed2. Para estudiar la ciclicidad estral se realizaron a diario extendidos vaginales hasta el momento del sacrificio en la semana 49,5 de edad, se extrajeron los ovarios para realizar el estudio histológico de los mismos y el cerebro donde se midieron los niveles de IGF-I.

\section{MODELOS EXPERIMENTALES.}

\subsection{Cultivos celulares.}

Como modelo de célula eucariota se utilizaron células HEK 293 (Microbix), las cuales provienen de riñón de embrión humano y son ampliamente utilizadas para la expresión heteróloga de proteínas.

\subsection{Modelo Animal}

En todos los experimentos con animales se utilizaron ratas hembra de la cepa Sprague Dawley (SD) criadas en el bioterio del INIBIOLP. Las ratas se mantuvieron en un cuarto de cría con temperatura controlada $\left(22 \pm 2{ }^{\circ} \mathrm{C}\right)$, bajo un ciclo luz/oscuridad de $12 / 12$ hs. Los animales tuvieron 
libre acceso a bebida y alimento balanceado comercial completo para roedores (Cooperación). Los protocolos experimentales se realizaron con animales de acuerdo con la Animal Welfare Guidelines de NIH. Certificación de bienestar animal N A5647-01 otorgada por los National Institutes of Health al INIBIOLP.

\section{VECTORES VIRALES.}

Para la realización de esta tesis se utilizaron dos vecotres derivados de virus adenoasociados serotipo 2, generados por Dra. Martha Bohn, North Western University, Chicago, como se detalla a continuación.

Los plásmidos de transferencia para la generación de los rAAV se construyeron utilizando técnicas de clonación estándar. El casete de expresión se clonó entre las dos ITR de un plásmido de transferencia AAV2. Ambos plásmidos contienen el casete de expresión bajo el control pCMV, la secuencia potenciadora del intrón de la $\beta$ globina y un sitio de entrada al ribosoma (IRES, por sus siglas en inglés internal ribosomal entry site) aguas arriba del gen reportero de la proteína fluorescente roja de Discosoma sp (DsRed2). La secuencia del IGF- Ib de rata de 934 pb se obtuvo de Peter Rotwein de Oregon Health Sciences University y se insertó luego del intrón de la $\beta$ globina.

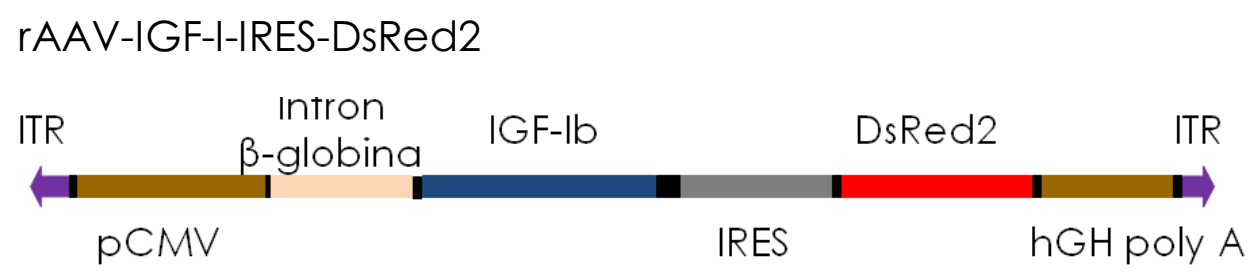

rAAV-IRES-DsRed2

$\begin{array}{llll}\text { IIR Intron } \beta \text {-globina DSRed2 } & \text { ITR } \\ \text { IRES } & \text { hGH poly A }\end{array}$

Figura 4: Representación esquemática del genoma de los vectores derivados de virus adenoasociados empleados en esta tesis. En el panel superior se muestra el 
esquema del genoma del rAAV-IGF-IIRES-DsRed2 y en el inferior el del rAAV- IRESDsRed2, ambas construcciones están flanqueadas por las repeticiones terminales invertidas (ITR) del virus adenoasociado recombinante serotipo 2 en sus extremos, ambos contienen un casete de expresión dirigido por un promotor de citomegalovirus (pCMV), la secuencia potenciadora del intrón de la $\beta$ globina (intrón $\beta$ globina), un sitio interno de entrada al ribosoma (IRES) aguas arriba del gen de la proteína reportero roja de Discosoma (DsRed2) y la señal de poliadenilación de la hormona de crecimiento humana (hGHpolyA).

Ambos vectores se empaquetaron como rAAV2/2 en el Children's Memorial Viral Vector Core siguiendo el protocolo de Zolotukhin y col. con modificaciones menores(Zolotukhin et al., 2002). En resumen, el plásmido de transferencia y el plásmido de empaquetamiento PDG (Grimm et al., 1998), generosamente proporcionado por Jürgen Kleinschmidt, se utilizaron en una proporción de 1:3, respectivamente para realizar una co-transfección con $\mathrm{CaCl}_{2}$ en células HEK293T. Las células se lisaron tres días después de la co-transfección por congelacióndescongelación con el fin de recoger el virus y los restos celulares se eliminaron por centrifugación. El sobrenadante se trató con octil- $\beta-D-$ glucopiranósido y benzonasa, a continuación se colocó en un gradiente discontinuo $15 \%-60 \%$ de iodixanol. Se centrifugó a 69,000rpm por 1 hs a $18{ }^{\circ} \mathrm{C}$. Se tomó la capa de $40 \%$ y se purificó adicionalmente usando una membrana de intercambio iónico Mustang Q. Para concentrar el virus se utilizó una membrana Centriplus 100000 MS. El virus se almacenó en PBS, pH 7,4 que contiene 5 \% de sorbitol y 0,001 \% PF-68. El título de los vectores se determinó por QRT-PCR. Los títulos virales fueron: rAAVIGF-I-IRES-DsRed2, 2,0 ×1012 genomas virales (vg)/ml; rAAV-IRES-DsRed2, $3.9 \times 10^{12} \mathrm{vg} / \mathrm{ml}$.

\section{PROtocolos Generales de tRabajo para el CULtivo DE CÉLULAS.}

Rutinariamente las células se cultivaron en botellas de $25 \mathrm{~cm}^{2}$ de superficie en medio esencial mínimo Eagle $(2 \mathrm{mM}$ glutamina, $0.1 \mathrm{mM}$ aminoácidos no esenciales, $\mathrm{NaHCO}_{3}(2.2 \mathrm{mg} / \mathrm{l})$ y $16.8 \mathrm{mM}$ Hepes buffer 
$\mathrm{pH} 7,0)$ (Gibco-Invitrogen), suplementado 10\% (v/v) de suero fetal bovino (Natocor, Córdoba), penicilina/estreptomicina (20mg/I) (PAA Laboratory, GMBH). Las botellas se mantuvieron en una estufa de cultivo a $37^{\circ} \mathrm{C}$, con una atmósfera de $5 \% \mathrm{CO}_{2}$ y humedad controlada. Los subcultivos se realizaron en placas de 12 pocillos. Para ello se aspiró el medio de cultivo de las botellas, se enjuagó la superficie celular con $5 \mathrm{ml}$ de buffer fosfato salino (PBS, $137 \mathrm{mM} \mathrm{NaCl}, 2.7 \mathrm{mM} \mathrm{KCl}, 10 \mathrm{mM} \mathrm{NaHPO}_{4}$, $2 \mathrm{mM} \mathrm{KH}_{2} \mathrm{PO}_{4}$ ) estéril para remover completamente el medio, luego se agregó $0,5 \mathrm{ml}$ de solución cítrico salina $(10 \mathrm{~g} / \mathrm{l}$ de $\mathrm{KCl}, 4.4 \mathrm{~g} / \mathrm{l}$ de citrato de sodio / y las células se observaron en un microscopio invertido. Una vez despegadas las células, se disgregaron mecánicamente y se las repicó, diluyéndolas 1/3.

Las placas fueron incubadas en iguales condiciones a las descriptas para las botellas.

\section{PROTOCOLOS GENERALES DE TRABAJO PARA EL MANEJO DE ANIMALES Y TÉCNICAS QUIRÚRGICAS.}

\subsection{Frotis vaginales.}

Se recogió la secreción vaginal de los animales utilizando una pipeta automática con $20 \mu \mathrm{l}$ de PBS estéril. La punta del tip plástico se insertó en la vagina de la rata, se descargó su contenido y se volvió a aspirar con la pipeta. El líquido aspirado se colocó en un portaobjetos. Para cada rata se utilizó un tip limpio. El material obtenido se observó sin teñir en un microscopio de campo claro con un aumento de10 y $40 \mathrm{X}$. (Marcondes et al., 2002). Se diferenciaron tres tipos celulares: 1) redondos y nucleadas (células epiteliales), 2) irregulares, sin núcleo (células cornificadas) y redondos pequeñas (leucocitos), según la proporción de los tres tipos celulares que se observó, se clasificaron las fases del ciclo estral (Fig.4).

Proestro $(\mathrm{P})$ : predominio de células epiteliales. 
Estro(E): predominio de células cornificadas.

Metestro (M): proporción similar de los tres tipos celulares.

Diestro (D): predominio de leucocitos.

Se observaron dos estadios de transición:

Proestro-estro (Pe): proporción similar de células epiteliales y células cornificadas.

Diestro-proestro (Dp): proporción similar de leucocitos y células epiteliales.

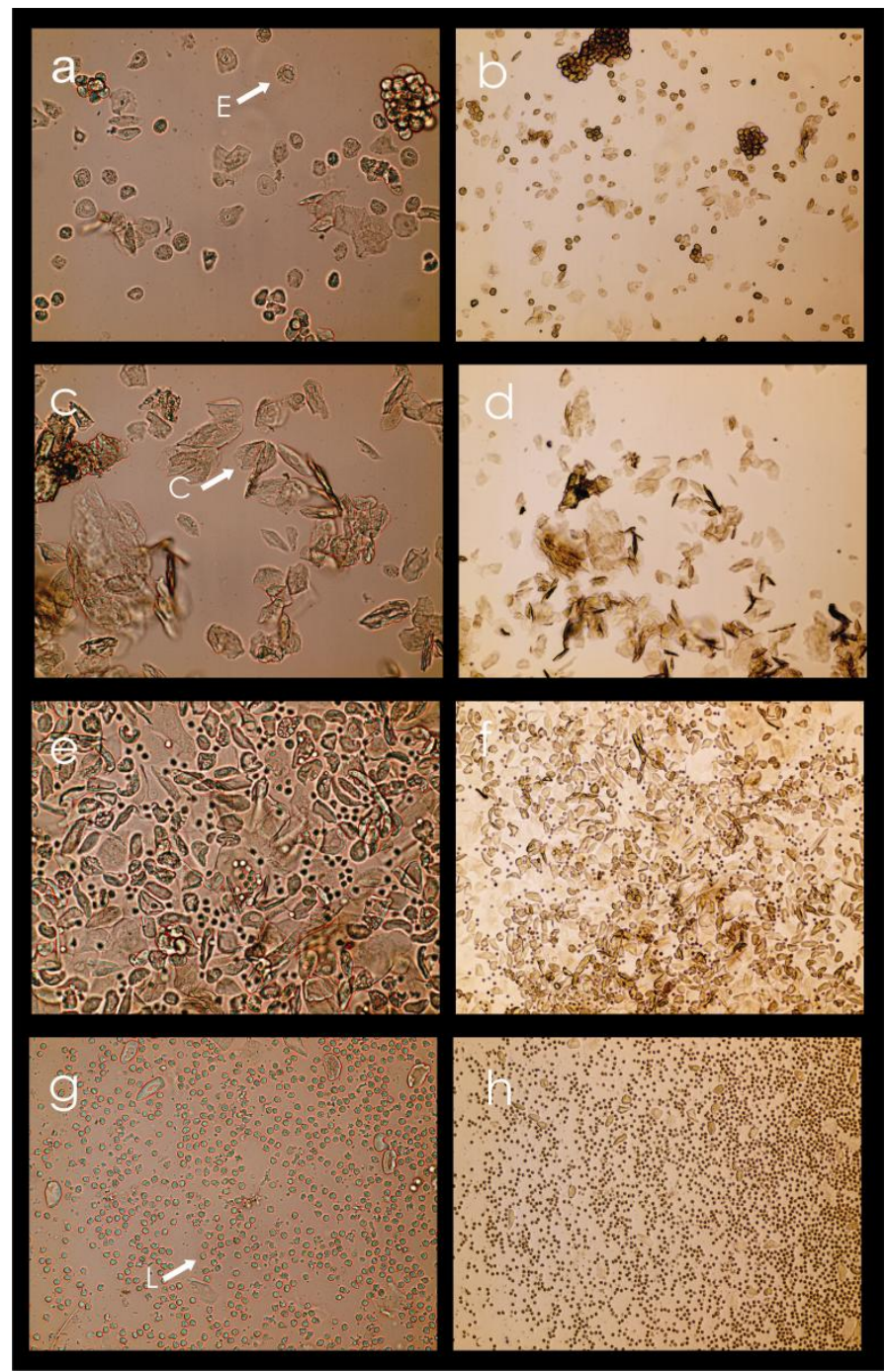

Figura 4: Frotis vagina-

les. Microfotografías de frotis vaginal de ratas hembra en proestro $(a, b)$, estro $(c, d)$, metestro $(e, f)$ y el diestro $(g, h)$. Se utilizó la proporción de los tres tipos de células para determinar las estadios del ciclo estral. Las células redondas y nucleadas son células epiteliales (E); las irregulares sin núcleo son células cornificadas (C), y las redondos pequeños son los leucocitos (L). Objetivo $40 \mathrm{x}$ (izquierda) y $10 \times$ (panel derecho). 


\subsection{Inyecciones estereotáxicas.}

Las ratas se anestesiaron con una inyección de ketamina (40 $\mathrm{mg} / \mathrm{kg}$ peso corporal, i.p.) y xilazina ( $8 \mathrm{mg} / \mathrm{kg}$ de peso corporal, i.m.) y se colocaron en un aparato estereotáxico. Se efectuó una incisión en la línea media de la cabeza y utilizando una fresa odontológica de 0.9 $\mathrm{mm}$ de diámetro se realizó un orificio en el cráneo. Para acceder al HMB se utilizaron las siguientes coordenadas respecto del bregma: $3.0 \mathrm{~mm}$ posterior, $8.0 \mathrm{~mm}$ ventral y $0.6 \mathrm{~mm}$ izquierda- derecha (Paxinos and Watson, 1998).

Para acceder al VL se utilizaron las siguientes coordenadas respecto del bregma: 0,8 $\mathrm{mm}$ posterior, 3,7 $\mathrm{mm}$ ventral y 1,5 $\mathrm{mm}$ izquierdaderecha (Paxinos and Watson, 1998).

\subsection{Perfusión intracardíaca de ratas.}

Los animales se anestesiaron y se fijaron a una plataforma. Se realizó una incisión entre la región torácica y peritoneal para acceder al corazón. Luego, se canuló el ventrículo izquierdo efectuando un pequeño corte en la aurícula derecha para permitir el drenaje del fluido del sistema vascular al final del circuito. Los animales canulados se perfundieron a una velocidad de $10 \mathrm{ml} / \mathrm{min}$ con una bomba peristáltica (Gilson modelo minipuls 2 MP312), primero pasando $200 \mathrm{ml}$ de PBS y luego $200 \mathrm{ml}$ de solución fijadora (paraformaldehido al 4\% p/v en PBS).

\subsection{Obtención de órganos para procedimientos histológicos.}

Los animales previamente se decapitaron con una guillotina, el encéfalo se disecó cuidadosamente y se dejó en solución fijadora durante toda la noche. Al día siguiente los cerebros se transfirieron a una solución criopreservadora (sacarosa $30 \% \mathrm{p} / \mathrm{v}$, polivinilpirrolidona $1 \% \mathrm{p} / \mathrm{v}$, etilenglicol $30 \% \mathrm{v} / \mathrm{v}$, buffer fosfato $1 \mathrm{M} 1 \% \mathrm{p} / \mathrm{v})$, se los mantuvo en ella durante un mínimo de $24 \mathrm{hs}$ a $4^{\circ} \mathrm{C}$ para luego almacenarlos a $-20^{\circ} \mathrm{C}$ hasta el momento de su análisis. 
El aparato genital se extirpó cortando el mesenterio de los cuernos del útero, oviducto (trompa), los ovarios y la unión entre el ano/recto y la vulva/vagina, quedando la unidad de los órganos sexuales y la vejiga urinaria aislados. Los ovarios se separaron cuidadosamente de los oviductos y la grasa que los rodea, posteriormente se pesaron y se colocaron en solución fijadora hasta el momento de su análisis.

\subsection{Procesamiento de los ovarios.}

Los ovarios previamente fijados se deshidrataron en sucesivos baños de soluciones de alcohol etílico de concentración creciente, posteriormente se aclararon en Xilol y se incluyeron en parafina. Los tacos parafinados se cortaron con un micrótomo y se obtuvieron láminas de 5 micras de espesor. Posteriormente se tiñeron con hematoxilina-eosina y se montaron. Las imágenes correspondientes fueron adquiridas con una cámara fotográfica digital DP70 acoplada a un microscopio Olympus BX51. Se seleccionaron 5 secciones de cada animal y se cuantificó de acuerdo a su morfología los folículos, cuerpos lúteos, quistes y folículos atrésicos.

\subsection{Obtención del encéfalo para la medida de IGF-I.}

Los animales se sacrificaron por decapitación bajo anestesia. El encéfalo se disecó cuidadosamente y se separaron los dos hemiencéfalos. El hemiencéfalo derecho se dejó en solución fijadora durante toda la noche, luego se transfirió a una solución criopreservadora en la que se lo mantuvo durante un mínimo de 24 hs a $4^{\circ} \mathrm{C}$ para luego almacenarlo a $-20^{\circ} \mathrm{C}$ hasta el momento de su análisis.

Del hemiencéfalo izquierdo se separó la corteza y el HMB, se pesaron cada una de las regiones y se almacenaron a $-70^{\circ} \mathrm{C}$ hasta que se midio el contenido de IGF-I de las mismas mediante un RIA específico. 


\subsection{Procesamiento del encéfalo.}

Los encéfalos fijados se cortaron con un vibrátomo, obteniendo secciones coronales seriadas de $40 \mu \mathrm{m}$ de espesor, se monatron con Fluoromount G (Electron Microscopy Sciences, Hatfield, PA, EEUU) en portaobjetos previamente gelatinizados para luego observarlos mediante un microscopio de alta performance para microscopía de luz blanca y de fluorescencia (Olympus BX51, Tokio, Japón).

Las imágenes fueron adquiridas con una cámara fotográfica digital DP70 acoplada a un microscopio Olympus BX51. El análisis de imágenes se realizó con el programa Image Pro Plus v5.2.

\section{PROTOCOLOS GENERALES DE TRABAJO PARA EL DOSAJE HORMONAL.}

\subsection{Extracción de IGF-I.}

Se mezclaron $100 \mu$ l de suero o $150 \mu$ de medio de cultivo con 4 volúmenes de solución ácido etanólica $(87.5 \%$ v/v, $\mathrm{E \dagger OH}, 12.5 \% \mathrm{v} / \mathrm{v} \mathrm{HCl}$ $2 \mathrm{~N})$, se incubaron 30 minutos a temp. ambiente, posteriormente se centrifugaron 30 minutos a $3000 \mathrm{~g} \mathrm{a} 4^{\circ} \mathrm{C}$, el sobrenadante se transvasó a tubos de 1,5 ml y se neutralizó con $200 \mu$ de Tris-Base 0,855M en las muestras provenientes de sueros o $300 \mu$ l en las de medio de cultivo, se incubaron a -70 C durante 1 hora y se centrifugaron 30 min a $3000 \mathrm{~g}$, a $4^{\circ} \mathrm{C}$. El sobrenadante se transvasó a tubos de 1,5 $\mathrm{ml}$ y posteriormente se usó para medir el contenido de IGF-I de los mismos mediante un RIA específico.

\subsection{RIA IGF-I.}

Los niveles de IGF-I se determinaron por RIA utilizando un anticuerpo (UB2-495) proporcionado por los Dres. L. Underwood y J.J. Van Wyk, y distribuido por el Programa de Distribución de la hormona de la NIDDK y el Dr. A. F. Parlow. Se utilizó el IGF-I recombinante humano (rh IGF-I, Chiron Corp.,Emeryville, CA) como radioligando y ligando sin marcar. 


\subsection{RIA LH.}

Los niveles séricos de LH se midieron por RIA usando materiales provistos por el Dr. A. F. Parlow, del Pituitary Hormones and Antisera Center, UCLA Med. Center, U.S.A. Las concentraciones de LH se expresaron según LH RP-2 de rata.

\subsection{RIA PRL.}

Los niveles séricos de PRL se midieron por RIA usando materiales provistos por el Dr. A. F. Parlow, del Pituitary Hormones and Antisera Center, UCLA Med. Center, U.S.A. Las concentraciones de PRL se expresaron según PRL RP-3 de rata.

\subsection{RIA E2.}

La concentración sérica de E2 se cuantificó con un kit comercial (DSL, Estradiol Ultrasensible DSL 4800, Webster, USA) siguiendo las instrucciones del fabricante.

\subsection{RIA P4.}

La concentración sérica de progesterona (P4) se cuantificó con un kit comercial (RIA PROGESTERONE, IM1 188, Prague, Czech Republic) siguiendo las instrucciones del fabricante.

\section{ANALISIS ESTADÍSTICO.}

Los resultados se expresan como la media \pm error estándar (SE). Las comparaciones estadísticas entre varios grupos experimentales se realizaron mediante ANOVA de 1 vía seguida por la prueba de Tukey pos hoc cuando el ANOVA fue significativo. Para las comparaciones entre pares de medias se utilizó la prueba † de Student cuando las varianzas no difirieron significativamente. De lo contrario, se utilizó el estimador aproximada $t$ de Welch. Valores con un valor de $p<0,05$ se consideraron estadísticamente significativos. 
RESULTADOS 


\section{RESULTADOS LA DETERMINACIÓN DE LOS PARAMETROS REPRODUCTI- VOS Y MORFOMÉTRICOS OBTENIDOS EN LAS RATAS HEMBRAS DE NUESTRA COLONIA.}

De acuerdo a lo que planteamos en el primer objetivo de esta tesis, inicialmente estudiamos los parámetros reproductivos y morfométricos de las ratas hembra de nuestra colonia.

\subsection{Patrón de ciclicidad}

Diariamente durante 32 días consecutivos se realizaron extendidos vaginales de 23 ratas hembras, las cuales pertenecían a 3 grupos etarios diferentes: ratas jóvenes de 13 semanas de edad (3 meses), ratas de mediana edad de 43 semanas (10 meses) y ratas seniles de 113 semanas de edad (26 meses), al inicio del estudio. Los extendidos frescos fueron observados en un microscopio de campo claro para determinar el perfil de ciclicidad estral de cada grupo (Fig.1).

A

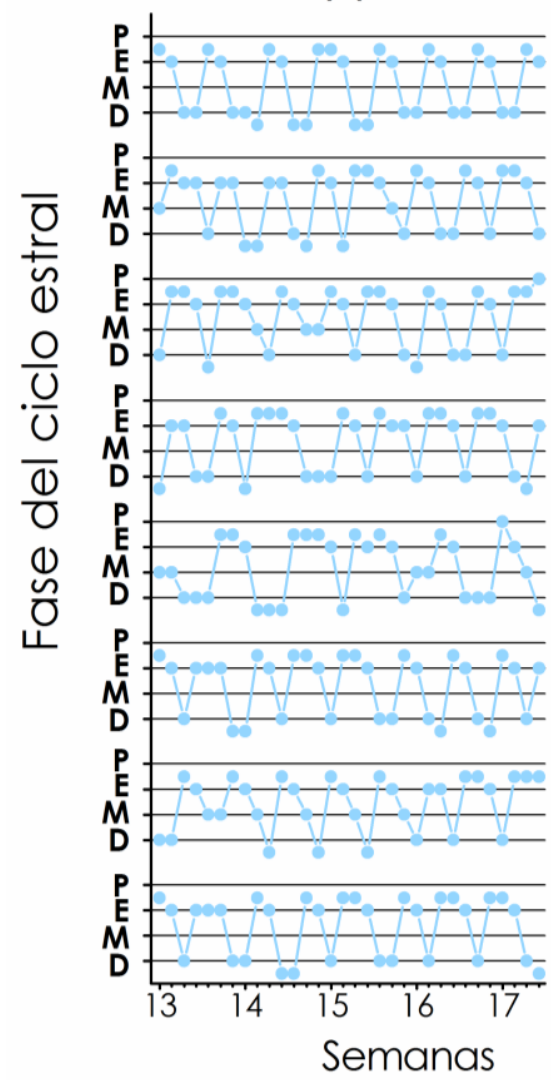

$\mathrm{B}$

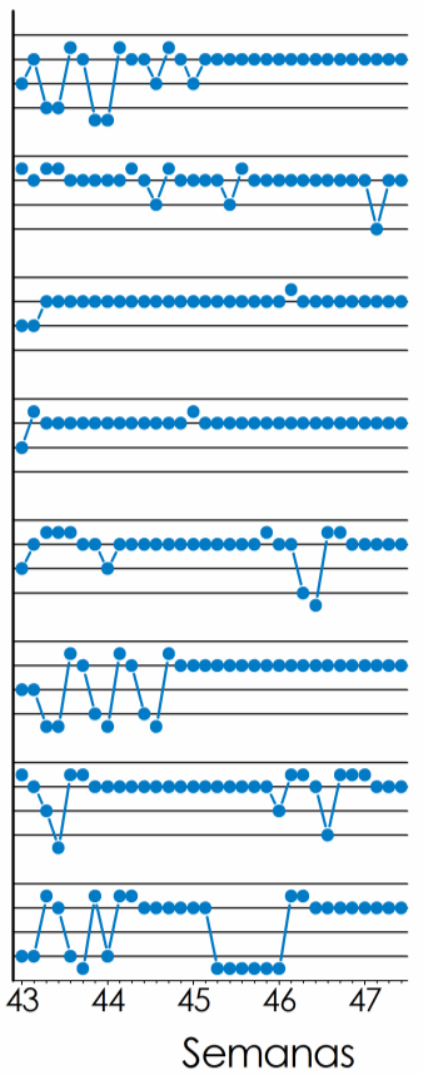

C

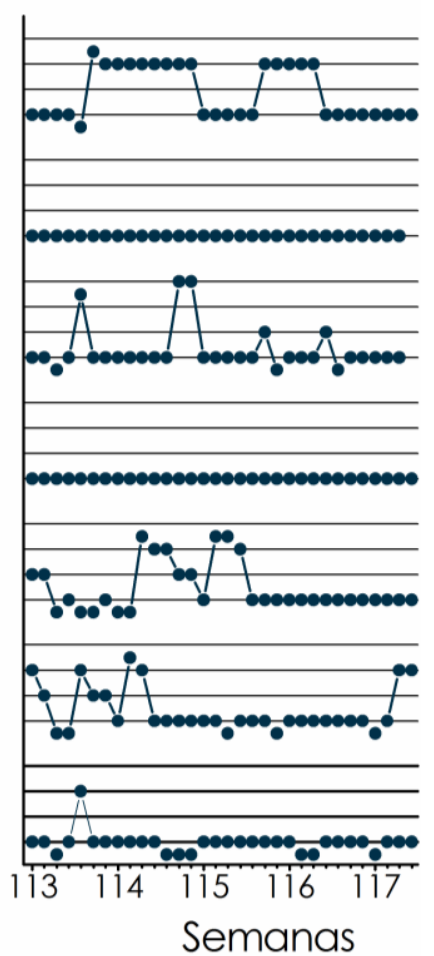

Figura 1: Perfil de ciclicidad estral de tres grupos de ratas hembra pertenecientes a nuestra colonia. En el eje de las abscisas se representan cada uno de 
los días en que se realizó el extendido vaginal y en el de las ordenadas las estadíos del ciclo estral ( $P$, proestro, E, estro, M, metestro, D, diestro)que se determinaron de acuerdo al tipo celular predominante en el frotis vaginal; se observaron estadios intermedios entre la fase $\mathrm{P}$ y $\mathrm{E}$, a la que llamamos Proestro-estro $(\mathrm{Pe})$ y otro entre el $\mathrm{D}$ y el $\mathrm{P}$, a la que llamamos Diestro-proestro (Dp) que en el gráfico se corresponden con los puntos que caen entre líneas. En los paneles se muestra el patrón de ciclicidad estral de A ratas jóvenes, $\mathrm{B}$ ratas de mediana edad y $\mathrm{C}$ ratas seniles.

Como puede observarse en el panel A de la figura 1 los animales jóvenes presentan ciclos de entre 4 y 5 días de duración donde ninguno de los estadíos es predominante, es decir que no se presenta en un $50 \%$ o más de los días estudiados (Tabla 1). Por otra parte en los animales de mediana edad puede observarse una pérdida de la ciclicidad presentando un predominio de los días que pasaron en estro, 70,7 \% (Fig 1 panel B), mientras que las ratas seniles pasaron un $73,1 \%$ del tiempo en diestro (Fig 1 panel C,Tabla 1).

\begin{tabular}{|c|c|c|c|}
\cline { 2 - 4 } \multicolumn{1}{c|}{} & \multicolumn{3}{c|}{ Porcentaje de días en cada fase del ciclo estral } \\
\hline Fase del ciclo estral & Ratas jóvenes & $\begin{array}{c}\text { Ratas mediana } \\
\text { edad }\end{array}$ & Ratas seniles \\
\hline P & $0.8 \pm 0.5$ & $0 \pm 0.0$ & $0.9 \pm 0.9$ \\
\hline PE & $29.7 \pm 1.4$ & $13.7 \pm 2.7$ & $2.7 \pm 1.3$ \\
\hline E & $27.7 \pm 2.1$ & $70.7 \pm 5.1$ & $10.7 \pm 5.4$ \\
\hline M & $6.3 \pm 2.7$ & $5.5 \pm 1.0$ & $3.1 \pm 2$ \\
\hline DP & $24.2 \pm 1.7$ & $4.3 \pm 1.4$ & $73.1 \pm 7.8$ \\
\hline
\end{tabular}

Iabla 1: Incidencia relativa de las estadíos del ciclo estral en ratas de diferen-

tes edades. La incidencia relativa de cada una de las estadíos del ciclo estral se expresa como porcentaje de días en cada fase del total de los 32 días de observación. Las estadíos del ciclo estral se determinaron de acuerdo al tipo celular predominante en el frotis vaginal $(P$, proestro, $E$, estro, $M$, metestro, $D$, diestro, Pe, proestro-estro, Dp, diestro-proestro). Los valores se expresan como la media \pm el error medio estándar (EMS).

En base a las observaciones anteriores, definimos cuatro tipos de ciclos: 
Ciclos regulares: ciclos de 4-5 días de duración caracterizados por un día de $\mathrm{P}$ o $\mathrm{Pe}$, un día de $\mathrm{E}$ y $1-3$ de $\mathrm{M}$ y/o $\mathrm{D}$.

Estro constante: ciclos que fueron una sucesión de 5 o más días en estro.

Diestro constante: ciclos que fueron una sucesión de 5 o más días en Diestro.

Ciclos irregulares: ciclos que no cumplían ninguna de las condiciones anteriores.

Posteriormente a fin de analizar la ciclicidad estral de los grupos etarios estudiados calculamos la frecuencia (cantidad de cada uno de estos ciclos por semana) que presentaron los animales (Fig. 2).

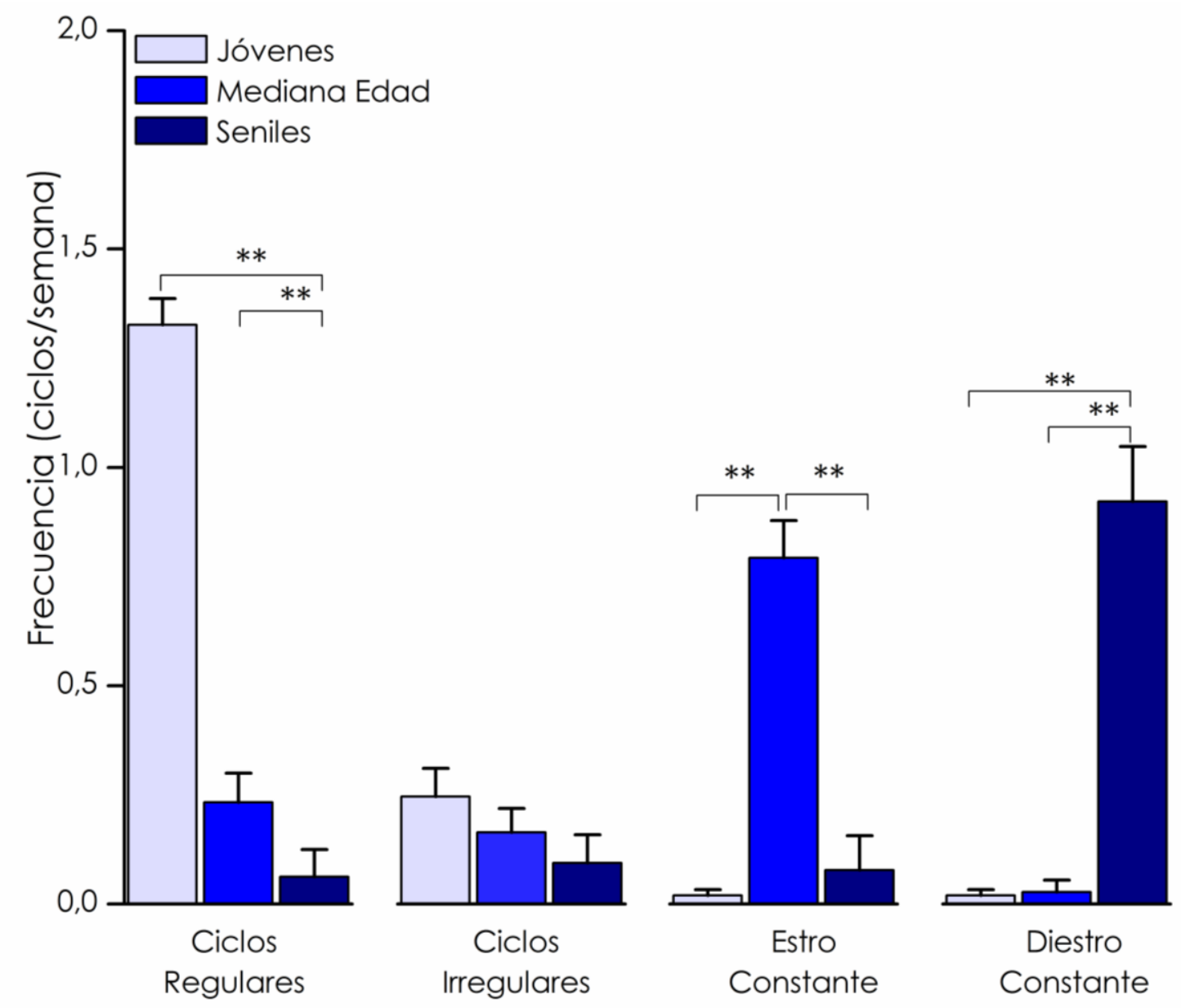

Figura 2: Analisis de la frecuencia de los ciclos regulares, irregulares, estro constante y diestro constante en ratas hembras jóvenes, de mediana edad y séniles. En el gráfico se muestra el número de ciclos regulares, ciclos irregulares, estro constante y diestro constante por semana para tres grupos etarios de ratas hembras. El $\mathrm{N}$ fue 
de 8 tanto para el grupo de ratas jóvenes como de mediana edad y 7 para el de seniles. Cada columna representa la media + EMS; los asteriscos indican diferencias altamente significativas $(* * p<0,01)$ entre cada grupo etario.

A partir de este análisis se puede observar que los ciclos regulares son significativamente más frecuentes en ratas jóvenes, mientras que los ciclos irregulares no presentan una mayor frecuencia en ninguno de los tres grupos etarios estudiados, en tanto que el estro constante es significativamente más frecuente en ratas de mediana edad y el diestro constante en ratas seniles (Fig. 2).

De modo que las ratas hembras criadas en nuestro bioterio presentan a las 47 semanas de edad un estado de estro constante, el cual indica una disminución de la funcionalidad reproductiva.

\subsection{Perfil hormonal.}

Para determinar los parámetros hormonales de los animales estudiados se midieron los niveles de cuatro hormonas relevantes a nivel reproductivo, LH, E2, P4 y PRL, mediante RIAs específicos (Fig.3). En todos los casos comparamos dos estadíos del ciclo estral de ratas jóvenes (E y D) con los estadios predominantes en ratas de mediana edad (E) y ratas seniles (D).

En los niveles para LH no se encontraron diferencias significativas cuando se compararon las diferentes edades y estadios del ciclo. Tampoco se observaron diferencias significativas en los niveles séricos de P4 en ninguno de los grupos y estadíos estudiados. Cuando se analizaron los niveles séricos de E2 se hallaron aumentos significativos de los mismos en las ratas de mediana edad con respecto a los niveles encontrados tanto en las ratas jóvenes como en las ratas seniles. Al comparar los niveles de E2 de ratas seniles con los dos estadios del ciclo estral de ratas jóvenes estos no resultaron significativamente diferentes. En cuanto a los niveles de prolactina sérica fueron significativamente mayores en ratas

de seniles comparados con los hallados en ratas jóvenes, tanto en estro 
como en diestro, y ratas de mediana edad. También se observó que los niveles de prolactina en ratas de mediana edad fueron significativamente menores que en ratas jóvenes en estro.
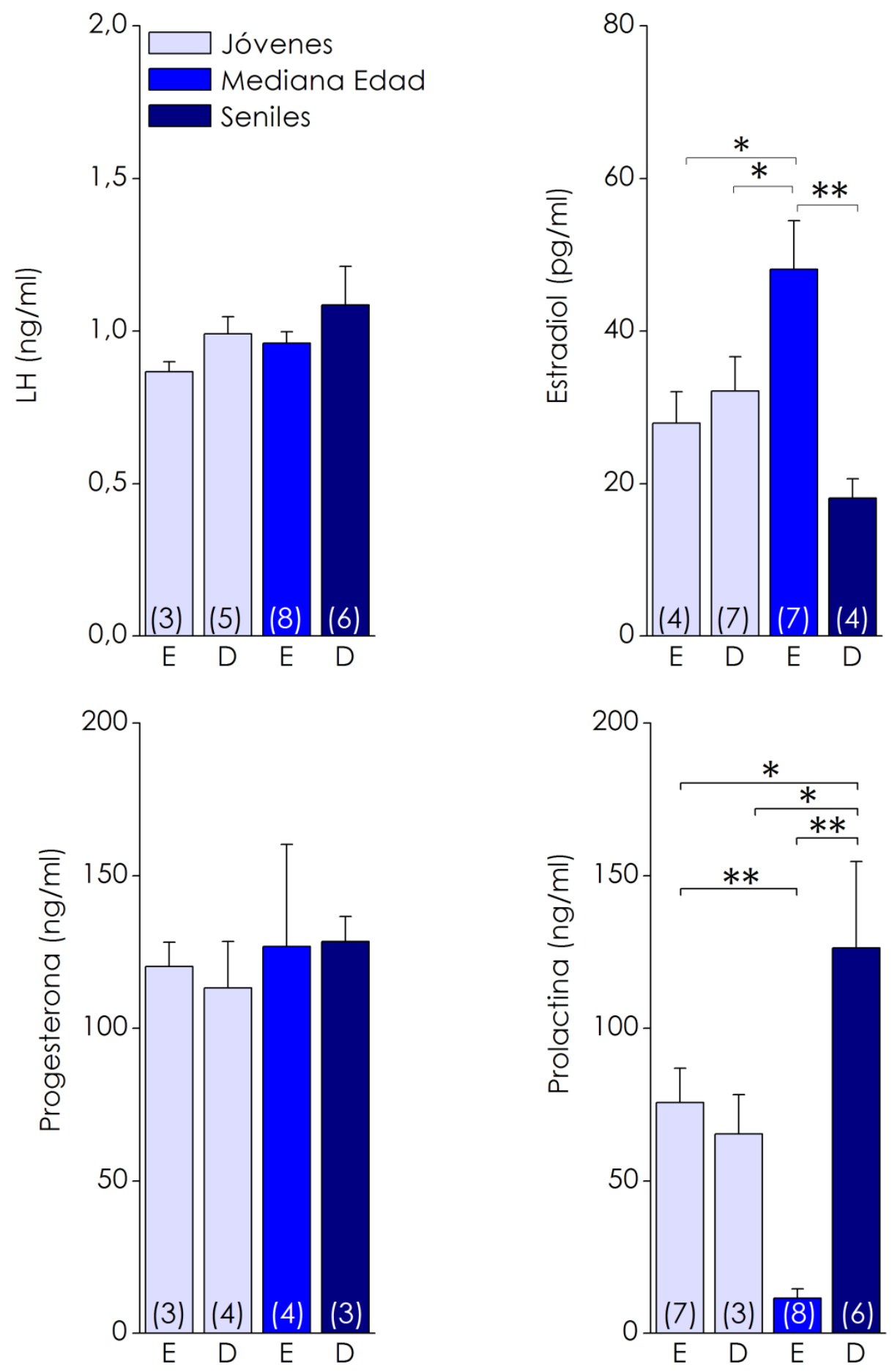

Figura 3: Niveles de LH, E2, P4 y PRL séricos de ratas hembra jóvenes, de mediana edad y seniles pertenecientes a nuestra colonia. En el gráfico se muestra los niveles de LH, E2, P4 y PRL de las ratas hembras de ratas jóvenes, de mediana edad y seniles. En el eje de las abscisas se representan los estadios del ciclo estral entre los que se realizó la comparación (E, estro, $D$, diestro).En el eje de las ordenadas se repre- 
sentan los niveles hormonales. Cada columna representa la media + EMS; ${ }^{*} P<0,05,{ }^{* *} P$ $<0,01$.

\subsection{Parámetros morfométricos.}

Al final del periodo de seguimiento las ratas fueron pesadas y se extrajeron los ovarios que también fueron pesados.

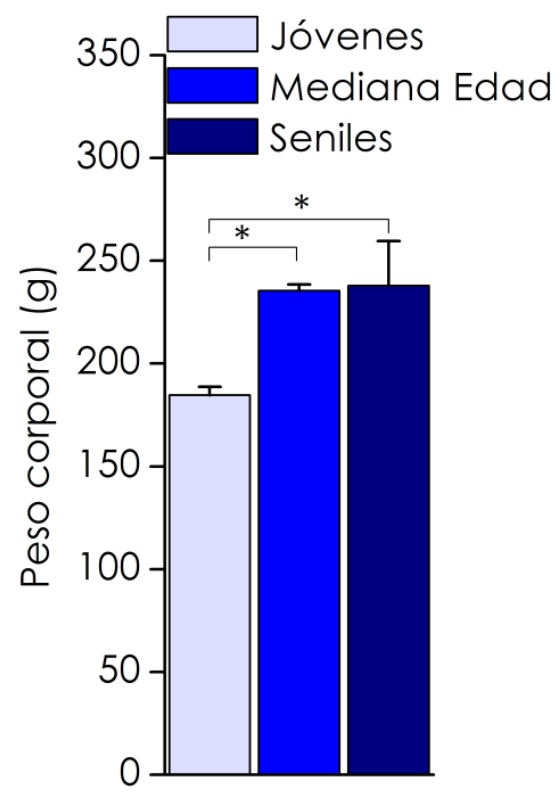

Figura 4: Peso corporal de tres grupos de ratas hembra pertenecientes a nuestra colonia. En el eje de las ordenadas se representan los pesos corporales expresados en gramos de las ratas hembras de tres grupos etarios de nuestra colonia de ratas. . El $\mathrm{N}$ fue de 8 tanto para el grupo de ratas jóvenes como de mediana edad y 5 para el de seniles.

* Cada columna representa la media + EMS; * $P<0,05$.

Los pesos corporales de los animales aumentaron significativamente con la edad (Fig. 4). No se encontraron diferencias entre el peso medio de las ratas de mediana edad y las ratas seniles.

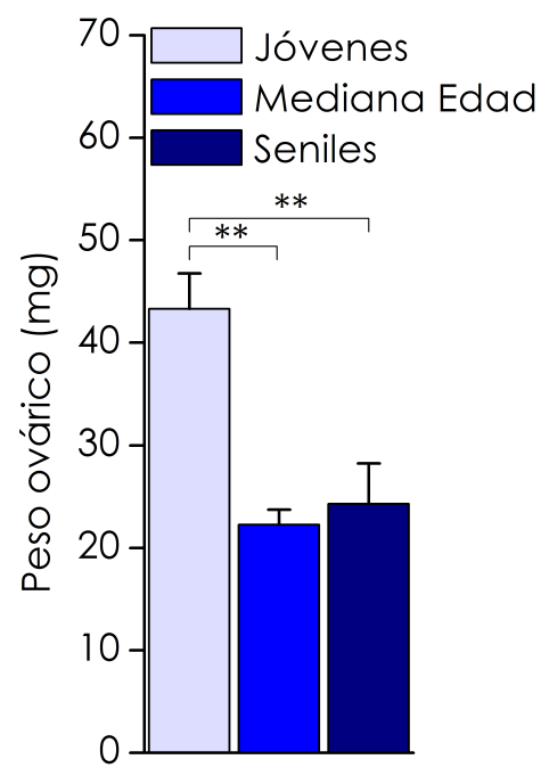

Figura 5: Peso de los ovarios de tres grupos etarios de ratas hembra pertenecientes a nuestra colonia. En la figura se muestran las medias de los pesos de los ovarios de las ratas de tres grupos etarios de nuestra colonia de ratas expresados en miligramos. . El $\mathrm{N}$ fue de 8 tanto para el grupo de ratas jóvenes como de mediana edad y 5 para el de seniles. Cada columna representa la media + EMS, ${ }^{* *} \mathrm{P}<0,01$. 
Por otra parte, el peso ovárico se redujo significativamente en los animales de mediana edad y seniles respecto al de las ratas jóvenes (Fig.5).

\subsection{Morfología ovárica.}

Los ovarios fueron fijados y posteriormente procesados para estudiar su histología. Se realizó la cuantificación de folículos maduros, cuerpos lúteos, quistes ováricos y folículos atrésicos (Fig. 6 y 7).

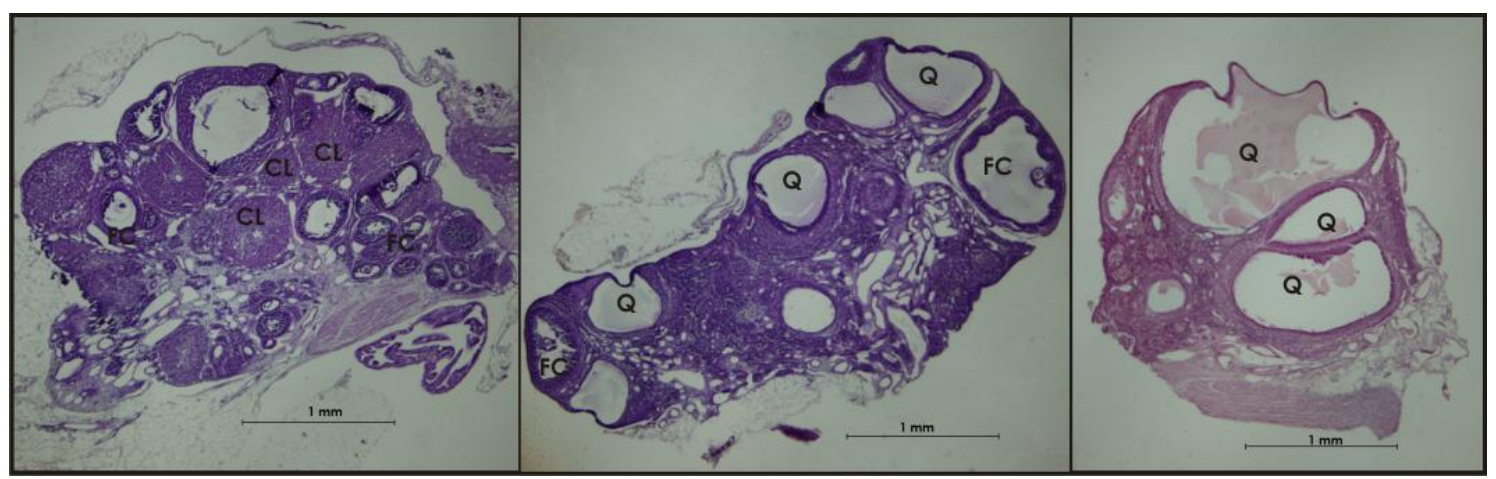

Figura 6: Morfologia ovárica. Fotografías mostrando la histología representativa de los ovarios de las ratas jóvenes, de mediana edad y seniles. La fotografía izquierdapertenece al ovario de un animal joven que muestra numerosos cuerpos lúteos (CL) o folículos en crecimiento (FC). La fotografía del medio corresponde a la sección de un ovario de una rata de mediana edad que muestra dos FC y varios quistes. La fotografía derecha pertenece al ovario de un animal senil que presenta quistes ováricos (Q).

Como puede observarse en la fotografía de la izquierda, la cual es representativa de los ovarios de las ratas jóvenes, predominaron los cuerpos lúteos y folículos en diferentes estadios del crecimiento. En la fotografía del medio, característica de los ovarios de las ratas de mediana edad, si bien se encontraron folículos en crecimiento, había mayor cantidad de quistes y no se observaron cuerpos lúteos. Los ovarios de los animales seniles, representados en la fotografía de la derecha, presentaron mayoritariamente quistes. 

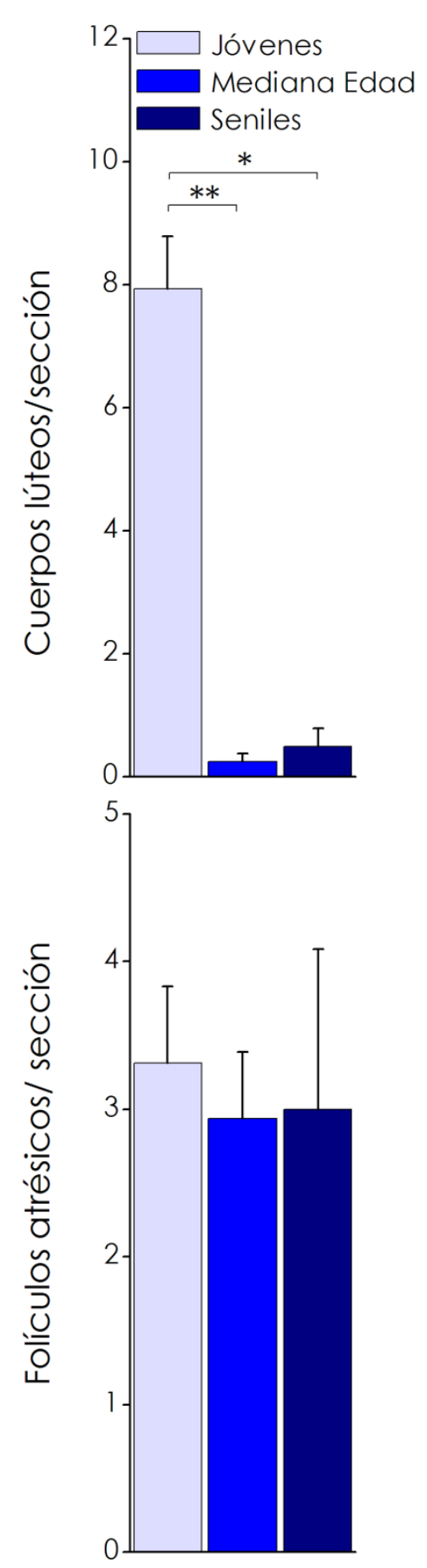
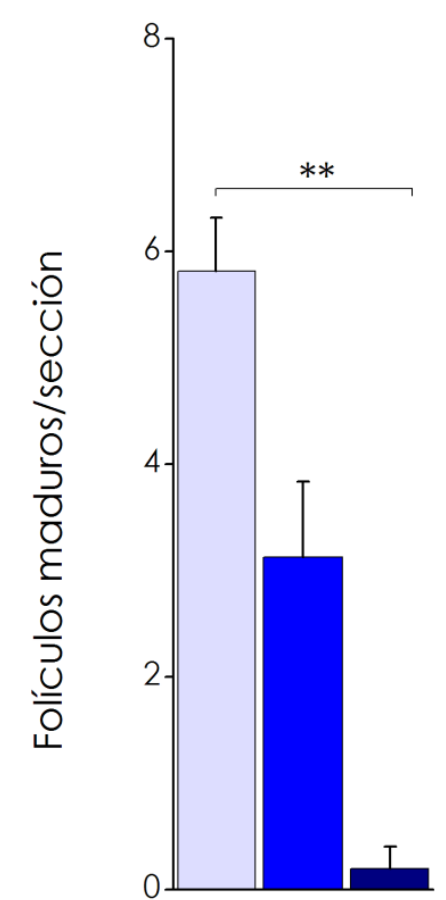

Figura 7: Efecto de la edad sobre la histología ovárica. Se cuantifico el número de cuerpos lúteos, folículos maduros, quistes y folículos atresicos en los ovarios de las ratas jóvenes, de mediana edad y seniles. . El $\mathrm{N}$ fue de 8 tanto para el grupo de ratas jóvenes como de mediana edad y 5 para el de seniles. Cada columna representa la media + EMS; * $\mathrm{P}<0,05,{ }^{* *} \mathrm{P}<0,01$.

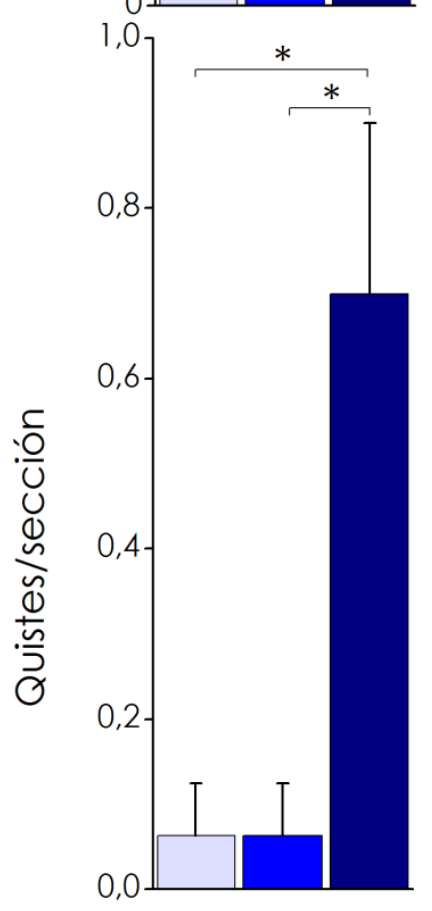

Al cuantificar, se encontró que en los ovarios de las ratas jóvenes había una cantidad significativamente mayor de cuerpos lúteos por sección comparado con los que había en las ratas de mediana edad y las ratas seniles. También se hallaron una mayor cantidad de folículos maduros en los ovarios de las ratas jóvenes siendo esta diferencia significativa respecto a las ratas seniles. No se encontraron diferencias entre los folículos maduros que había en los ovarios de las ratas de mediana 
edad comparados con las ratas jóvenes y seniles. No se observaron diferencias significativas en la cantidad de folículos atrésicos que presentaban los ovarios de los tres grupos estudiados. Por otra parte, la cantidad de quistes que tenían los ovarios de las ratas seniles fue significativamente superior a los que había en las ratas jóvenes y de mediana edad.

Considerando que los cuerpos lúteos son el resultado del proceso de ovulación, la ausencia de los mismos denotan la perdida de la fertilidad en las ratas de 47 semanas de edad criadas en nuestro bioterio.

\section{CARACTERIZACIÓN DE LOS VECTORES ADENOASOCIADOS.}

De acuerdo a lo que planteamos en el segundo objetivo de esta tesis, estudiamos la funcionalidad de los vectores derivados de virus adenoasociados.

\subsection{Expresión de IGF-I y DsRed2 en células en cultivo.}

Se realizaron transducciones de células HEK 293 utilizando el rAAVIGF-I-IRES-DsRed2. Además, para descartar que la DsRed2 estimule inespecíficamente la producción de IGF-I endógeno de las células transducidas, paralelamente, se realizaron transducciones con rAAV- IRESDsRed2. A las 24,48 y 72 hs se recogió el sobrenadante de los cultivos para realizar la determinación del IGF-I mediante un RIA específico. Pasadas 48 hs de la transducción, las células fueron observadas en un microscopio invertido de fluorescencia para visualizar la expresión de la DsRed2. A las 72 hs las células fueron procesadas para obtener los lisados celulares los que se utilizaron para medir los niveles de fluorescencia del DsRed2 por fluorometría. 


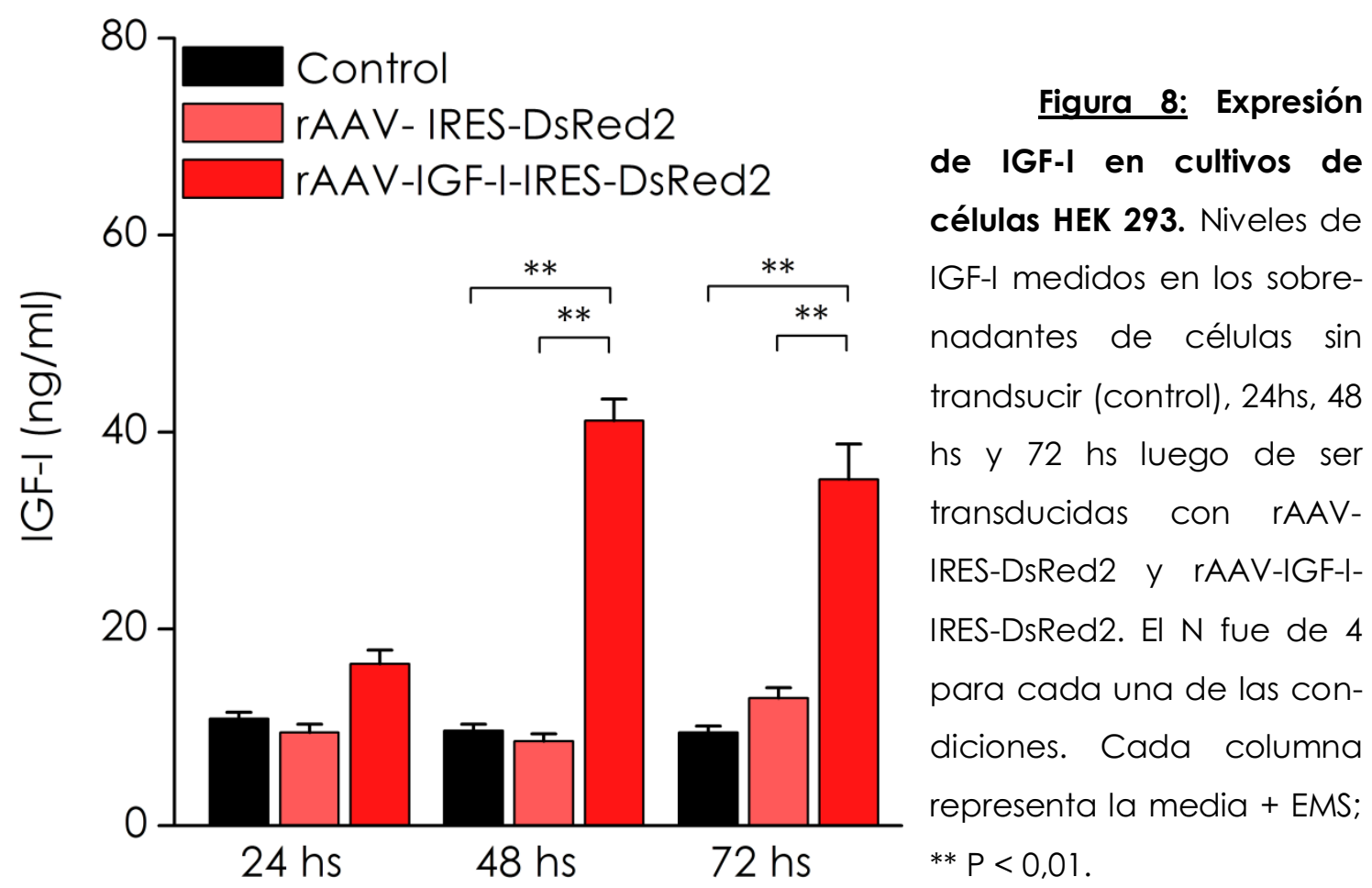

En los sobrenadantes de los cultivos de células HEK293 transducidos con rAAV-IGF-I-IRES-DsRed2 se observó un aumento significativo de IGF-I a partir de las 48 hs. Por el contrario los niveles del péptido se mantuvieron sin cambios en los sobrenadantes de las células transducidas con rAAV- IRES-DsRed2 y en las no transducidas (Fig.8).

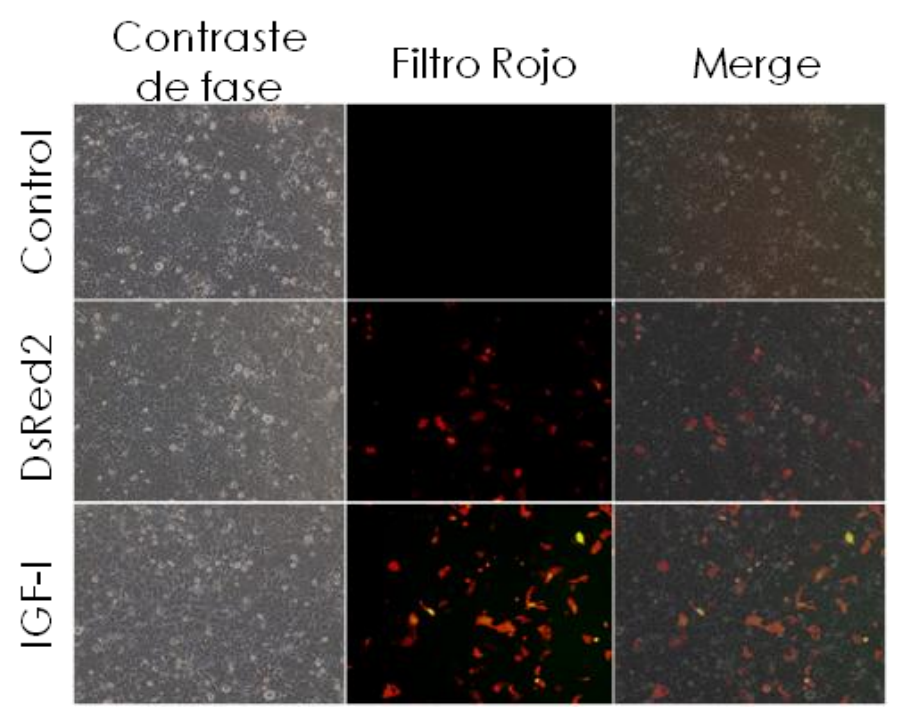

Figura 9: Expresión de DsRed2 en cultivos de células HEK 293. En el panel superior, medio e inferior se muestran las imágenes de los cultivos sin transducir (control), 48 hs luego de ser transducidas con rAAVIRES-DsRed2 (DsRed2) y rAAVIGF-I-IRES-DsRed2 (IGF-I), respectivamente. Objetivo X10. 
Ambos vectores indujeron fluorescencia roja en las células transducidas a las 48 hs (Fig.9).

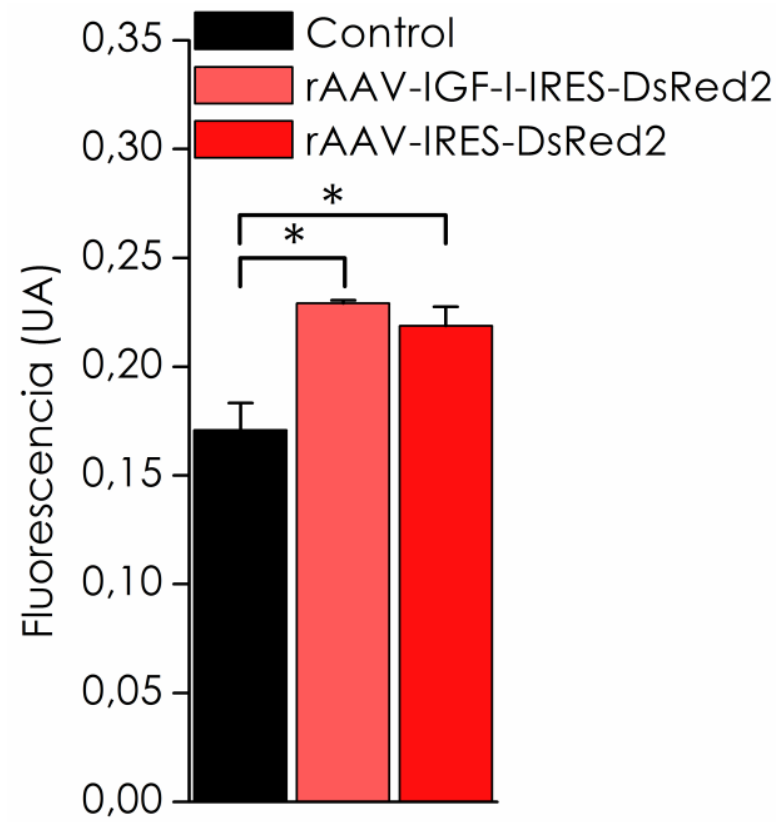

Figura 10: Expresión de DsRed2 en lisados provenientes de cultivos de células HEK 293. Niveles de fluorescencia en unidades arbitrarias (UA) medidos en los lisados de células sin tranucir (control) y 72 hs luego de ser tranucidas con rAAV- IRES-DSRed2 o rAAV-IGF-IIRES-DsRed2. El $N$ fue de 4 para cada una de las condiciones. Cada columna representa la media + EMS; * $\mathrm{P}<0,05$.

Al cuantificar los niveles de fluorescencia 72 hs postransducción se hallaron que estos eran significativamente mayores en los lisados celulares provenientes de los cultivos transducidos con rAAV- IRES-DsRed2 o rAAV-IGF-IIRES-DsRed2, respecto de aquellos que no habían sido transducidos (Fig.10).

\subsection{Expresión de DsRed2 en cerebro de rata.}

Para estudiar la duración de la expresión de estos vectores en diferentes regiones del cerebro, los vectores fueron inyectados en ventrículo lateral y en HMB. A las 4, 8, 10 y 14 semanas post inyección los animales fueron sacrificados y los cerebros procesados para ser observados en un microscopio de fluorescencia y así confirmar la expresión de la DsRed2. 


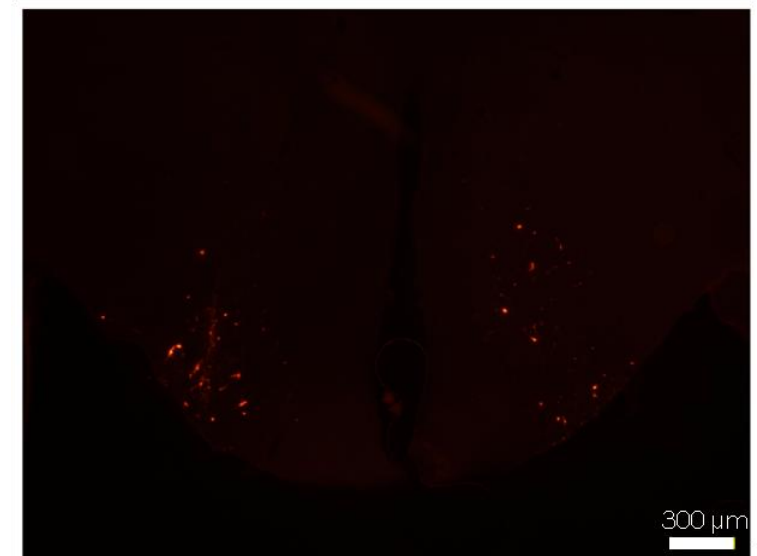

Figura 11: Expresión de DsRed2 en HMB de rata. Micrografías de baja (panel superior) y alta (panel inferior) magnificación que muestran la expresión de rAAV-IGF-I-IRES-DsRed2 en el HMB de una rata hembra. El animal fue sacrificado 14 semanas post inyección de $4 \times 10^{9}$ vg de rAAV-IGF-I-IRES-DsRed2

por lado.

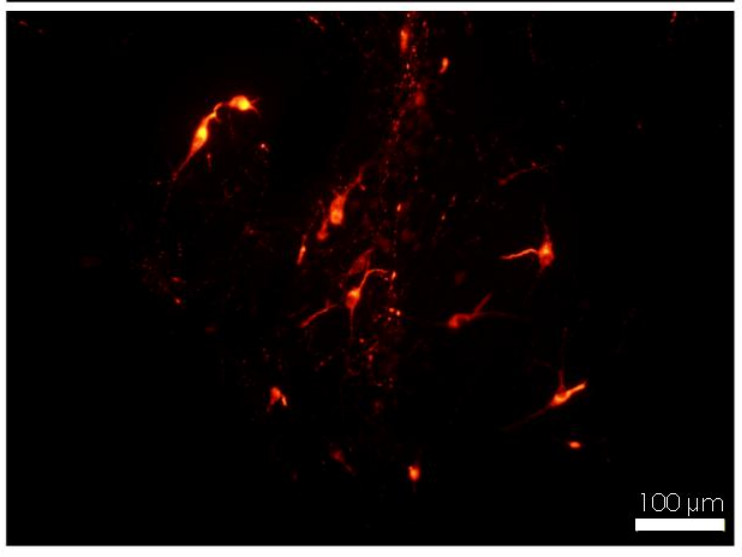

La expresión de la DsRed2 se mantuvo al menos hasta las 14 semanas postinyección del vector en HMB (Fig.11). En ventrículo lateral no se observó expresión de la misma.

\section{EFECTO DEL IGF-I SOBRE LOS PARAMETROS REPRODUCTIVOS DE} RATAS HEMBRAS DE MEDIANA EDAD.

El siguiente objetivo de esta tesis fue estudiar el efecto del IGF-I sobre los parámetros reproductivos de ratas hembras de mediana edad de nuestra colonia. 


\subsection{Patrón de ciclicidad.}

El experimento fue diseñado en base a los resultados obtenidos en los dos objetivos anteriores, es decir, que los animales a las 47 semanas de edad ya presentaban un estado de estro constante y que los vectores expresaban eficientemente la proteína de interés al menos por 14 semanas. Así, se realizaron extendidos vaginales a 32 ratas hembras de 34,5 semanas de edad, durante por 12 días consecutivos para posteriormente agruparlas al azar en:

Un grupo de ratas intactas a las que en adelante llamaremos Control.

Un grupo de ratas que inyectamos intrahipotalámicamente con rAAV-IRES-DsRed2, en adelante DsRed.

Un grupo de ratas que inyectamos intrahipotalámicamente con un rAAV-IGF-I-IRES-DsRed2, en adelante IGF-I.

Una vez que los animales fueron agrupados a las 36 semanas de vida, fueron inyectados con el vector correspondiente y se continuó con la realización diaria de los extendidos vaginales hasta el momento del sacrificio en la semana 49,5 de edad (momento en el cual se esperaba que los animales presentaran un estado de estro constante). De este modo se obtuvo un registro de la ciclicidad estral antes y después de la inyección de los rAAV (Fig.12).

Como puede observarse en los perfiles de ciclicidad estral, al momento del sacrificio, todos los animales del grupo control presentaban un estado de estro constante, mientras que en los tratados con el vector que expresa solo el DsRed cuatro animales aún ciclaban y en los tratados con el vector que expresa el IGF-I fueron seis los animales que ciclaban. 


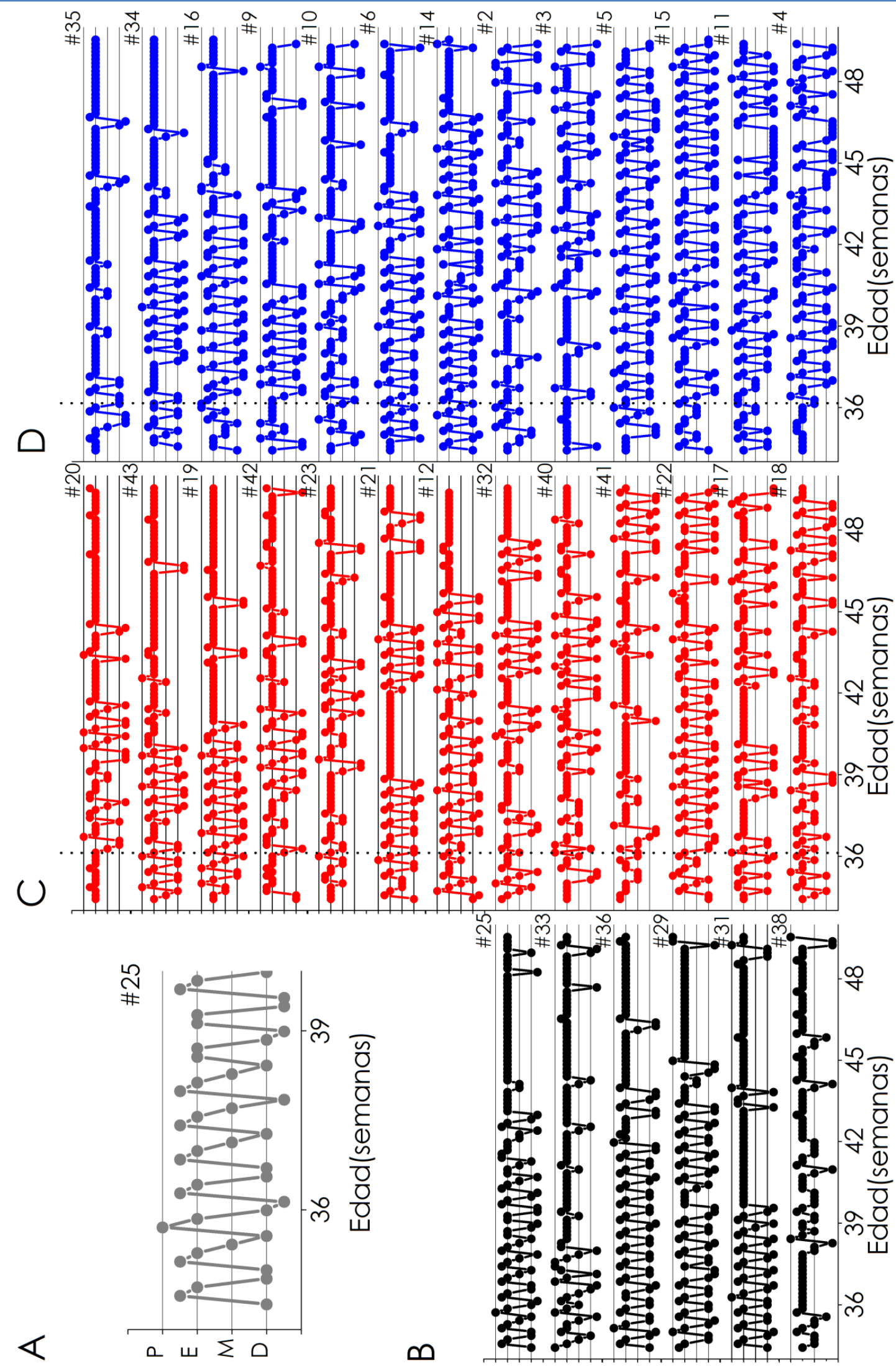

Figura 12: Perfil de ciclicidad estral de ratas hembra de mediana edad. En el panel A se esquematiza el patrón de ciclicidad de una rata, el eje de las abscisas representa cada uno de los días en que se realizó el extendido vaginal, la escala expre- 
sa la edad de las ratas en semanas. El eje de las ordenadas representa los estadíos del ciclo estral que se determinaron de acuerdo al tipo celular predominante en el frotis vaginal ( $P$, proestro, $E$, estro, $M$, metestro, $D$, diestro). Los estadios intermedios que se observaron, uno entre la fase $\mathrm{P}$ y $\mathrm{E}$, a la que llamamos Proestro-estro (Pe) y otro entre el $D$ y el $P$, a la que llamamos Diestro-proestro (Dp) en el gráfico se corresponden con los puntos que caen entre líneas. B perfil de ciclicidad estral en el grupo control, C grupo DsRed y D grupo IGF-I.

Así, en base a los patrones de ciclicidad estral encontrados, se determinaron las diferencias en el estado reproductivo de las ratas de los diferentes grupos al finalizar el estudio. Para ello se definieron tres categorías de ciclos: ciclos de 4-5 días de duración caracterizados por un día de $\mathrm{P}$ o $\mathrm{Pe}$, un día de $\mathrm{E}$ y 2-3 de $\mathrm{M}$ y/o D, denominados ciclos regulares; ciclos con una sucesión de 5 o más días en estro denominados ciclos en estro constante y por último aquellos ciclos que no cumplían ninguna de las condiciones anteriores se denominaron ciclos irregulares. Posteriormente calculamos la frecuencia de cada uno de estos ciclos (cantidad de ciclos por semana) que observamos en cada grupo antes y después del tratamiento (Fig.13).

Al realizar el análisis de las frecuencias de los ciclos se observó que tanto las ratas del grupo control como las que las del grupo DsRed mostraban una disminución significativa en la frecuencia de ciclos regulares, además presentaban un aumento significativo de la frecuencia de estros constantes respecto del pretratamiento. Por el contrario, no se hallaron cambios significativos en las frecuencias de ciclos regulares y estro constante en las ratas que habían recibido el vector que expresaba IGFI. La frecuencia de ciclos irregulares no presentó cambios significativos en ninguno de los tres grupos antes y después del tratamiento (Fig.13). 


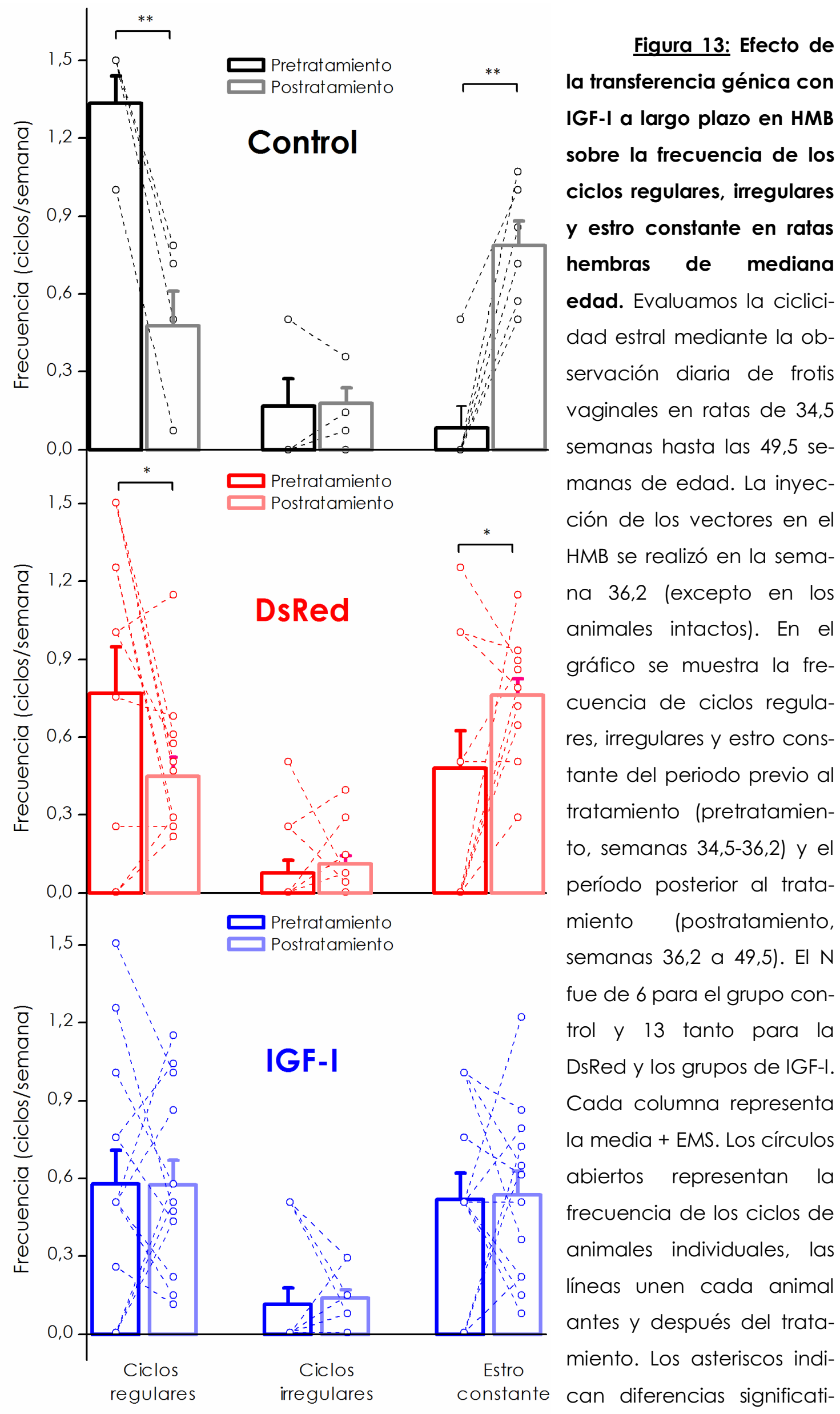


vas $\left({ }^{*} p<0,05\right)$ o altamente significativas $(* * p<0,01)$ en comparación con los valores encontrados para el pretratamiento correspondiente.

También se analizó la diferencia $(\Delta)$ en la frecuencia de ciclos antes y después del tratamiento en cada grupo de animales (Fig.14).

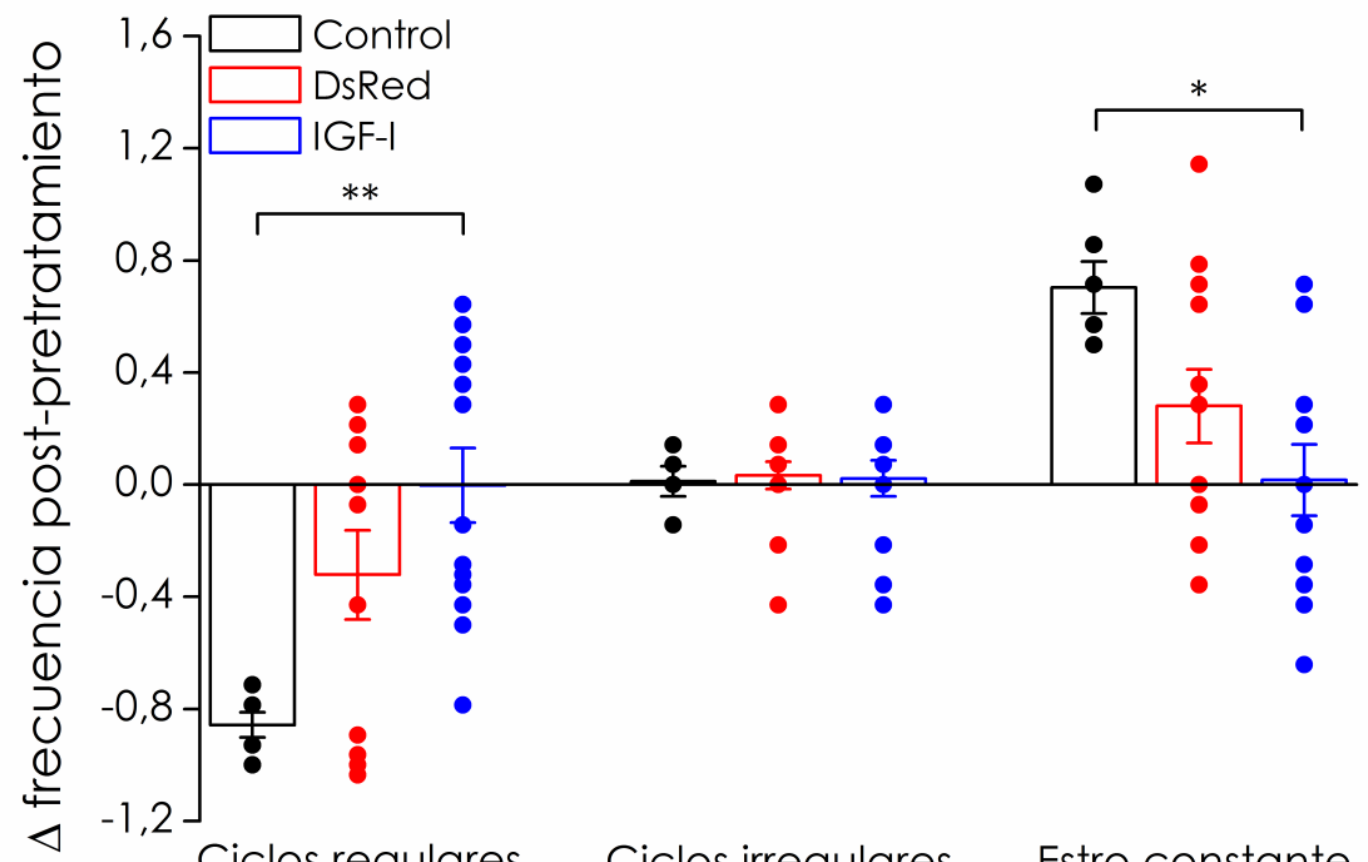

Ciclos regulares Ciclos irregulares Estro constante

Figura 14: Diferencia de frecuencia de los ciclos antes $y$ despues del tratamiento. En el grafico se muestra la diferencia en la frecuencia de los ciclos regulares, irregulares y estro constante del periodo previo al tratamiento (semanas 34,5-36,2) y el período posterior al tratamiento (semanas 36,2 a 49,5). El $N$ fue de 6 para el grupo intacto y 13 tanto para la DsRed y los grupos de IGF-I. Cada columna representa la media + EMS. Los círculos representan las diferencias de frecuencia de los ciclos de animales individuales. Los asteriscos indican diferencias significativas ( $\left.{ }^{*} p<0,05\right) \circ$ altamente significativas (** $p<0,01)$ entre las diferencias de frecuencia.

Las diferencias en la frecuencia promedio de los ciclos regulares en el grupo control fueron negativas, observándose que todos los animales del grupo mostraban una disminución en la frecuencia de los mismos, siendo esta significativamente diferente que el grupo IGF-I. En el grupo DsRed también se vio un cambio de frecuencia negativa, aunque se observan animales en los que disminuyó la frecuencia $(53,8 \%$ de 
los animales), otros que no presentaron variaciones $(7,7 \%$ de los animales) y otros que aumentaron su frecuencia de ciclos regulares luego del tratamiento (38,5\% de los animales). En el grupo IGF-I no hubo variación en la frecuencia de ciclos regulares y aquí se halló que los animales presentaron un aumento $(46,2 \%$ de los animales) o una disminución de la frecuencia $(53,8 \%$ de los animales).

Las diferencias en la frecuencia de los ciclos irregulares fueron en promedio positivas en los tres grupos estudiados y no se observaron diferencia significativa entre los tres grupos de animales estudiados.

Las deferencias de frecuencias de los estros constantes del grupo control fueron en promedio positivas, aquí también se observó que todos los animales presentaron un aumento significativo de la frecuencia de estos ciclos salvo en el caso del grupo IGF-I. En el grupo DsRed las diferencias en las frecuencias también fue en promedio positivas, encontrándose animales que habían aumentado (53,8\% de los animales), no habían sufrido modificación (7,7 \% de los animales) y habían disminuido (38,5\% de los animales) la frecuencia de este tipo de ciclos. En el grupo IGF-I las diferencias en las frecuencias fueron en promedio positivas, presentando animales con un aumentó (38,5\% de los animales), sin modificación $(7,7 \%$ de los animales) o una disminución $153,8 \%$ de los animales) de las frecuencias de los estros constantes.

\subsection{Dosaje hormonal.}

Para determinar los parámetros hormonales de los tres grupos de animales, se extrajo sangre semanalmente de la vena de la cola y se midieron los niveles de LH, E2, P4 y PRL mediante RIAs específicos (Fig. 15). 

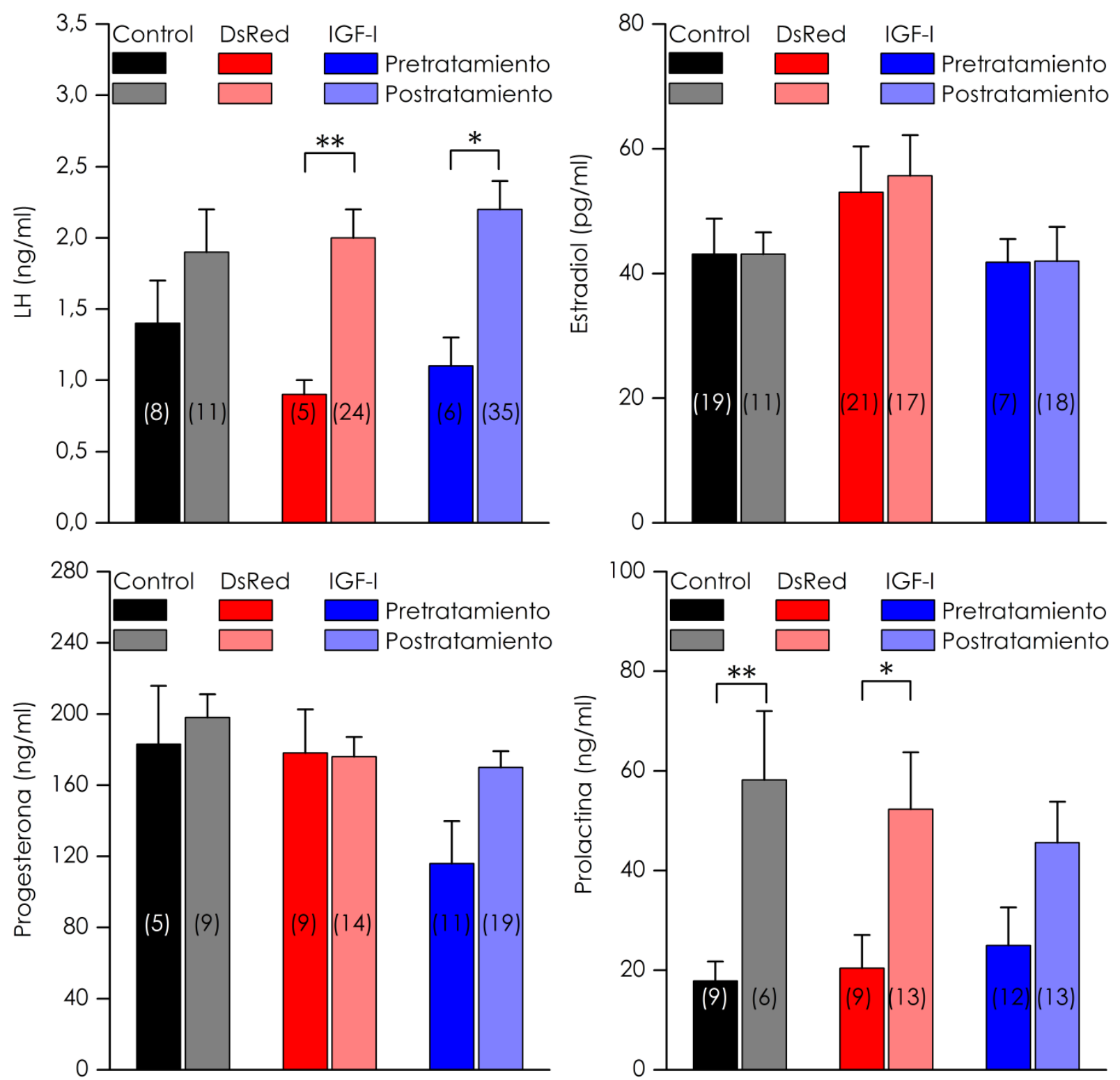

Figura 15: Niveles de LH, E2, P4 y PRL séricos. En el eje de las ordenadas se representan los niveles de LH, E2, P4 y PRL séricos para cada uno de los grupos en el periodo previo (Pretratamiento: semanas 34,5 a 36,2) y posterior (Postratamiento: semanas 36,2 a 49,5) a la inyección del rAAV correspondiente, excepto en las control que no recibieron inyección pero se respetaron estos periodos). Cada columna representa la media + EMS; * $P<0,05,{ }^{* *} P<0,01$.

Se observó un aumento significativo en los niveles de LH sérico postratamiento (Fig. 15, panel superior izquierdo) en el grupo DsRed e IGF-I respecto de los niveles medidos en el pretratamiento, también se halló un aumento significativo en los niveles de PRL (Fig. 15, panel inferior derecho) en los grupos Control y DsRed. 
No se observaron cambios significativos en los niveles de E2 (Fig. 15, panel superior derecho) ni en los de P4 (Fig. 15, panel inferior izquierdo) en ninguno de los tres grupos antes y después del tratamiento.

\subsection{Parámetros morfométricos.}

Durante el periodo de experimentación las ratas fueron pesadas semanalmente, al final del experimento los ovarios fueron disecados y pesados (Fig.16 y 17).

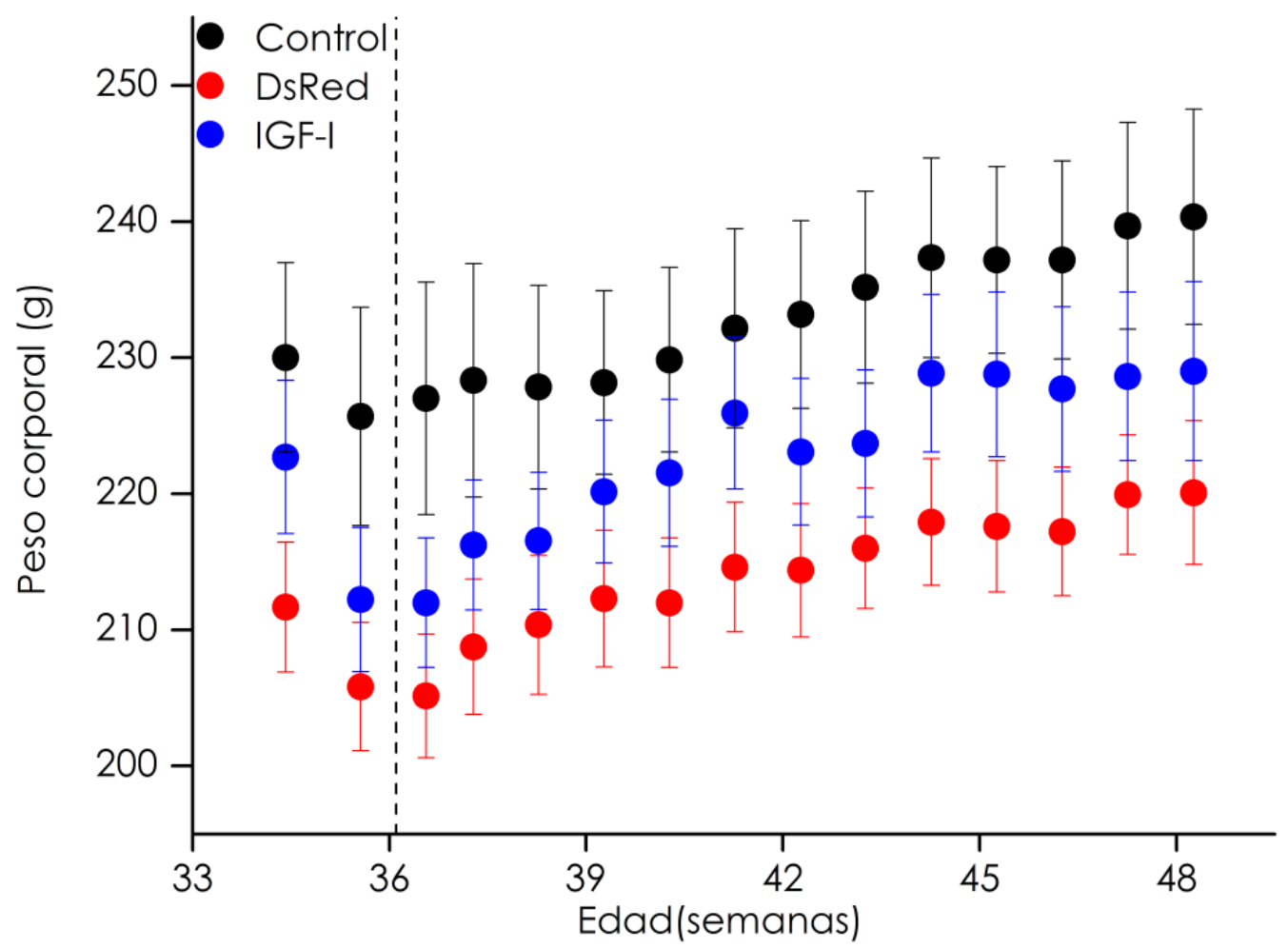

Figura 16: Peso corporal. En el eje de las ordenadas se representan los pesos corporales expresados en gramos de las ratas pertenecientes a cada grupo experimental, en el eje de las abscisas la edad de las mismas expresado en semanas. La línea punteada indica el momento de la inyección de los rAAV. Ratas control( $N=6)$, DsRed $(N=13)$ e IGF-I $(N=13)$. Cada punto representa la media \pm EMS.

En los pesos corporales de los animales no se encontraron diferencias significativas entre cada grupo experimental, tampoco se observaron diferencias respecto al tiempo de tratamiento (Fig.16). 


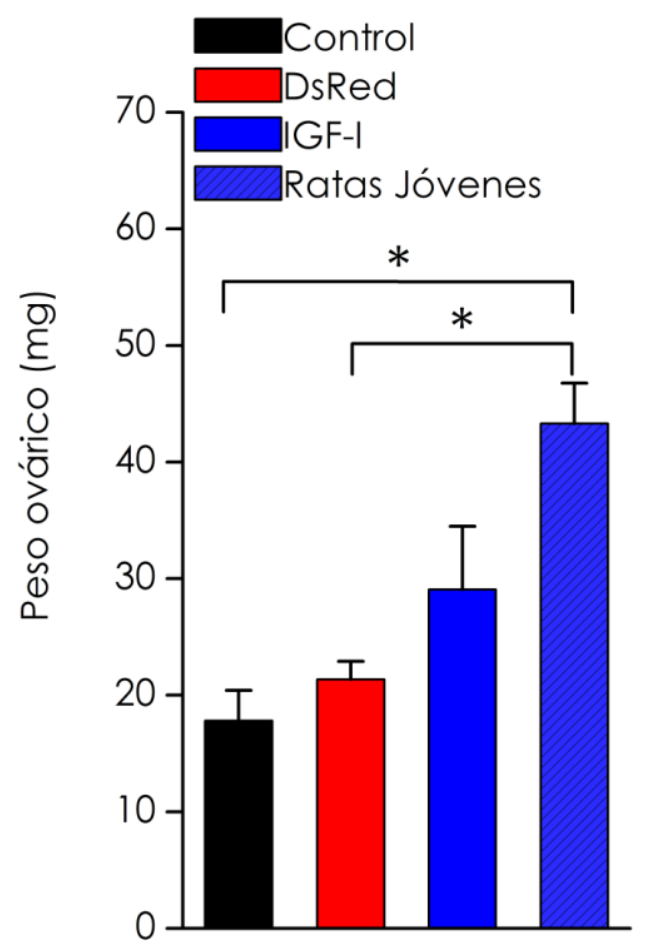

Figura 17: Peso de los ovarios de tres

grupos postratamiento. En la figura se muestran las medias de los pesos de los ovarios de las ratas de tres grupos al final del experimento expresados en miligramos. Ratas control( $N=6)$, DsRed $(N=13)$, IGF-I $(N=13)$ y ratas jóvenes $(N=8)$. Cada columna representa la media + EMS, $* \mathrm{P}<$ 0,05 .

Al analizar el peso de los ovarios y compararlos con el peso de los ovarios de las ratas jóvenes se encontró que tanto las ratas del grupo control como la del grupo DsRed eran significativamente más livianos, mientras que el peso de los ovarios de las ratas del grupo IGF-I no difería significativamente del de las ratas jóvenes.

\subsection{Niveles de IGF-I en HMB.}

El encéfalo de loa animales fue disecado cuidadosamente y se separaron los dos hemiencéfalos. La corteza y el HMB del hemiencéfalo izquierdo se separaon para posteriormente medir los niveles de IGF-I mediante un RIA específico.

Para minimizar las variaciones en los niveles de IGF-I propias de cada animal los niveles de IGF-I del HMB fueron normalizados con los de corteza (Fig.18). 


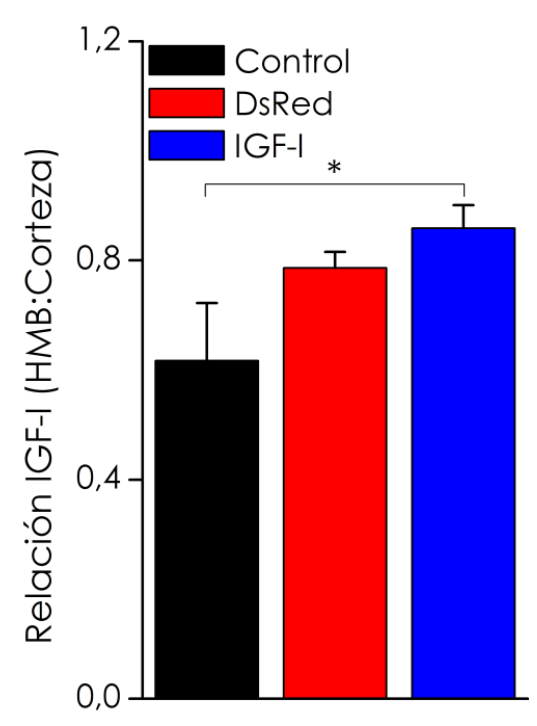

Figura 18: Niveles de IGF-I en HMB. Niveles de IGF-I medidos en los hemicerébros de ratas intactas (control), inyectadas con rAAV- IRES-DsRed2 y rAAVIGF-IIRES-DsRed2 al finalizar el experimento. En el eje de las ordenadas se muestra la relación de los niveles de IGF-I medidos en HMB normalizados respecto de los medidos en corteza. Ratas control $(\mathrm{N}=6)$, DsRed $(\mathrm{N}=$ 13) e IGF-I $(N=13)$. Cada columna representa la media + EMS; *P $<0,05$ respecto del control.

Los niveles de IGF-I en hipotálamo medio basal están aumentados respecto del control, este aumento fue significativo en las ratas que se inyectaron con el vector que expresa IGF-I.

\subsection{Morfología ovárica.}

En los ovarios de las ratas de los tres grupos se estudiaron las características histológicas de los mismos. Para ello se contaron el número de folículos maduros, de cuerpos lúteos, folículos atrésicos y quistes de ovaricos (Fig. 19). 

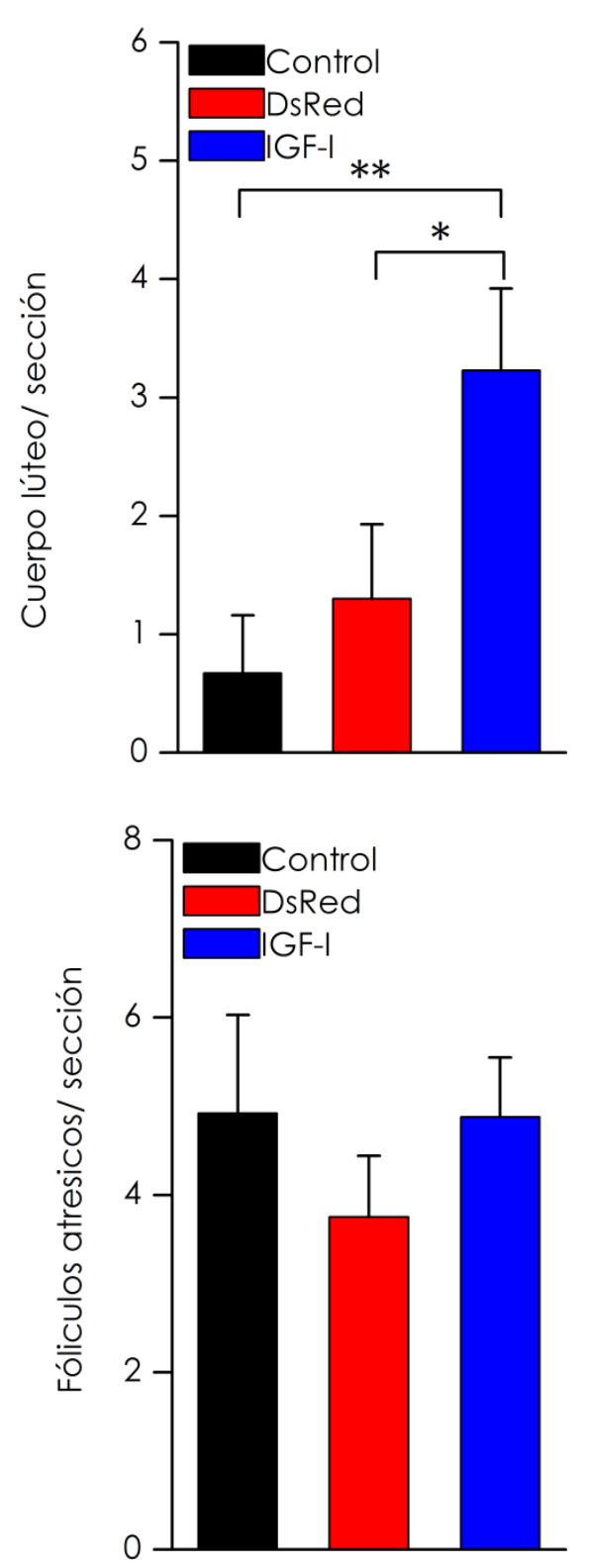
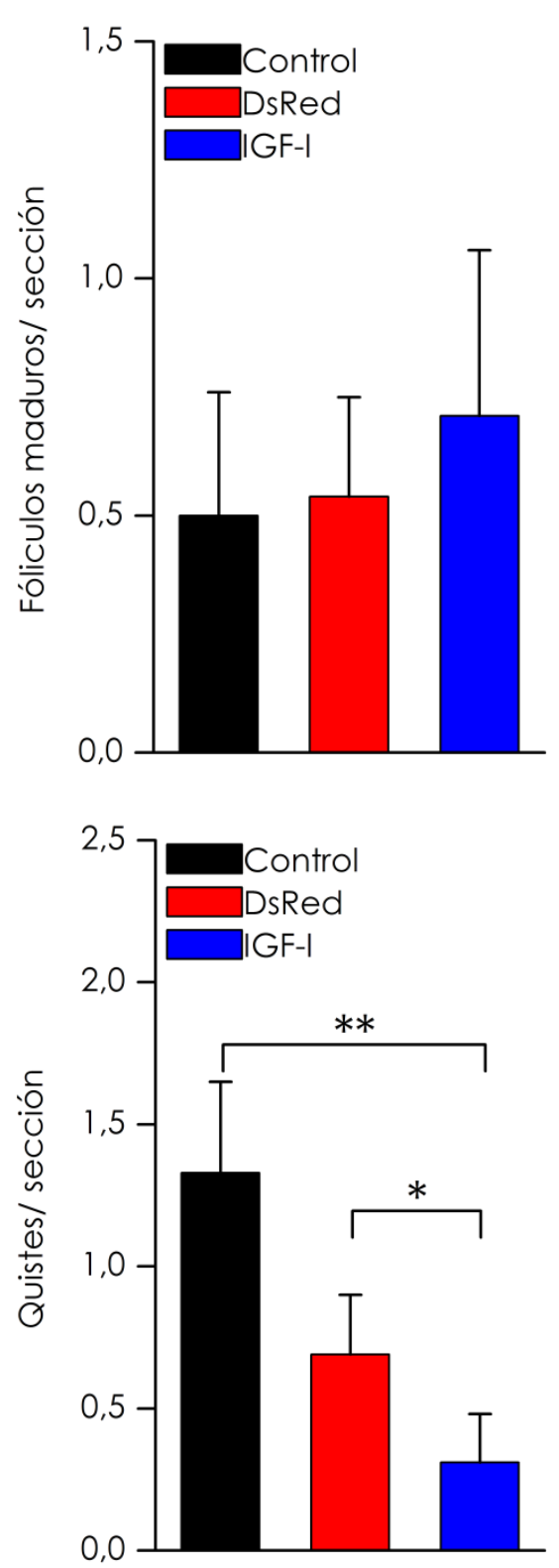

Figura 19: Efecto del tratamiento sobre la morfologia ovárica. Evaluación histomorfométrico de los ovarios de hembras de mediana edad posterior a la inyección del vector adenoasociado correspondiente, excepto en las control que no recibieron inyección. Evaluamos el número de cuerpos lúteos (panel superior izquierdo), folículos maduros (panel superior derecho), folículos atrésicos (panel inferior izquierdo) y quistes (panel inferior derecho) por sección en ratas control $(N=6)$, DsRed ( $N=13)$ e IGF-I $(N=$ 13). Los asteriscos se refieren a diferencias vs el grupo de IGF-I; ${ }^{* *} \mathrm{P}<0,01$ y $\mathrm{P} *<0.05$.

La cantidad de cuerpos lúteos por sección fue significativamente mayor en las ratas del grupo IGF-I comparada con la cantidad de cuerpos lúteos en los de las ratas pertenecientes al grupo control y DsRed. En cuanto a los quistes, las ratas del grupo IGF-I contenían una cantidad significativamente menor de los mismos respecto de los en- 
contrados en las ratas del grupo control y DsRed. No se hallaron diferencias significativas en la cantidad de folículos maduros ni en la de los foliculos atrésicos.

También se realizó una clasificación histológica de los ovarios, para ello los ovarios se clasificaron en tres grados:

Grado 1, corresponde a los ovarios con un promedio de uno o más quistes grandes, menos de un cuerpo lúteo y menos del un folículo maduro por sección;

Grado 2, corresponde a los ovarios muestran quistes pequeños o medianos pero no grandes, entre uno y 2,5 cuerpos lúteos y entre uno y 1,5 folículos maduros o en crecimiento por sección;

Grado 3, corresponde a los ovarios sin quistes medianos o grandes y con un promedio de 2,5 o más cuerpos lúteos, así como más de 1,5 folículos maduros por sección.
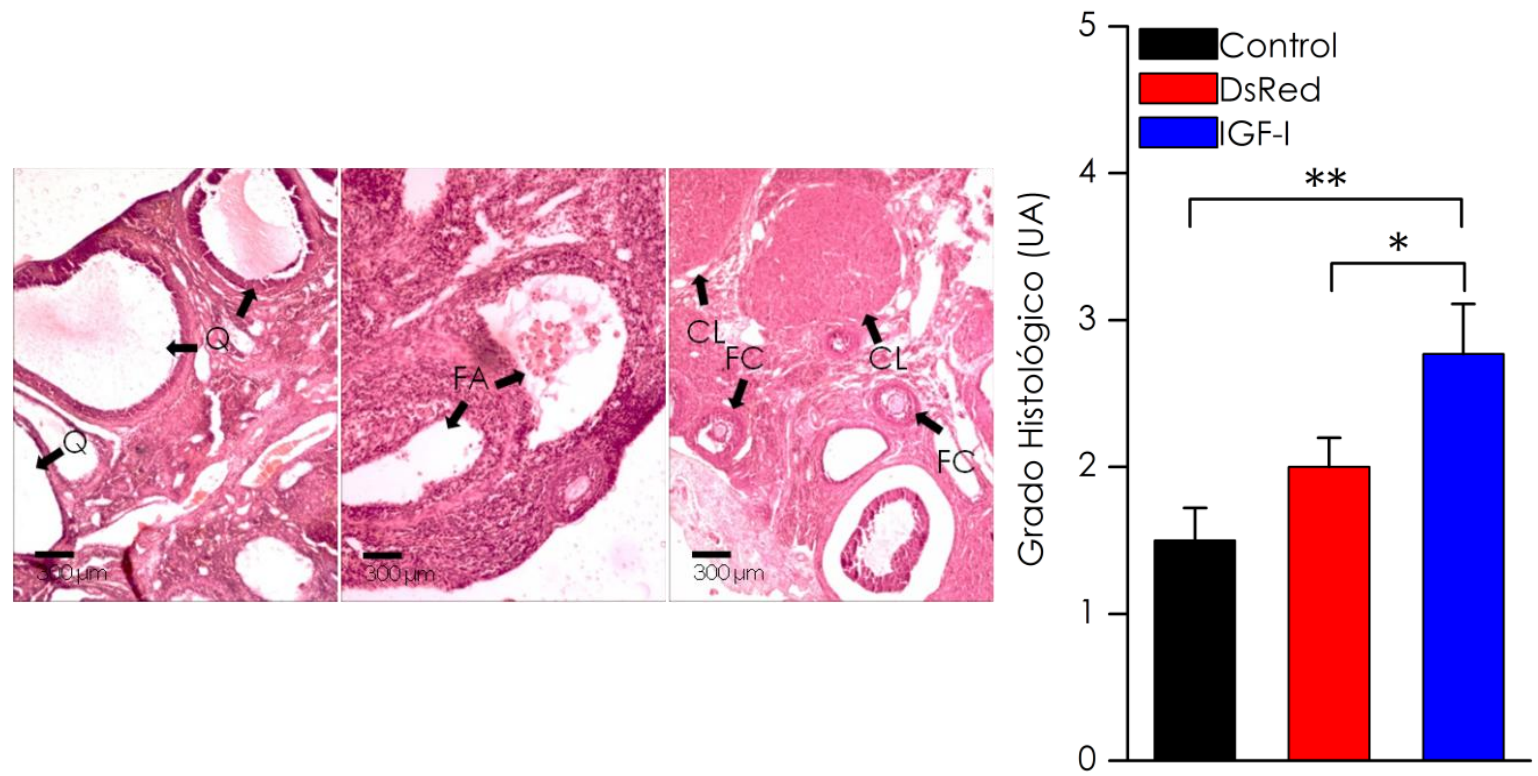

Figura 20: Efecto del tratamiento sobre la grado histológico de los ovarios. Panel izquierdo, fotografías mostrando la histología representativa de los ovarios de las ratas control, DsRed e IGF-I de 49,5 semanas de edad. Fotografía izquierda, ovario perteneciente a un animal control, con grado histológico 1, muestra quistes ováricos grandes $(Q)$, pero no cuerpos lúteos $(C L)$ o folículos en crecimiento $(F C)$ o maduros. Fotografía del medio, sección de ovario de una rata DsRed, al cual le asignamos el grado 2 , muestra numerosos folículos atresicos (FA), pero no CL o FC. Las células apoptóticas se 
pueden observar en el espacio folicular. Fotografía derecha sección de ovario de un animal IGF-I, grado 3, muestra folículos FC y CL de aspecto normal. Panel derecho, evaluación histomorfométrico de los ovarios de hembras de mediana edad posterior a la inyección del rAAV correspondiente, excepto en los animales control que no recibieron inyección. Evaluamos el grado histológico de los ovarios en ratas control $(N=6)$, DsRed $(N=13)$ e IGF-I $(N=13)$. Los asteriscos se refieren a diferencias vs el grupo de IGF-I (ANOVA seguido por el test de Tukey) ; ${ }^{* *} \mathrm{P}<0,01$ y $\mathrm{P} *<0.05$.

A medida que el grado histológico aumenta la integridad de la estructura ovárica es más conservada. Los ovarios en el grupo de IGF-I presentaron un grado histológico significativamente mayor que en las ratas intactas y DsRed (Fig. 20). 
DISCUSIÓN 


\section{PARAMETROS REPRODUCTIVOS EN LAS RATAS HEMBRAS DE NUESTRA} COLONIA.

En esta parte de la tesis determinamos los parámetros reproductivos y morfométricos de ratas hembras adultas jóvenes, de mediana edad y seniles que fueron criadas en el bioterio de nuestro Instituto.

La primera ovulación en ratas hembras de la mayoría de las cepas se produce entre los 35 y 45 días de edad, la cual se evidencia por la apertura del canal vaginal (Ojeda and Skinner, 2006). A partir de este momento los animales pueden, si son fertilizadas, concebir con éxito (Evans, 1986), y comienzan a experimentar un conjunto de cambios reproductivos regulares conocidas como ciclo estral. Tanto la ciclicidad estral regular como la fertilidad decrece con la edad hasta que se alcanza un estado de infertilidad cuando los ciclos estrales regulares cesan(Acuña et al., 2009; Matt et al., 1986). En términos cualitativos, la senescencia reproductiva en las ratas hembras se describe como una sucesión de estados reproductivos diferentes. Todas las ratas progresan desde ciclos estrales regulares a ciclos irregulares, posteriormente ingresan en un estado de estro constante, diestro persistente y finalmente anestro (Huang and Meites, 1975). Si bien esta secuencia de cambios es cualitativamente similar en la mayoría de las cepas, el momento en que estos cambios ocurren puede diferir entre las diferentes cepas y entornos de laboratorio. Es por ello que consideramos necesario determinar los cambios reproductivos que presentaban las ratas hembras de la coIonia criadas en el bioterio de nuestro Instituto.

En términos cualitativos, los cambios que observamos con la edad en la citología vaginal en las ratas hembras Sprague -Dawley que estudiamos, están de acuerdo con estudios previos en ratas Long-Evans (Ingram, 1959; Lu et al., 1979; Wilkes et al., 1978). Según estos estudios, los frotis vaginales de estas ratas muestran ciclos regulares de 4 - 5 días hasta los 9 meses de edad (93\% de los animales estudiados), a los 12 meses de edad se observa la mayor incidencia de ratas que ciclan irregular- 
mente (65\% de los animales estudiados). Entre los 12 y 19 meses de edad la incidencia de ciclos irregulares decrece lentamente. A los 19 meses de edad se observa la mayor incidencia de ratas que muestran un estado de estro constante (65\% de los animales estudiados). La mayor incidencia de diestro persistente se produce a los 27 meses de edad (Lu et al., 1979). En las hembras que nosotros estudiamos encontramos que la transición a un estado de estro constante se produce con anterioridad, ya que a los 11 meses los animales estudiados presentaban un estado de estro constante. Tanto las ratas Long Evans como las ratas hembras que estudiamos a los 27 meses presentaban un estado de diestro persistente. Los resultados que observamos en nuestro estudio coinciden con los obtenidos por LeFevre \& McClintock en ratas Sprague Dawley donde, en promedio, las ratas entran en un estado de ciclos irregulares a los $8 \pm 0,6$ meses de edad, y presentan el primer estro constante a los $10 \pm 0,5$ meses de edad, en promedio (LeFevre and McClintock, 1988).

En función de la edad, las ratas hembras presentan cambios en todos los aspectos del sistema reproductivo. Las interacciones coordinadas entre los tres niveles del eje hipotálamo-hipófiso-ovárico controlan la función reproductiva de las hembras, por lo que los niveles hormonales que estas glándulas producen también se ven alterados con la edad (Huang et al., 1976; Huang et al., 1978; Lu et al., 1979; Wise and Ratner, 1980b). Por este motivo, además del patrón de ciclicidad estral, determinamos los niveles hormonales en las mismas ratas. Nosotros evaluamos los niveles hormonales en el suero que extrajimos entre las 11 y 13 hs, por lo que en ellos no abarcamos los picos de las hormonas que estudiamos, los que se producen en la tarde del proestro, es decir determinamos niveles hormonales basales. La mayoría de los estudios que determinan niveles hormonales basales de ratas hembras se realizaron a los 19 meses o más (Huang et al., 1976; Huang et al., 1978; Lu et al., 1979), cuando los animales ya han pasado un periodo prolongado en el estado de estro constante, siendo muy pocos los estudios realizados en ratas 
de entre 8 y 12 meses, cuando este estado recién comienza(Wise and Ratner, 1980b).

Los valores basales de LH que se describen en la literatura son disimiles. Wise \&Ratner en un estudio realizado en ratas de la misma cepa y edad que la que nosotros utilizamos, y otro estudio realizado en ratas Long Evans (Lu et al., 1979; Wise and Ratner, 1980b) describen que los valores basales de LH no se ven modificados con la edad, mientras que un estudio realizado con ratas hembras de entre 16 y 30 meses presentan niveles de LH inferiores o superiores a las ratas jóvenes(Huang et al., 1976). Nuestras determinaciones hormonales, fueron coincidentes con los estudios de Wise \&Ratner y LU. En nuestro estudio encontramos que las ratas de mediana edad, que se encontraban en estro constante, presentaban valores de E2 sérico más altos que las ratas jóvenes en los dos estadios estudiados, de manera similar a los reportados por otros laboratorios (Gore et al., 2000; Huang et al., 1978; Lu et al., 1979; Wise and Ratner, 1980b). Los niveles de E2 que encontramos en las ratas seniles que presentan un estado de diestro constante resultaron significativamente menores que los que presentaban las ratas de mediana edad, un hallazgo también coincidente con lo descripto por Lu et al para ratas Long Evans(Lu et al., 1979). Respecto a los niveles basales de P4 no encontramos diferencias con la edad en coincidencia con lo reportado por otros grupos (Lu et al., 1979). Los niveles basales de prolactina que encontramos fueron más altos en ratas seniles comparadas con las ratas jóvenes y de mediana edad en estro constante, lo que coincide con los estudios encontrados en literatura (H. Huang et al., 1976; Lu et al., 1979). A diferencia de estos estudios en donde no se encuentran diferencia entre los niveles basales de prolactina en ratas que recientemente entran en estro constante con las ratas jóvenes en estro o diestro, nosotros encontramos que eran inferiores a los valores basales de ratas jóvenes en estro. 
Según algunos autores las ratas hembras de la cepa Sprague Dawley alimentadas ad libitum crecen y ganan peso durante una gran parte de su vida. Hasta los 100 días de edad presentan un aumento de peso rápido, la ganancia de peso posterior a esa edad es más lenta (Berg, 1960). Otros autores informan que el incremento de peso se produce de manera rápida hasta las 24 semanas de edad, después de lo cual el crecimiento continúa, pero a un ritmo más lento hasta alcanzar su máximo de peso entre los 18 y 24 meses. Luego de los dos años de edad, los animales mantienen su peso o presentan una disminución, debido a la pérdida de masa corporal durante la vejez (Altun et al., 2007). Nosotros determinamos el peso corporal de los animales al final del periodo de seguimiento, encontrando que las ratas de mediana edad y seniles tuvieron pesos similares entre ellas y mayores que las ratas jóvenes que aún están en un periodo de aumento rápido de peso.

A nivel del ovario se ha descripto que el peso de los mismos presenta una disminución con la edad en diferentes cepas, entre ellas las Long Evans (H. Huang et al., 1976; D. W. Matt, Dahl, Sarkissian, \& Sayles, 1993), Wistar(Arai, 1963; Fujii and Yamamoto, 1983) y Holtzman (Butcher, 1985).Nosotros encontramos lo mismo en ratas Sprague Dawley.

El ovario posee una estructura compleja y su aspecto cambia con la edad, en el estudio histológico de los ovarios de ratas jóvenes de la cepa Long Evans se ha descripto que contienen folículos en todos los estadios de maduración y cuerpos lúteos, en contraste con los animales que presentan estro constante donde se informa que los ovarios contienen folículos maduros, pero no se hallan cuerpos lúteos (Everett, 1939; Huang and Meites, 1975; Matt et al., 1993; Steger et al., 1976). En nuestro estudio en ratas Sprague Dawley encontramos que había una disminución en la cantidad de folículos maduros con la edad, siendo significativamente menor la cantidad de folículos maduros por sección encontrados en ratas seniles comparada con los encontrados en ratas jóvenes. En las ratas de mediana edad si bien hay una disminución de los 
mismos esta no es significativa respecto de los otros dos grupos estudiados. También encontramos una disminución significativa de los cuerpos lúteos por sección tanto en las ratas de mediana edad como en las ratas seniles respecto de las ratas jóvenes. En cuanto a los folículos quísticos encontramos un aumento significativo en las ratas seniles comparado con las ratas jóvenes y de mediana edad. No hallamos diferencia en la cantidad de folículos atresicos por sección entre los tres grupos de ratas estudiadas. Estos resultados son consistentes con los estudios realizados en otros laboratorios previamente (Acuña et al., 2009; Everett, 1939; Huang and Meites, 1975; Matt et al., 1993; Steger et al., 1976)

\section{CARACTERIZACIÓN DE LOS VECTORES ADENOASOCIADOS.}

En esta parte de la tesis determinamos que los vectores adenoasociados que planeábamos utilizar en esta tesis expresaban las proteínas cuyos transgenes estaban clonados en el vector. Determinamos también que los niveles de expresión logrados eran detectables con las técnicas que estaban disponibles en nuestro laboratorio. Estos experimentos nos permitieron elegir la vía de administración que se utilizaría en el experimento que realizaríamos posteriormente.

En nuestro laboratorio teníamos experiencia en la generación, producción y utilización de vectores derivados de adenovirus, los cuales han sido utilizados para la transferencia de genes en el sistema nervioso central con el objetivo de estudiar la capacidad terapéutica de los mismos para revertir la neurodegeneración en neuronas dopaminérgicas (Hereñú et al., 2007; Morel et al., 2010). Una de las características de los vectores adenovirales es que la expresión del transgén se produce por tiempos cortos, aproximadamente 45 días en cerebro (Akli et al., 1993; Parr et al., 1998). Nosotros necesitábamos vectores que expresaran el transgén de interés por periodos más prolongados. Los vectores derivados de virus adenoasociados son capaces de transducir células que no se están dividiendo y el transgén se expresa por periodos largos de tiempo, de hasta 25 meses (Klein et al., 2002). Además, mediante una 
colaboración que establecimos con la Dra. Martha Bohn quien había construido vectores derivados de virus adenoasociados logramos contar con los vectores que necesitábamos. Al ser la primera vez que trabajamos con estos vectores creímos necesario confirmar que los mismos eran capaces de expresar los transgenes que contenían, para lo cual realizamos el estudio in vitro.

En este estudio observamos que ambos vectores expresaban la proteína fluorescente roja. Cuando cuantificamos la expresión de la misma esta resultó, como era de esperarse, significativamente superior respecto del control. Además el rAAV-IGF-IIRES-DsRed expresaba también el transgén del IGF-I. Los niveles de expresión de IGF-I que se obtuvieron in vitro fueron similares a los logrados por el vector adenoviral construido en nuestro laboratorio anteriormente, los que resultaron suficientes para lograr a corto plazo efectos restaurativos sobre neuronas dopaminérgicas (Hereñú et al., 2007).

Los AAV serotipo 2 fueron los primeros en ser utilizados para transferir genes (Hermonat and Muzyczka, 1984) y uno de los más utilizados para modificar la expresión génica en hipotálamo (Garza et al., 2008; McCrimmon et al., 2008; Yang et al., 2009). Nosotros inyectamos el vector en HMB observamos expresión del transgén reportero hasta los 100 días post inyección, por lo que la duración de la expresión fue sustancialmente mayor que la lograda con el adenovector RAd-IGFI, como era de esperar para este tipo de vectores(Hereñú et al., 2007; Klein et al., 2002). Cuando lo inyectamos en el ventrículo lateral no logramos niveles de expresión detectables con los métodos que contábamos en el laboratorio, a diferencia de lo documentado en ratones(Davidson et al., 2000; Lo et al., 1999). 


\section{EFECTO DEL IGF-I SOBRE LOS PARAMETROS REPRODUCTIVOS DE RATAS HEMBRAS DE MEDIANA EDAD.}

Basados en los resultados obtenidos al estudiar los parámetros reproductivos de las ratas criadas en el bioterio del INIBIOLP, donde vimos que a los 47 semanas las ratas mostraban una frecuencia elevada de estro constante, comenzamos a estudiar la ciclicidad estral de un grupo de ratas de 34,5 semanas, para realizar la transferencia de un gen neuroprotector en la semana 36 de edad, cuando la mayoría de nuestras ratas seguían ciclando con regularidad. Al caracterizar la expresión del gen reportero que contenían los AAV en el cerebro encontramos que la misma no era detectable cuando los vectores se inyectaban vía intraventricular, pero si logramos niveles de expresión detectable y duradera cuando lo inyectamos la vía intrahipotálamica. Por tal motivo elegimos esta vía de inyección para acceder a las terminales nerviosas de las neuronas productoras de GnRH, ya que estudios previos realizados por otros grupos lo señalan como el sitio donde el IGF-I podría estar ejerciendo sus efectos (Miller and Gore, 2001; Sun et al., 2011; Todd et al., 2010).

Para evaluar la capacidad reproductiva de las ratas realizamos el seguimiento del ciclo estral, tomando la frecuencia de ciclos regulares y estro constante como un índice de la capacidad reproductiva, siendo la primera alta en ratas que aún tienen capacidad ovulatoria y la segunda es elevada en ratas anovulatorios (Matt et al., 1987). Al finalizar el estudio, también evaluamos la histología ovárica y los parámetros hormonales. Los animales intactos y tratados con el vector reportero mostraron una disminución en la frecuencia de ciclos regulares y un aumento en la frecuencia de estros constantes, lo que nos estaría indicando una pérdida de la capacidad reproductiva. De manera consistente con la citología vaginal, cuando analizamos la histología ovárica encontramos que los ovarios de las ratas de estos grupos presentaban numerosos quistes ováricos y escasos cuerpos lúteos. Estos resultados están de 
acuerdo con los obtenidos por otros autores en ratas durante la transición y establecimiento del estado de estro constante (Acuña et al., 2009; Everett, 1939; Huang and Meites, 1975; Lu, 1983; Lu et al., 1979; Matt et al., 1993; Steger et al., 1976). En contraste, en las ratas que recibieron el vector que expresa IGF-I las frecuencias de ciclos regulares, irregulares y estro constante no se vieron modificadas, observandose animales que luego de la inyección del AAV mostraban un claro aumento de la frecuencia de ciclos regulares, lo cual indicaría que la capacidad reproductiva de las mismas se mantuvo e incluso en algunos animales mejoró. Cuando realizamos el análisis histológico de los ovarios de esos animales encontramos que presentaban una mayor cantidad de cuerpos lúteos y menos quistes ováricos, es decir mostraban ovarios estructuralmente mejor conservados. Asimismo, los datos hormonales indican que el tratamiento aumentó los niveles de LH en suero y atenuó la hiperprolactinemia progresiva que se desarrolla durante el envejecimiento en ratas hembra (Goya et al., 1990; Lu et al., 1979). En conjunto las observaciones que encontramos en las ratas del grupo IGF-I son similares a las encontradas en ratas adultas con una funcionalidad reproductiva conservada.

Aunque el trabajo realizado no permite establecer el mecanismo por el cual se logró retrasar el inicio de la senescencia reproductiva de los animales tratados con IGF-I, podemos adelantar una hipótesis. Alguno de los estudios realizados por otros grupos muestran al IGF-I como un factor permisivo necesario para un normal funcionamiento de la retroalimentación positiva de E2 en la liberación de GnRH desde terminales de las neuronas productoras de GnRH en el sistema portal de la EM (Miller and Gore, 2001; Sun et al., 2011; Todd et al., 2010). Esta idea es coherente con la evidencia de que el IGF - I y los estrógenos actúan de forma sinérgica en el cerebro, tanto en la función reproductiva como en la neuroprotección (Azcoitia et al., 1999; Cardona-Gómez et al., 2001; Quesada and Etgen, 2002). En efecto, una amplia colocalización de los receptores de estrógenos e IGF-I ha sido documentada tanto en 
neuronas como en astrocitos (Cardona-Gómez et al., 2000). Esta colocalización sugiere una intercomunicación entre los dos receptores (Mendez et al., 2006). Recientemente se ha demostrado que la señalización del IGF-IR en el cerebro juega un papel esencial en la modulación de la neurotransmisión de Kiss y glutamato mediada por E2 en el hipotálamo tanto de ratas hembras jóvenes como de mediana edad. En el hipotálamo de ratas de mediana edad la señalización de IGF-IR esta reducida deteriorando la capacidad de E2 para aumentar los niveles de ARNm del receptor de Kiss y de glutamato como también la cantidad de estas proteínas, afectando negativamente a la liberación de GnRH-LH. Así también, la edad reproductiva afecta significativamente la capacidad de señalización de IGF-IR para activar las neuronas productoras de GnRH y sus terminales nerviosas bajo condiciones de retroalimentación positiva de E2, de manera que la senescencia reproductiva se podría caracterizar, en parte, por la desensibilización hipotalámico a IGF-I(Neal-Perry et al., 2014). Dado que el contenido de IGF -I se reduce en el hipotálamo de ratas de mediana edad (Miller and Gore, 2001), hipotetizamos que al evitar la reducción de los niveles de IGF-I en el hipotálamo medio basal de nuestras ratas, preservamos la retroalimentación positiva de E2 sobre la liberación de GnRH.

En cualquier caso, el IGF-I es probablemente una de las muchas moléculas permisivas que contribuyen a un adecuado funcionamiento del mecanismo de retroalimentación positiva de esteroides en la GnRH. De este modo, resulta previsible que la sobreexpresión hipotalámica IGF - por sí sola no sea suficiente para prolongar indefinidamente la ciclicidad regular en ratas de mediana edad. 
CONCLUSIONES 
En base a los resultados obtenidos en los experimentos realizados podemos concluir que los animales criados en la colonia de nuestro Instituto, presentan a las 47 semanas de edad el cese de la funcionalidad reproductiva evidenciado por la pérdida de la ciclidad estral, como también por los cambios histológicos que se encontramos en los ovarios de las mismas.

En cuanto a los vectores adenoasociados que estudiamos, concluimos que resultan ser adecuados como herramientas de transferencia génica en experimentos que requieren niveles de expresión sostenidos por periodos prolongados, al menos por 100 días.

Nuestros resultados demuestran que el IGF-I es un factor necesario para el funcionamiento del eje hipotalámo-hipófiso-ovárico. Siendo posible retrasar el deterioro reproductivo que se presenta en ratas de mediana edad aumentando los niveles de IGF-I en el HMB-EM. 
Acuña, E., Fornes, R., Fernandois, D., Garrido, M. P., Greiner, M., Lara, H. E. and Paredes, A. H. (2009). Increases in norepinephrine release and ovarian cyst formation during ageing in the rat. Reprod. Biol. Endocrinol. 7, 64.

Adachi, S., Yamada, S., Takatsu, Y., Matsui, H., Kinoshita, M., Takase, K., Sugiura, H., Ohtaki, T., Matsumoto, H., Uenoyama, Y., et al. (2007). Involvement of anteroventral periventricular metastin/kisspeptin neurons in estrogen positive feedback action on luteinizing hormone release in female rats. J. Reprod. Dev. 53, 367-378.

Akli, S., Caillaud, C., Vigne, E., Strafford-Perricaudet, L. D., Poenaru, L., Perricaudet, M., Kahn, A. and Peschanski, M. R. (1993). Transfer of a foreign gene into the brain using adenovirus vectors. Nat. ... 3, 224-228.

Alba, R., Bosch, a and Chillon, M. (2005). Gutless adenovirus: last-generation adenovirus for gene therapy. Gene Ther. 12 Suppl 1, S18-27.

Altun, M., Bergman, E., Edström, E., Johnson, H. and Ulfhake, B. (2007). Behavioral impairments of the aging rat. Physiol. Behav. 92, 911-23.

Anderson, R., Zwain, I. and Arroyo, A. (1999). The insulin-like growth factor system in the GT1-7 GnRH neuronal cell line. Neuroendocrinology 70, 353359.

Arai, H. (1920). On the postnatal development of the ovary (albino rat), with especial reference to the number of ova. Am. J. Anat. 27, 405-462.

Arai, Y. (1963). luteinizing hormone of the anterior pituitary and of luteinizing hormone releasing factor of the hypothalamus in estrogen-induced persistent-diestrous rats. Proc. Jpn. Acad. 39, 605.

Aschheim, P. (1964). Résultats fournis par la greffe hétérochrone des ovaires dans l'étude de la régulation hypothalamo-hypophyso-ovarienne de la ratte sénile. Gerontologia 10, 65-75.

Atchison, R. W., Casto, B. C. and Hammon, W. M. (1965). Adenovirus-associated defective virus particles. Science $149,754-756$.

Aubert, M., Begeot, M., Winiger, B., Morel, G., Sizonenko, P. and Dubois, P. (1985). Ontogeny of hypothalamic luteinizing hormone-releasing hormone (GnRH) and pituitary GnRH receptors in fetal and neonatal rats. Endocrinology 116, 1565-1576.

Ayalon, D., Tsafriri, A., Lindner, H., Cordova, T. and Harell, A. (1972). Serum gonadotrophin levels in pro-oestrous rats in relation to the resumption of meiosis by the oocytes. J. Reprod. Fertil. 31, 51-58.

Azcoitia, I., Sierra, a and Garcia-Segura, L. M. (1999). Neuroprotective effects of estradiol in the adult rat hippocampus: interaction with insulin-like growth factor-I signalling. J. Neurosci. Res. 58, 815-22. 
Bartlett, J. S., Wilcher, R. and Samulski, R. J. (2000). Infectious entry pathway of adeno-associated virus and adeno-associated virus vectors. J. Virol. 74, 2777-2785.

Beauverd, M., Mitchell, J., Wokke, J. and Borasio, G. (2012). Recombinant human insulin-like growth factor I ( rhIGF-I) for the treatment of amyotrophic lateral sclerosis / motor neuron disease ( Review ). Cochrane.

Bellomo, G., Santambrogio, L., Fiacconi, M., Scarponi, a. M. and Ciuffetti, G. (1991). Plasma profiles of adrenocorticotropic hormone, cortisol, growth hormone and prolactin in patients with untreated parkinson's disease. J. Neurol. 238, 19-22.

Berg, B. (1960). Nutrition and longevity in the rat. 1. Food intake in relation to size, health and fertility. J. Nutr. 71, 242-254.

Berto, E., Bozac, A. and Marconi, P. (2005). Development and application of replication-incompetent HSV-1-based vectors. Gene Ther. 12, 98-102.

Bett, A. J., Haddara, W., Prevec, L. and Graham, F. I. (1994). An efficient and flexible system for construction of adenovirus vectors with insertions or deletions in early regions 1 and 3. Proc. Natl. Acad. Sci. U. S. A. 91, 88028806.

Blömer, U., Naldini, L., Kafri, T., Trono, D., Verma, I. M. and Gage, F. H. (1997). Highly efficient and sustained gene transfer in adult neurons with a lentivirus vector. J. Virol. 71, 6641-6649.

Blundell, T. and Humbel, R. (1980). Hormone families: pancreatic hormones and homologous growth factors. Nature 287, 781-787.

Bondy, C. A. (1991). Transient IGF-I gene expression during the maturation of functionally related central projection neurons. J. Neurosci. 11, 3442-55.

Brooker, G. J., Kalloniatis, M., Russo, V. C., Murphy, M., Werther, G. a and Bartlett, P. F. (2000). Endogenous IGF-1 regulates the neuronal differentiation of adult stem cells. J. Neurosci. Res. 59, 332-341.

Burns, J. C., Friedmann, T., Driever, W., Burrascano, M. and Yee, J.-K. (1993). Vesicular stomatitis virus $G$ glycoprotein pseudotyped retroviral vectors: concentration to very high titer and efficient gene transfer into mammalian and nonmammalian. Proc. Natl. Acad. Sci. U. S. A. 90, 8033-8037.

Butcher, R. (1985). Effect of reduced ovarian tissue on cyclicity, basal hormonal levels and follicular development in old rats. Biol. Reprod. 32, 315-321.

Cappellen, G. van (1998). Ovarian follicle dynamics in the rat: regulation and flexibility. Erasmus University Rotterdam.

Cardona-Gómez, G. P., DonCarlos, L. and Garcia-Segura, L. M. (2000). Insulinlike growth factor I receptors and estrogen receptors colocalize in female rat brain. Neuroscience $99,751-60$. 
Cardona-Gómez, G. P., Mendez, P., DonCarlos, L. L., Azcoitia, I. and GarciaSegura, L. M. (2001). Interactions of estrogens and insulin-like growth factor-1 in the brain: implications for neuroprotection. Brain Res. Brain Res. Rev. 37, 320-34.

Carro, E., Trejo, J. L., Gerber, a., Loetscher, H., Torrado, J., Metzger, F. and TorresAleman, I. (2006). Therapeutic actions of insulin-like growth factor I on APP/PS2 mice with severe brain amyloidosis. Neurobiol. Aging 27, 12501257.

Chen, R.-F. and Lee, C.-Y. (2014). Adenoviruses types, cell receptors and local innate cytokines in adenovirus infection. Int. Rev. Immunol. 33, 45-53.

Christian, C. a and Moenter, S. M. (2007). Estradiol induces diurnal shifts in GABA transmission to gonadotropin-releasing hormone neurons to provide a neural signal for ovulation. J. Neurosci. 27, 1913-1921.

Clemmons, D. (1990). Insulinlike growth factor binding proteins. Trends Endocrinol. Metab. 1, 412-417.

Consiglio, A., Gritti, A., Dolcetta, D., Follenzi, A., Bordignon, C., Gage, F. H., Vescovi, A. L. and Naldini, L. (2004). Robust in vivo gene transfer into adult mammalian neural stem cells by lentiviral vectors. Proc. Natl. Acad. Sci. U. S. A. 101, 14835-40.

D'Ercole, A. J., Stiles, A. D. and Underwood, L. E. (1984). Tissue concentrations of somatomedin C: further evidence for multiple sites of synthesis and paracrine or autocrine mechanisms of action. Proc. Natl. Acad. Sci. U. S. A. 81, 935-9.

Davidson, B. L., Stein, C. S., Heth, J. A., Martins, I., Kotin\| , R. M., Derksen, T. A., Zabner, J., Ghodsi, A. and Chiorini, J. A. (2000). Recombinant adenoassociated virus type 2,4 , and 5 vectors: transduction of variant cell types and regions in the mammalian central nervous system. Proc. Natl. Acad. Sci. United States Am. 97, 3428-3432.

Davison, A. J., Benkó, M. and Harrach, B. (2003). Genetic content and evolution of adenoviruses. J. Gen. Virol. 84, 2895-2908.

De Laporte, L., Cruz Rea, J. and Shea, L. D. (2006). Design of modular non-viral gene therapy vectors. Biomaterials 27, 947-54.

Doré, S., Kar, S. and Quirion, R. (1997). Insulin-like growth factor I protects and rescues hippocampal neurons against beta-amyloid- and human amylininduced toxicity. Proc. Natl. Acad. Sci. U. S. A. 94, 4772-4777.

Dueñas, M., Torres-Aleman, I., Naftolin, F. and Garcia-Segura, L. (1996). Interaction of insulin-like growth factor-I and estradiol signaling pathways on hypothalamic neuronal differentiation. Neuroscience 74, 531-539.

Edson, M. a., Nagaraja, A. K. and Matzuk, M. M. (2009). The mammalian ovary from genesis to revelation. Endocr. Rev. 30, 624-712. 
Epstein, A. (2009). HSV-1-derived amplicon vectors: recent technological improvements and remaining difficulties-a review. Mem. Inst. Oswaldo Cruz $104,399-410$.

Evans, A. M. (1986). Age at puberty and first litter size in early and late paired rats. Biol. Reprod. 34, 322-6.

Everett, J. W. (1939). Spontaneous Persistent Estrus In A Strain Of Albino Rats. Endocrinology 25, 123-127.

Eyigor, O. and Jennes, L. (1996). Identification of glutamate receptor subtype mRNAs in gonadotropin-releasing hormone neurons in rat brain. Endocrine 4, 133-139.

Fernandez, A. M., Garcia-Estrada, J., Garcia-Segura, L. M. and Torres-Aleman, I. (1997). Insulin-like growth factor I modulates C-Fos induction and astrocytosis in response to neurotoxic insult. Neuroscience 76, 117-22.

Fernandez-Galaz, M. C., Morschl, E., Chowen, J. a, Torres-Aleman, I., Naftolin, F. and Garcia-Segura, L. M. (1997). Role of astroglia and insulin-like growth factor-l in gonadal hormone-dependent synaptic plasticity. Brain Res. Bull. 44, 525-31.

Fernandez-Galaz, M. C., Naftolin, F. and Garcia-Segura, L. M. (1999). Phasic synaptic remodeling of the rat arcuate nucleus during the estrous cycle depends on insulin-like growth factor-I receptor activation. J. Neurosci. Res. 55, 286-92.

Firth, S. M. and Baxter, R. C. (2002). Cellular actions of the insulin-like growth factor binding proteins. Endocr. Rev. 23, 824-54.

Flügge, G., Oertel, W. H. and Wuttke, W. (1986). Evidence for estrogen-receptive GABAergic neurons in the preoptic/anterior hypothalamic area of the rat brain. Neuroendocrinology 43, 1-5.

Fujii, T. and Yamamoto, N. (1983). Delayed onset of persistent estrus in aged rats raised from parathyroidectomized mothers. Exp. Aging Res. 9, 129-133.

García-Segura, L. M., Pérez, J., Pons, S., Rejas, M. T. and Torres-Alemán, I. (1991). Localization of insulin-like growth factor I (IGF-I)-like immunoreactivity in the developing and adult rat brain. Brain Res. 560, 167-74.

Garza, J. C., Kim, C. S., Liu, J., Zhang, W. and Lu, X.-Y. (2008). Adeno-associated virus-mediated knockdown of melanocortin-4 receptor in the paraventricular nucleus of the hypothalamus promotes high-fat dietinduced hyperphagia and obesity. J. Endocrinol. 197, 471-82.

Gene therapy Clinical Trials Worldwide. (2014).

Georg-Fries, B., Biederlack, S., Wolf, J. and zur Hausen, H. (1984). Analysis of proteins, helper dependence, and seroepidemiology of a new human parvovirus. Virology 134, 64-71. 
Gluckman, P., Klempt, N., Guan, J., Mallard, C., Sirimanne, E., Dragunow, M., Klempt, M., Singh, K., Williams, C. and Nikolics, K. (1992). A role for IGF-1 in the rescue of CNS neurons following hypoxic-ischemic injury. Biochem. Biophys. Res. Commun. 182, 593-599.

Goldman, J. M., Murr, A. S. and Cooper, R. L. (2007). The rodent estrous cycle: characterization of vaginal cytology and its utility in toxicological studies. Birth defects Res. Part B Dev. Reprod. Toxicol. 80, 84-97.

Goodyer, C. G., De Stéphano, L., Lai, W. H., Guyda, H. J. and Posner, B. I. (1984). Characterization of insulin-like growth factor receptors in rat anterior pituitary, hypothalamus, and brain. Endocrinology 114, 1187-95.

Gore, A. C., Yeung, G., Morrison, J. H. and Oung, T. (2000). Neuroendocrine aging in the female rat: the changing relationship of hypothalamic gonadotropin-releasing hormone neurons and $\mathrm{N}$-methyl-D-aspartate receptors. Society $141,4757-67$.

Goya, R., Lu, J. and Meites, J. (1990). Gonadal function in aging rats and its relation to pituitary and mammary pathology. Mech. Ageing Dev. 56, 7788.

Gray, S. J., Woodard, K. T. and Samulski, R. J. (2010). Viral vectors and delivery strategies for CNS gene therapy. Ther. Deliv. 1, 517-534.

Greenwald, G. and Rothchild, I. (1968). Formation and maintenance of corpora lutea in laboratory animals. J. Anim. Sci. 27, 139-162.

Grimm, D., Kern, A., Rittner, K. and Kleinschmidt, J. A. (1998). Nove I Tool s for Production an d Purification of Recombinant Adenoassociated Virus Vectors. Hum. Gene Ther. 9, 2745-2760.

Heape, W. (1900). Memoirs: The" Sexual Season" of Mammals and the Relation of the "Pro-œstrum" to Menstruation. Q. J. Microsc. Sci. 2, 1-70.

Herbison, A. E., Heavens, R. P., Dye, S. and Dyer, R. G. (1991). Acute action of oestrogen on medial preoptic gamma-aminobutyric Acid neurons: correlation with oestrogen negative feedback on luteinizing hormone secretion. J. Neuroendocrinol. 3, 101-106.

Hereñú, C. B., Cristina, C., Rimoldi, O. J., Becú-Villalobos, D., Cambiaggi, V., Portiansky, E. L. and Goya, R. G. (2007). Restorative effect of insulin-like growth factor-I gene therapy in the hypothalamus of senile rats with dopaminergic dysfunction. Gene Ther. 14, 237-45.

Hermonat, P. L. and Muzyczka, N. (1984). Use of adeno-associated virus as a mammalian DNA cloning vector: transduction of neomycin resistance into mammalian tissue culture cells. Proc. Natl. Acad. Sci. U. S. A. 81, 6466-70.

Hilliard, J. (1973). Corpus luteum function in guinea pigs, hamsters, rats, mice and rabbits. Biol. Reprod. 8, 203-221. 
Hiney, J. K., Ojeda, S. and Dees, W. (1991). Insulin-like growth factor I: a possible metabolic signal involved in the regulation of female puberty. Neuroendocrinology 54, 420-423.

Hiney, J. K., Srivastava, V., Nyberg, C. L., Ojeda, S. R. and Dees, W. L. (1996). Insulin-like growth factor I of peripheral origin acts centrally to accelerate the initiation of female puberty. Endocrinology 137, 3717-3728.

Hsich, G., Sena-Esteves, M. and Breakefield, X. O. (2002). Critical issues in gene therapy for neurologic disease. Hum. Gene Ther. 13, 579-604.

Hsueh, a. J. W., Billig, H. and Tsafriri, a. (1994). Ovarian follicle atresia: A hormonally controlled apoptotic process. Endocr. Rev. 15, 707-724.

Huang, H. H. and Meites, J. (1975). Reproductive capacity of aging female rats. Neuroendocrinology 17, 289-295.

Huang, H., Marshall, S. and Meites, J. (1976). Capacity of Old Versus Young Female Rats to Secrete LH , FSH and Prolactin. Biol. Reprod. 14, 538-543.

Huang, H. H., Steger, R. W., Bruni, J. F. and Meites, J. (1978). Patterns of sex steroid and gonadotropin secretion in aging female rats. Endocrinology 103, 1855-9.

Hwang, H. J., Kwon, M. J. and Nam, T. J. (2007). Chemoprotective effect of insulin-like growth factor I against acetaminophen-induced cell death in Chang liver cells via ERK1/2 activation. Toxicology 230, 76-82.

Ingram, D. (1959). The vaginal smear of senile laboratory rats. J. Endocrinol. 182188.

Ingram, D. L., Mandl, A. M. and Zuckerman, S. (1958). The influence of age on litter size. J. Endocrinol. 17, 280-285.

Jarry, H., Leonhardt, S., Schwarze, T. and Wuttke, W. (1995). Preoptic rather than mediobasal hypothalamic amino acid neurotransmitter release regulates $\mathrm{GnRH}$ secretion during the estrogen-induced LH surge in the ovariectomized rat. Neuroendocrinology 62, 479-486.

Kashiwakura, Y., Tamayose, K., Iwabuchi, K., Hirai, Y., Shimada, T., Matsumoto, K., Nakamura, T., Watanabe, M. and Oshimi, K. (2005). Hepatocyte Growth Factor Receptor Is a Coreceptor for Adeno-Associated Virus Type 2 Infection. J. Virol. 79, 609-614.

Kaspar, B. K., Lladó, J., Sherkat, N., Rothstein, J. D. and Gage, F. H. (2003). Retrograde viral delivery of IGF-1 prolongs survival in a mouse ALS model. Science 301, 839-842.

Kazanis, I., Giannakopoulou, M., Philippidis, H. and Stylianopoulou, F. (2004). Alterations in IGF-I, BDNF and NT-3 levels following experimental brain trauma and the effect of IGF-I administration. Exp. Neurol. 186, 221-234. 
Kelly, M. J. and Qiu, J. (2010). Estrogen signaling in hypothalamic circuits controlling reproduction. Brain Res. 1364, 44-52.

Kim, B., Cheng, H. L., Margolis, B. and Feldman, E. L. (1998). Insulin receptor substrate 2 and Shc play different roles in insulin-like growth factor I signaling. J. Biol. Chem. 273, 34543-34550.

Klein, R. L., Hamby, M. E., Gong, Y., Hirko, A. C., Wang, S., Hughes, J. a., King, M. a. and Meyer, E. M. (2002). Dose and Promoter Effects of AdenoAssociated Viral Vector for Green Fluorescent Protein Expression in the Rat Brain. Exp. Neurol. 176, 66-74.

Krajnak, K., Rosewell, K. and Wise, P. (2001). Fos-induction in gonadotropinreleasing hormone neurons receiving vasoactive intestinal polypeptide innervation is reduced in middle-aged female rats. Biol. Reprod. 64, 1160-4.

Kurihaar, S., Hakuno, F. and Takahashi, S. (2000). Insulin-like Growth Factor-IDependent Signal Transduction Pathways Leading to the Induction of Cell Growth and Differentiation of Human Neuroblastoma Cell Line SH-SY5Y: The Roles of MAP Kinase Pathway and PI 3-Kinase Pathway. Endocr. J. 47, 739751.

Lederman, M. a., Lebesgue, D., Gonzalez, V. V., Shu, J., Merhi, Z. O., Etgen, A. M. and Neal-Perry, G. (2010). Age-related LH surge dysfunction correlates with reduced responsiveness of hypothalamic anteroventral periventricular nucleus kisspeptin neurons to estradiol positive feedback in middle-aged rats. Neuropharmacology 58, 314-320.

LeFevre, J. and McClintock, M. (1988). Reproductive senescence in female rats: a longitudinal study of individual differences in estrous cycles and behavior. Biol. Reprod. 38, 780-789.

Lehman, M. N., Merkley, C. M., Coolen, L. M. and Goodman, R. L. (2010). Anatomy of the kisspeptin neural network in mammals. Brain Res. 1364, 90102.

Lentz, T. B., Gray, S. J. and Samulski, R. J. (2012). Viral vectors for gene delivery to the central nervous system. Neurobiol. Dis. 48, 179-88.

LeRoith, D., Werner, H., Beitner-Johnson, D. and Roberts, C. (1995). Molecular and cellular aspects of the insulin-like growth factor I receptor. Endocr. Rev. $16,143-163$.

Levine, J. E. and Ramirez, V. D. (1982). Luteinizing Hormone-Releasing Hormone Release during the Rat Estrous Cycle and after Ovariectomy, as Estimated with Push-Pull Cannulae. Endocrinology III, 1439-1448.

Li, J., Samulski, R. J. and Xiao, X. (1997). Role for highly regulated rep gene expression in adeno-associated virus vector production. J. Virol. 71, 52365243. 
Li, X. F., Kinsey-Jones, J. S., Cheng, Y., Knox, A. M. I., Lin, Y., Petrou, N. a., Roseweir, A., Lightman, S. L., Milligan, S. R., Millar, R. P., et al. (2009). Kisspeptin signalling in the hypothalamic arcuate nucleus regulates $\mathrm{GnRH}$ pulse generator frequency in the rat. PLoS One 4,.

Lo, W. D., Qu, G., Sferra, T. J., Clark, R., Chen, R. and Johnson, P. R. (1999). Adeno-associated virus-mediated gene transfer to the brain: duration and modulation of expression. Hum. Gene Ther. 10, 201-13.

Longo, K. M., Sun, Y. and Gore, A. C. (1998). Insulin-like growth factor-l effects on gonadotropin-releasing hormone biosynthesis in GT1-7 cells. Endocrinology $139,1125-32$.

Lu, J. (1983). Changes in ovarian function and gonadotropin and prolactin secretion in aging female rats. In Neuroendocrinology of Aging (ed. Meites, J.), pp. 103-122. New York: Plenum Press.

Lu, K., Hopper, B., Vargo, T. and Yen, S. (1979). Chronological changes in sex steroid, gonadotropin and prolactin secretion in aging female rats displaying different reproductive states. ... Reprod. 203, 193-203.

Lusby, E., Fife, K. H. and Berns, K. I. (1980). Nucleotide sequence of the inverted terminal repetition in adeno-associated virus DNA. J. Virol. 34, 402-409.

Madathil, S. K., Carlson, S. W., Brelsfoard, J. M., Ye, P., D'Ercole, a. J. and Saatman, K. E. (2013). Astrocyte-Specific Overexpression of Insulin-Like Growth Factor-1 Protects Hippocampal Neurons and Reduces Behavioral Deficits following Traumatic Brain Injury in Mice. PLoS One 8 ,

Maffucci, J. A. and Gore, A. C. (2009). Chapter 2: hypothalamic neural systems controlling the female reproductive life cycle gonadotropin-releasing hormone, glutamate, and GABA. 1st ed. Elsevier Inc.

Mandl, A. M. (1963). Pre-Ovulatory Changes in the Oocyte of the Adult Rat. Proc. R. Soc. B Biol. Sci. 158, 105-1 18.

Marcondes, F., Bianchi, F. and Tanno, A. (2002). Determination of the estrous cycle phases of rats: some helpful considerations. Brazilian J. Biol. 62, 609614.

Marks, J. L., Porte, D. and Baskin, D. G. (1991). Localization of type I insulin-like growth factor receptor messenger RNA in the adult rat brain by in situ hybridization. Mol. Endocrinol. 5, 1158-68.

Mastakov, M. Y., Baer, K., Symes, C. W., Leichtlein, C. B., Kotin, R. M., Matthew, J. and During, M. J. (2002). Immunological Aspects of Recombinant AdenoAssociated Virus Delivery to the Mammalian Brain Immunological Aspects of Recombinant Adeno-Associated Virus Delivery to the Mammalian Brain. J. Virol. 76, 8446-8454. 
Matt, D., Lee, J., Sarver, P., Judd, H. L. and Lu, J. (1986). Chronological Changes in Fertility, Fecundity and Steroid Hormone Secretion during Consecutive Pregnancies in Aging Rats. Biol. 34, 478-487.

Matt, D., Sarver, P. and Lu, J. (1987). Relation of Parity and Estrous in Aging Cyclicity to the Biology Female of Pregnancy Rats. Biol. Reprod. 37, 421430.

Matt, D. W., Dahl, K. D., Sarkissian, A. and Sayles, T. E. (1993). Apparent Absence of Negative Feedback in Middle-Aged Persistent-Estrous Rats Following Luteinizing Hormone-Releasing Hormone Agonist Treatment : Relation to Plasma Inhibin and 170-Estradioll. Biol. Reprod. 339, 333-339.

McCrimmon, R. J., Shaw, M., Fan, X., Cheng, H., Ding, Y., Vella, M. C., Zhou, L., McNay, E. C. and Sherwin, R. S. (2008). Key role for AMP-activated protein kinase in the ventromedial hypothalamus in regulating counterregulatory hormone responses to acute hypoglycemia. Diabetes 57, 444-450.

Mendez, P., Wandosell, F. and Garcia-Segura, L. M. (2006). Cross-talk between estrogen receptors and insulin-like growth factor-I receptor in the brain: cellular and molecular mechanisms. Front. Neuroendocrinol. 27, 391-403.

Miller, B. H. and Gore, A. C. (2001). Alterations in hypothalamic insulin-like growth factor-l and its associations with gonadotropin releasing hormone neurones during reproductive development and ageing. J.

Neuroendocrinol. 13, 728-36.

Monahan, M., Rivier, J., Burgus, R., Amoss, M., Blackwell, R., Vale, W. and Guillemin, R. (1971). Total synthesis by solid phase of a decapeptide stimulating the secretion of LH and FSH pituitary gonadotropins]. C. R. Acad. Sci. Hebd. Seances Acad. Sci. D. 273, 508-510.

Morel, G. R., Sosa, Y. E., Bellini, M. J., Carri, N. G., Rodriguez, S. S., Bohn, M. C. and Goya, R. G. (2010). Glial cell line-derived neurotrophic factor gene therapy ameliorates chronic hyperprolactinemia in senile rats. Neuroscience $167,946-953$.

Naldini, L., Blömer, U., Gallay, P., Ory, D., Mulligan, R., Gage, F. H., Verma, I. M. and Trono, D. (1996a). In vivo gene delivery and stable transduction of nondividing cells by a lentiviral vector. Science (80-. ). 272, 263-267.

Naldini, L., Blömer, U., Gage, F. H., Trono, D. and Verma, I. M. (1996b). Efficient transfer, integration, and sustained long-term expression of the transgene in adult rat brains injected with a lentiviral vector. Proc. Natl. Acad. Sci. U. S. A. 93, 11382-11388.

Neal-Perry, G. S., Zeevalk, G. D., Santoro, N. F. and Etgen, A. M. (2005). Attenuation of preoptic area glutamate release correlates with reduced luteinizing hormone secretion in middle-aged female rats. Endocrinology 146, 4331-4339. 
Neal-Perry, G. S., Zeevalk, G. D., Shu, J. and Etgen, A. M. (2008). Restoration of the luteinizing hormone surge in middle-aged female rats by altering the balance of GABA and glutamate transmission in the medial preoptic area. Biol. Reprod. 79, 878-888.

Neal-Perry, G. S., Lebesgue, D., Lederman, M., Shu, J., Zeevalk, G. D. and Etgen, A. M. (2009). The excitatory peptide kisspeptin restores the luteinizing hormone surge and modulates amino acid neurotransmission in the medial preoptic area of middle-aged rats. Endocrinology 150, 3699-708.

Neal-Perry, G., Yao, D., Shu, J., Sun, Y. and Etgen, A. M. (2014). Insulin-like growth factor-I regulates $\mathrm{LH}$ release by modulation of kisspeptin and NMDAmediated neurotransmission in young and middle-aged female rats. Endocrinology 155, 1827-1837.

O'Kusky, J. R., Ye, P. and D'Ercole, a J. (2000). Insulin-like growth factor-I promotes neurogenesis and synaptogenesis in the hippocampal dentate gyrus during postnatal development. J. Neurosci. 20, 8435-42.

Ocrant, I., Fay, C. T. and Parmelee, J. T. (1990). Characterization of insulin-like growth factor binding proteins produced in the rat central nervous system. Endocrinology 127, 1260-7.

Ojeda, S. R. and Skinner, M. K. (2006). Puberty in the rat. In Physiology of Reproduction (ed. Knobil, E. and Neill, J. D.), pp. 2061-2226. Academic Press.

P. de Lima, M. C., Girao da Cruz, M. T., C. Cardoso, A. L., Simoes, S. and de Almeida, L. P. (2005). Liposomal and viral vectors for gene therapy of the central nervous system. Curr. Drug Targets-CNS Neurol. Disord. 4, 453-465.

PåhIman, S., Meyerson, G., Lindgren, E., Schalling, M. and Johansson, I. (1991). Insulin-like growth factor I shifts from promoting cell division to potentiating maturation during neuronal differentiation. Proc. Natl. Acad. Sci. U. S. A. 88, 9994-8.

Park, G. H. and Buetow, D. E. (1991). Genes for insulin-like growth factors I and II are expressed in senescent rat tissues. Gerontology 37, 310-316.

Parks, R. and Graham, F. (1997). A helper-dependent system for adenovirus vector production helps define a lower limit for efficient DNA packaging. J. Virol. 71, 3293-3298.

Parr, M. J., Wen, P. Y., Schaub, M., Khoury, S. J., Sayegh, M. H. and Fine, H. a (1998). Immune parameters affecting adenoviral vector gene therapy in the brain. J. Neurovirol. 4, 194-203.

Patil, S. D., Rhodes, D. G. and Burgess, D. J. (2005). DNA-based therapeutics and DNA delivery systems: a comprehensive review. AAPS J. 7, E61-77.

Pauwels, K., Gijsbers, R., Toelen, J., Schambach, A., Willard-Gallo, K., Verheust, C., Debyser, Z. and Herman, P. (2009). State-of-the-Art Lentiviral Vectors for 
Research Use: Risk Assessment and Biosafety Recommendations. Curr. Gene Ther. 9, 459-474.

Paxinos, G. and Watson, C. (1998). The Rat Brain: In Stereotaxic Coordinates. San Diego: Academic Press, Incorporated.

Petersen, S. L., Ottem, E. N. and Carpenter, C. D. (2003). Direct and indirect regulation of gonadotropin-releasing hormone neurons by estradiol. Biol. Reprod. 69, 1771-8.

Qing, K., Mah, C., Hansen, J., Zhou, S., Dwarki, V. and Srivastava, a (1999). Human fibroblast growth factor receptor 1 is a co-receptor for infection by adeno-associated virus 2. Nat. Med. 5, 71-77.

Quesada, A. and Etgen, A. M. (2002). Functional interactions between estrogen and insulin-like growth factor-l in the regulation of alpha 1B-adrenoceptors and female reproductive function. J. Neurosci. 22, 2401-2408.

Rabinowitz, J. E., Rolling, F., Li, C., Conrath, H., Xiao, W., Xiao, X. and Samulski, R. J. (2002). Cross-packaging of a single adeno-associated virus (AAV) type 2 vector genome into multiple AAV serotypes enables transduction with broad specificity. J. Virol. 76, 791-801.

Radovick, S., Levine, J. E. and Wolfe, A. (2012). Estrogenic regulation of the GnRH neuron. 3, 1-11.

Rivera, E. J., Goldin, A., Fulmer, N., Tavares, R., Wands, J. R. and de la Monte, S. M. (2005). Insulin and insulin-like growth factor expression and function deteriorate with progression of Alzheimer's disease: link to brain reductions in acetylcholine. J. Alzheimers. Dis. 8, 247-268.

Rønnekleiv, O. K., Bosch, M. a and Zhang, C. (2010). Regulation of endogenous conductances in GnRH neurons by estrogens. Brain Res. 1364, 25-34.

Rotwein, P., Burgess, S. K., Milbrandt, J. D. and Krause, J. E. (1988). Differential expression of insulin-like growth factor genes in rat central nervous system. Proc. Natl. Acad. Sci. U. S. A. 85, 265-9.

Rubin, B. S. and Bridges, R. S. (1989). Alterations in luteinizing hormone-releasing hormone release from the mediobasal hypothalamus of ovariectomized, steroid-primed middle-aged rats as measured by push-pull perfusion. Neuroendocrinology 49, 225-232.

Rubin, B. S., King, J. C. and Bridges, R. S. (1984). Immunoreactive forms of luteinizing hormone-releasing hormone in the brains of aging rats exhibiting persistent vaginal estrus. Biol. Reprod. 31, 343-351.

Rubin, B. S., Lee, C. E. and King, J. C. (1994). A reduced proportion of luteinizing hormone (LH)-releasing hormone neurons express Fos protein during the preovulatory or steroid-induced LH surge in middle-aged rats. Biol. Reprod. 51, 1264-72. 
Sakuma, T., Barry, M. a and Ikeda, Y. (2012). Lentiviral vectors: basic to translational. Biochem. J. 443, 603-18.

Samulski, R. J., Zhu, X., Xiao, X., Brook, J. D., Housman, D. E., Epstein, N. and Hunter, L. a (1991). Targeted integration of adeno-associated virus (AAV) into human chromosome 19. EMBO J. 10, 3941-3950.

Sapolsky, R. M. (2003). Neuroprotective gene therapy against acute neurological insults. Nat. Rev. Neurosci. 4, 61-9.

Sarkar, D. K. and Fink, G. (1980). Luteinizing hormone releasing factor in pituitary stalk plasma from long-term ovariectomized rats: Effects of steroids. J. Endocrinol. 86, 511-524.

Schally, A., Arimura, A., Baba, Y., Nair, R., Matsuo, H., Redding, T., Debeljuk, L. and White, W. (1971 a). Isolation and properties of the FSH and LH-releasing hormone. Biochem. Biophys. Res. Commun. 43, 393-399.

Schally, A., Arimura, A., Kastin, A., Matsuo, H., Baba, Y., Redding, T., Nair, R. and Debeljuk, L. (1971b). Gonadotropin-releasing hormone: one polypeptide regulates secretion of luteinizing and follicle-stimulating hormones. Science (80-. ). 173,.

Shen, Y. and Post, L. (2007). Viral Vectors and Their Applications. In Fields Virology (ed. Knipe, D. M. and Howley, P. M.), pp. 539-564. Philadel phia: Lippincott Williams \& Wilkins.

Sisk, C. L. and Foster, D. L. (2004). The neural basis of puberty and adolescence. Nat. Neurosci. 7, 1040-1047.

Sisk, C., Richardson, H., Chappell, P. and Levine, J. (2001). In Vivo Gonadotropin-Releasing Hormone Secretion in Female Rats during Peripubertal Development and on Proestrus 1. Endocrinology 142, 29292936.

Sonntag, F., Schmidt, K. and Kleinschmidt, J. A. (2010). A viral assembly factor promotes AAV2 capsid formation in the nucleolus. Proc. Natl. Acad. Sci. U. S. A. 107, 10220-10225.

Srivastava, a, Lusby, E. W. and Berns, K. I. (1983). Nucleotide sequence and organization of the adeno-associated virus 2 genome. J. Virol. 45, 555-564.

Steen, E., Terry, B. M., Rivera, E. J., Cannon, J. L., Neely, T. R., Tavares, R., Xu, X. J., R.Wands, J. and Monte, S. M. de la (2005). Impaired insulin and insulin-like growth factor expression and signaling mechanisms in Alzheimer's diseaseis this type 3 diabetes? J. Alzheimer's Dis. 7, 63-80.

Steger, R. W., Peluso, J. J., Huang, H., Hafez, E. S. and Meites, J. (1976).

Gonadotrophin-binding sites in the ovary of aged rats. J. Reprod. Fertil. 48, 205-7. 
Stypuła, G., Kunert-Radek, J., Stepień, H., Zylińska, K. and Pawlikowski, M.

(1996). Evaluation of interleukins, ACTH, cortisol and prolactin concentrations in the blood of patients with Parkinson's disease. Neuroimmunomodulation 3, 131-134.

Summerford, C. and Samulski, R. J. (1998). Membrane-associated heparan sulfate proteoglycan is a receptor for adeno-associated virus type 2 virions. J. Virol. 72, 1438-1445.

Summerford, C., Bartlett, J. S. and Samulski, R. J. (1999). AlphaVbeta5 integrin: a co-receptor for adeno-associated virus type 2 infection. Nat. Med. 5, 7882.

Sun, Y., Todd, B. J., Thornton, K., Etgen, A. M. and Neal-Perry, G. S. (2011). Differential Effects of Hypothalamic IGF-I on Gonadotropin Releasing Hormone Neuronal Activation During Steroid-Induced LH Surges in Young and Middle-Aged Female Rats. Endocrinology 152, 4276-87.

Takakura, Y., Nishikawa, M., Yamashita, F. and Hashida, M. (2001).

Development of gene drug delivery systems based on pharmacokinetic studies. Eur. J. Pharm. Sci. 13, 71-76.

Todd, B. J., Fraley, G. S., Peck, A. C., Schwartz, G. J. and Etgen, A. M. (2007). Central insulin-like growth factor 1 receptors play distinct roles in the control of reproduction, food intake, and body weight in female rats. Biol. Reprod. 77, 492-503.

Todd, B. J., Merhi, Z. O., Shu, J., Etgen, A. M. and Neal-Perry, G. S. (2010). Hypothalamic insulin-like growth factor-I receptors are necessary for hormone-dependent luteinizing hormone surges: implications for female reproductive aging. Endocrinology 151, 1356-66.

Torres-Aleman, I. (1999). Insulin-like growth factors as mediators of functional plasticity in the adult brain. Horm. Metab. Res. 31, 114-9.

Torres-Aleman, I., Naftolin, F. and Robbins, R. J. (1990). Trophic effects of insulinlike growth factor-I on fetal rat hypothalamic cells in culture. Neuroscience 35, 601-8.

Torres-Aleman, I., Pons, S. and Santos-Benito, F. F. (1992). Survival of Purkinje cells in cerebellar cultures is increased by insulin-like growth factor I. Eur. J. Neurosci. 4, 864-869.

Tsafriri, A. and Kraicer, P. (1972). The time sequence of ovum maturation in the rat. J. Reprod. Fertil. 29, 387-393.

Uenoyama, Y., Tsukamura, H. and Maeda, K. I. (2009). Kisspeptin/metastin: A key molecule controlling two modes of gonadotrophin-releasing hormone/luteinising hormone release in female rats. J. Neuroendocrinol. 21, 299-304. 
Valentinis, B., Morrione, a, Peruzzi, F., Prisco, M., Reiss, K. and Baserga, R. (1999). Anti-apoptotic signaling of the IGF-I receptor in fibroblasts following loss of matrix adhesion. Oncogene 18, 1827-1836.

Vendola, K., Zhou, J., Wang, J. and Bondy, C. a (1999). Androgens promote insulin-like growth factor-I and insulin-like growth factor-I receptor gene expression in the primate ovary. Hum. Reprod. 14, 2328-2332.

Werther, G. a, Hogg, a, Oldfield, B. J., McKinley, M. J., Figdor, R. and Mendelsohn, F. a (1989). Localization and Characterization of Insulin-Like Growth Factor-I Receptors in Rat Brain and Pituitary Gland Using in vitro Autoradiography and Computerized Densitometry* A Distinct Distribution from Insulin Receptors. J. Neuroendocrinol. 1, 369-77.

Werther, G. A., Cheesman, H. and Vincenzo, R. (1993). Olfactory bulb organ culture is supported by combined insulin-like growth factor-I and basic fibroblast growth factor. Brain Res. 617, 339-342.

Wilczak, N., Vos, R. de and Keyser, J. De (2003). Free insulin-like growth factor (IGF)-I and IGF binding proteins 2, 5, and 6 in spinal motor neurons in amyotrophic lateral sclerosis. Lancet 361, 1007-1011.

Wilkes, M. M., Lu, K. H., Fulton, S. L. and Yen, S. S. (1978). Hypothalamic-pituitaryovarian interactions during reproductive senescence in the rat. Adv. Exp. Med. Biol. 113, 127-147.

Wise, P. P. M. (1982). Alterations in the proestrous pattern of median eminence $\mathrm{LHRH}$, serum LH, FSH, estradiol and progesterone concentrations in middleaged rats. Life Sci. 31, 165-173.

Wise, P. M. (1984). Estradiol-induced daily luteinizing hormone and prolactin surges in young and middle-aged rats: Correlations with age-related changes in pituitary responsiveness and catecholamine turnover rates in microdissected brain areas. Endocrinology 115, 801-809.

Wise, P. M. and Ratner, a (1980a). LHRH-induced LH and FSH responses in the aged female rat. J. Gerontol. 35, 506-511.

Wise, P. and Ratner, A. (1980b). Effect of ovariectomy on plasma LH, FSH, estradiol, and progesterone and medial basal hypothalamic LHRH concentrations in old and young rats. Neuroendocrinology 30, 15-19.

Wu, Z., Asokan, A. and Samulski, R. J. (2006). Adeno-associated Virus Serotypes: Vector Toolkit for Human Gene Therapy. Mol. Ther. 14, 316-327.

Yamaguchi, F., Itano, T., Miyamoto, O., Janjua, N. a., Ohmoto, T., Hosokawa, K. and Hatase, O. (1991). Increase of extracellular insulin-like growth factor I (IGF-I) concentration following electrolytical lesion in rat hippocampus. Neurosci. Lett. 128, 273-276. 
Yang, L., Scott, K. a, Hyun, J., Tamashiro, K. L., Tray, N., Moran, T. H. and Bi, S. (2009). Role of dorsomedial hypothalamic neuropeptide $Y$ in modulating food intake and energy balance. J. Neurosci. 29, 179-90.

Yuan, J. and Yankner, B. A. (2000). Apoptosis in the nervous system. Nature 407, 802-809.

Zhen, S., Zakaria, M., Wolfe, A. and Radovick, S. (1997). Regulation of Gonadotropin- Releasing Hormone (GnRH) Gene Expression by Insulin-Like Growth Factor I in a Cultured GnRH- Expressing Neuronal Cell Line Shanjun. Mol. Endocrinol. 11, 1145-55.

Zincarelli, C., Soltys, S., Rengo, G. and Rabinowitz, J. E. (2008). Analysis of AAV serotypes 1-9 mediated gene expression and tropism in mice after systemic injection. Mol. Ther. 16, 1073-1080.

Zolotukhin, S., Potter, M., Zolotukhin, I., Sakai, Y., Loiler, S., Fraites, T. J., Chiodo, V. a, Phillipsberg, T., Muzyczka, N., Hauswirth, W. W., et al. (2002). Production and purification of serotype 1,2, and 5 recombinant adenoassociated viral vectors. Methods 28, 158-67.

Zou, L., Zhou, H., Pastore, L. and Yang, K. (2000). Prolonged transgene expression mediated by a helper-dependent adenoviral vector (hdAd) in the central nervous system. Mol. Ther. 2, 105-13. 